\title{
Poster Exhibit 3: Endourology
}

Cite as: Can Urol Assoc / 2021;15(6S2):S99-124. http://dx.doi.org/10.5489/cuaj.7402

\section{UP-56}

Pooled analysis of bladder function post-Aquablation

Dean S. Elterman ${ }^{1}$, Peter Gilling², Claus Roehrborn ${ }^{3}$, Neil Barber ${ }^{4}$, Vincent Misrai $^{5}$, Kevin C. Zorn ${ }^{6}$, Naeem Bhojani ${ }^{6}$, Alexis Te ${ }^{7}$, Mitch Humphreys ${ }^{8}$, Steven Kaplan ${ }^{9}$, Mihir Desail ${ }^{10}$, Thorsten Bach ${ }^{11}$

${ }^{1}$ University Health Network, Toronto, ON, Canada; ${ }^{2}$ Tauranga Urology Research, Tauranga, New Zealand; ${ }^{3}$ University of Texas Southwestern, Dallas, TX, United States; ${ }^{4}$ Frimley Park Hospital, Frimley Health Foundation Trust, Surrey, United Kingdom; ${ }^{5}$ Clinique Pasteur, Toulouse, France; ${ }^{6}$ University of Montreal Hospital Centre, Université de Montréal, Montreal, QC, Canada; ${ }^{7}$ Weill Cornell Medical College, New York Presbyterian, New York, NY, United States; ${ }^{8}$ Mayo Clinic Arizona, Arizona, AZ, United States; ${ }^{9}$ Mount Sinai Medical Center, New York, NY, United States; ${ }^{10}$ University of Southern California, Los Angeles, CA, United States; ${ }^{11}$ Asklepios Westklinikum Hamburg, Hamburg, Germany

Introduction: Aquablation therapy (AQUABEAM Robotic System, PROCEPT BioRobotics, Inc., U.S.) is an ultrasound-guided, robotically executed, waterjet ablative procedure used to treat men with lower urinary tract symptoms (LUTS) due to benign prostatic hyperplasia (BPH). It has demonstrated treatment in a wide range of prostate sizes while minimizing irreversible complications (erectile dysfunction, ejaculatory dysfunction, incontinence). This analysis explores the bladder function following Aquablation in various prostate volume and anatomical subgroups.

Methods: Four prospective, global, clinical studies have been conducted with Aquablation with a minimum followup of one year: WATER, WATER II, FRANCAIS WATER, and OPEN WATER. The focus of the analysis is the seven individual questions from International Prostate Symptom Score (IPSS) and postoperative Incontinence Symptom Index (ISI).

Results: A total of 425 men with prostates ranging in size from 20-150 cC were treated with Aquablation therapy. Outcomes from the seven questions from the IPSS questionnaire are shown in Fig. 1 for prostates $<100$ cc, prostates $>100 \mathrm{cc}$, prostate anatomy with median lobe, and prostate anatomy without median lobe. Regardless of subgroup, all outcomes are consistent and show a significant improvement from baseline. Specifically, improvements in frequency, urgency, and nocturia demonstrate bladder function improvement. Patients entering treatment with severe incontinence and ISI score $>4$ showed a reduction in incontinence during patient followup regardless of prostate size.

Conclusions: Aquablation therapy showed remarkable bladder function improvement following the index procedure. Additionally, men with severe incontinence showed a reduction in incontinence post-procedure.

\section{UP-57}

Randomized controlled trial comparing holmium laser $\mathrm{Xpeeda}^{\mathrm{TM}}$ Vaporesection and GreenLight XPS vaporization of the prostate: 6-month followup

Waleed Shabana', Abdulrhman Ahmed', Fabiola Oquendo' , Amr Hodhod', Rayan Kelly', Shalyn Littlefield', Ahmed Kotb', Walid Shahrour', Elmansy'

${ }^{1}$ Northern Ontario School of Medicine, Thunder Bay, ON, Canada

Introduction: We aimed to compare the safety and efficacy of holmium laser Xpeeda ${ }^{\mathrm{TM}}$ Vaporesection and GreenLight XPSTM vaporization of the prostate in patients with prostate glands $\leq 80 \mathrm{~g}$.

Methods: Eighty men with benign prostatic hyperplasia (BPH) and prostate glands $\leq 80$ g scheduled for laser prostatectomy were included in this pro-

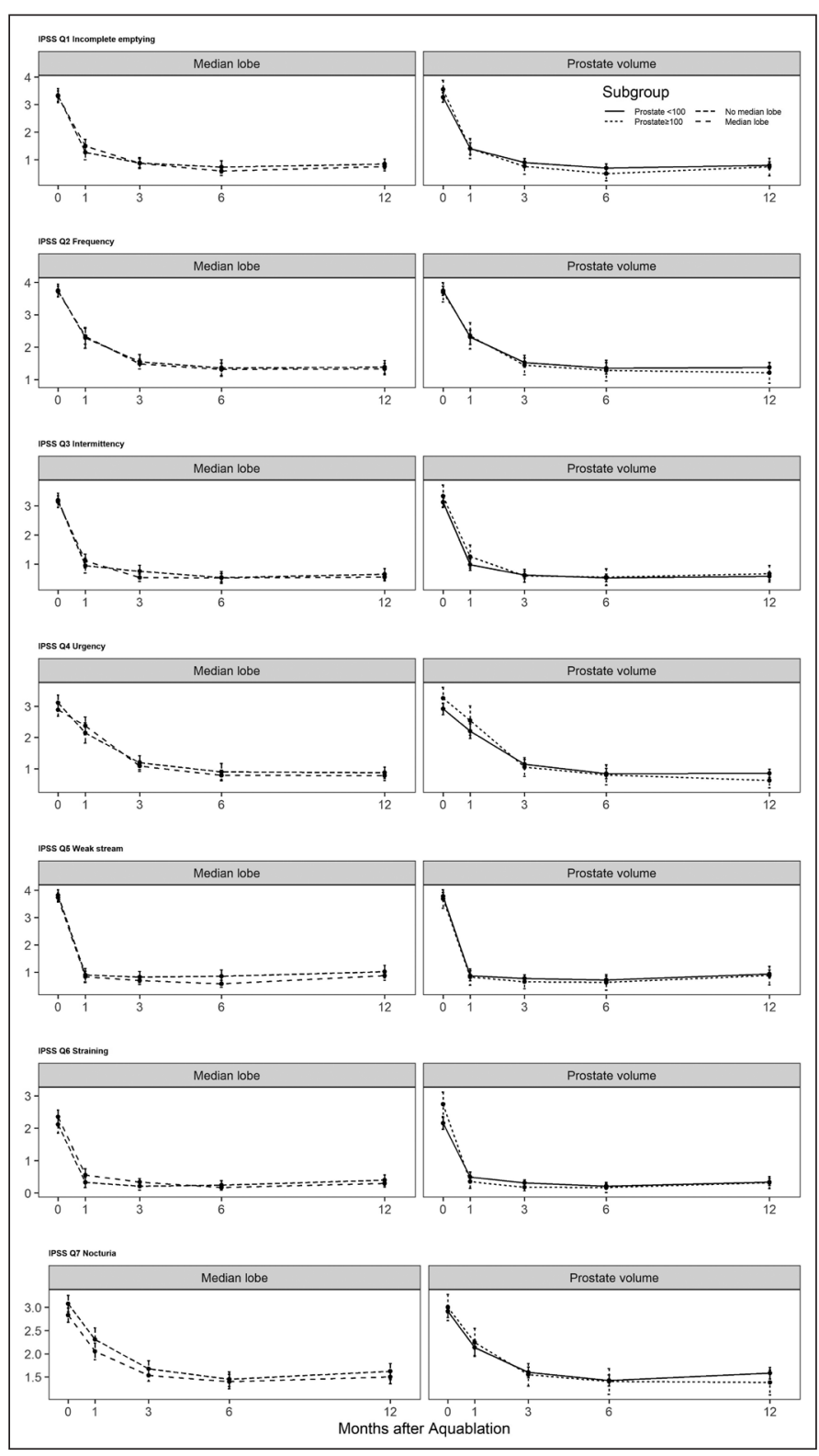

UP-56. Fig. 1. Outcomes from the seven questions from the IPSS questionnaire. 
spective, randomized trial. Outcome measures, including International Prostate Symptom Score (IPSS), quality of life (QoL), flow rate, postvoid residual (PVR), International Index of Erectile Function (IIEF)-15, International Consultation on Incontinence Questionnaire-Urinary Incontinence Short Form (ICIQ-SF), prostate-specific antigen (PSA), catheterization time, and transrectal ultrasound (TRUS) prostate volume changes were collected and compared. Perioperative complications were also recorded. Patients were offered a trial of void (TOV) three hours after their procedures. All patients were discharged home on the same day and were followed up at one, three, and six months.

Results: There were no significant differences in preoperative baseline data between the two surgical groups. Successful TOV was noted in $70.5 \%$ and $70.8 \%$ of the Xpeeda and GreenLight XPSTM patients, respectively $(p=0.5)$. The laser energy used was significantly lower in Xpeeda group $(p=0.002)$. There were no significant differences in functional and sexual outcomes between both groups at six months. Operative parameters and postoperative outcomes are shown in Table 1.

Conclusions: Holmium laser Xpeeda Vaporesection and GreenLight XPSTM vaporization are safe and effective in the treatment of BPH. Sameday discharge with early trial of void is a feasible option.

\section{UP-58}

A novel method for GreenLight MoXy laser fiber irrigation system to improve performance and durability: A new standard of care? Kyle Law' ${ }^{1}$ Ahmed S. Zakaria', Dean S. Elterman ${ }^{3}$,Enrique Rijo ${ }^{4}$, Vincent Misrai ${ }^{5}$, David-Dan Nguyen ${ }^{7}$, Changyi Lai ${ }^{6}$, Earol Byrne ${ }^{6}$, John Taradis, James Baker ${ }^{7}$, Ray Langan ${ }^{8}$, Nick Fedas ${ }^{6}$, Ana Maria Mejia ${ }^{8}$, Paul O'Neill', Thomas Hasenberg ${ }^{8}$, Kevin C. Zorn ${ }^{2}$

${ }^{1}$ Faculty of Medicine, McGill University, Montreal, QC, Canada; ${ }^{2}$ Division of Urology, University of Montreal Hospital Centre (CHUM), Montreal, QC, Canada; ${ }^{3}$ Department of Urology, University of Toronto, Toronto, ON, Canada; ${ }^{4}$ Department of Urology, Hospital Quiron Barcelona, Barcelona, Spain; ${ }^{5}$ Division of Urology, Clinique Pasteur, Toulouse, France; ${ }^{6}$ Division of Urology \& Pelvic Health, Boston Scientific Corporation, Marlborough, MA, United States; ${ }^{7}$ Division of Urology \& Pelvic Health, Boston Scientific Corporation, San Jose, CA, United States; ${ }^{8}$ Department of Electrical and Computer Engineering, Georgia Institute of Technology, Atlanta, GA, United States

Introduction: We tested a novel principle in the GreenLight MoXy laser fiber to increase the saline irrigation flow rates beyond the current standard of gravity drip within the fiber-attached cooling system to prevent

\begin{tabular}{|c|c|c|c|}
\hline & Xpeeda $^{\mathrm{TM}}(40)$ & GreenLight XPS $^{\mathrm{TM}}(40)$ & $\mathbf{p}$ \\
\hline \multicolumn{4}{|l|}{ Preoperative criteria } \\
\hline Age, years & $69.79 \pm 8.32$ & $67.47 \pm 6.46$ & $0.19^{a}$ \\
\hline Urine retention, $\mathrm{n}(\%)$ & $9(22.5 \%)$ & $9(22.5 \%)$ & $0.07^{\mathrm{b}}$ \\
\hline Flow rate, $\mathrm{mL} / \mathrm{sec}$ & $9.35(4.7-12.3)$ & $7.7(4.9-10.15)$ & $0.38^{c}$ \\
\hline PVR, $\mathrm{mL}$ & $360(260-534)$ & $361(223-489)$ & $0.71^{\mathrm{c}}$ \\
\hline QoL & $4.50 \pm 1.29$ & $4.57 \pm 1.13$ & $0.8^{\mathrm{a}}$ \\
\hline IIEF-15 & $22(15-49)$ & $32(21-52)$ & $0.16^{c}$ \\
\hline \multicolumn{4}{|l|}{ Operative data } \\
\hline Operative time, hours & $56.5(40-70)$ & $51(36-60)$ & $0.16^{c}$ \\
\hline Energy, kJ & $162.72(90-231)$ & $263.71(183-337)$ & $0.002^{c *}$ \\
\hline Intra-op complications, $\mathrm{n}$ & $0 / 40$ & $1 / 40$ & $0.91^{\mathrm{b}}$ \\
\hline Catheter duration, hours & $3(3-24)$ & $3(3-18.9)$ & $0.12^{\mathrm{c}}$ \\
\hline \multicolumn{4}{|l|}{ Outcomes at 1 month } \\
\hline Flow rate, $\mathrm{mL} / \mathrm{sec}$ & $19.2(16-26)$ & $18.5(16.9-22.1)$ & $0.82^{\mathrm{c}}$ \\
\hline PVR, $\mathrm{mL}$ & $77(33-128)$ & $59(29-113)$ & $0.41^{c}$ \\
\hline IPSS & $8(6-13)$ & $10(4.5-13)$ & $0.83^{c}$ \\
\hline QoL & $2(1-2)$ & $2(1-3)$ & $0.06^{c}$ \\
\hline \multicolumn{4}{|l|}{ Outcomes at 3 months } \\
\hline Flow rate, $\mathrm{mL} / \mathrm{sec}$ & $20.7(17-25.6)$ & $21.8(19.5-28.6)$ & $0.26^{c}$ \\
\hline PVR, mL & $77.5(25-119)$ & $39(13.5-88.5)$ & $0.06^{c}$ \\
\hline PSA, ng/dl & $1.15(0.75-1.5)$ & $0.8(0.5-1.9)$ & $0.09^{c}$ \\
\hline IPSS & $6(3-9)$ & $7(3.5-9)$ & $0.40^{\mathrm{c}}$ \\
\hline QoL & $1(0-1)$ & $1(0-2)$ & $0.18^{c}$ \\
\hline
\end{tabular}




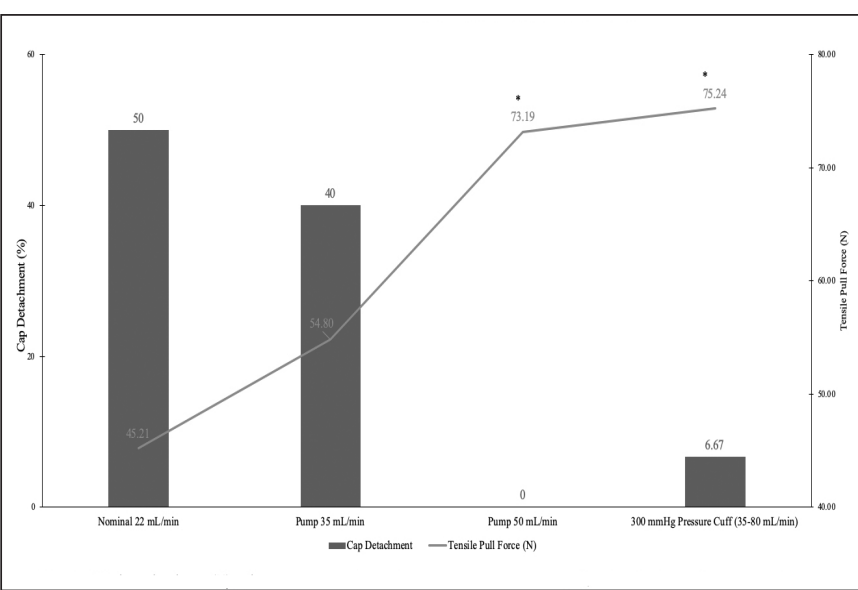

UP-58. Fig. 1. Failed cap detachment (\%) and average tensile pull force (N) evaluation after 30 minutes of tissue-contact laser conditioning to achieve $300 \mathrm{~kJ} .{ }^{*} \mathrm{p}<0.05$ when compared to nominal group.

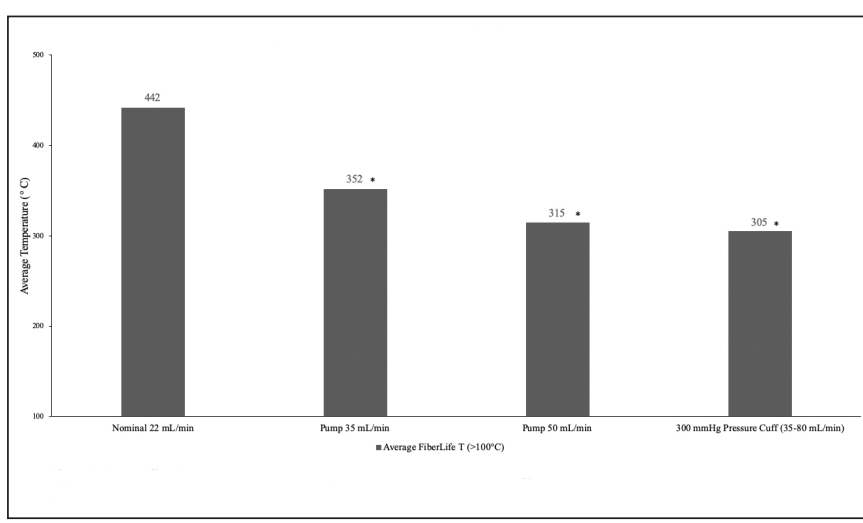

UP-58. Fig. 2. Average FiberLife temperature $\left({ }^{\circ} \mathrm{C}\right)$ recorded during the $30 \mathrm{~min}$ utes of tissue-contact laser conditioning. ${ }^{*} p<0.01$ when compared to nominal group.

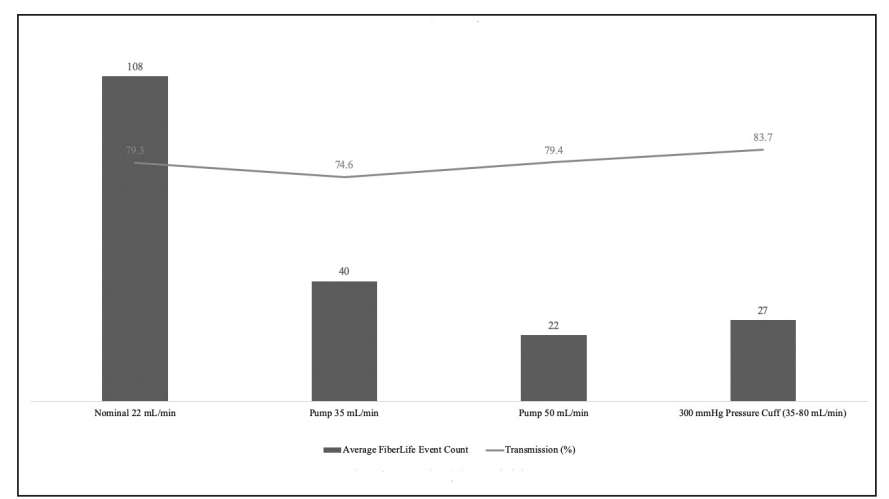

UP-58. Fig. 3. Average FiberLife event count and average laser transmission $(\%)$ recorded during the 30 minutes of tissue-contact laser conditioning. excessive tissue adherence and to eliminate the likelihood of degradation due to abnormal overheating. The objective was to assess differences between the ordinary and active pumping methods after conditioning of the laser fiber.

Methods: The MoXy laser fiber was conditioned with $180 \mathrm{~W}$ of vaporization mode of GreenLight XPS console for 30 continuous minutes in a porcine model. Four groups were evaluated; control group, $22 \mathrm{~mL} /$ min, digital pump set $(35 \mathrm{~mL} \& 50 \mathrm{~mL} / \mathrm{min})$ and a manual pressure cuff with hand pump set using a $3 \mathrm{~L}$ saline bag set at $300 \mathrm{mmHg}(35-80 \mathrm{~mL} /$ min). After conditioning, a mechanical pull force test was executed on the fiber metal cap to evaluate the bonding strength. Additional physical parameters, including fiber tip temperature information and laser beam power transmission efficiency were analyzed.

Results: Detachment of the cap occurred less frequently when using the $300 \mathrm{mmHg}$ pressure cuff saline bag compared to the nominal flow rate $(6.67 \%$ vs. $50 \%$, respectively). The average operating fiber tip temperature was measured at $305^{\circ} \mathrm{C}$ compared to $442^{\circ} \mathrm{C}$ in the pressure cuff and control group respectively.

Conclusions: Our study demonstrates superior results when using active pumping or high-pressure systems to increase saline flow rates in terms of laser fiber durability without any additional cost. More specifically, use of a manual pressure cuff with starting pressure at $300 \mathrm{mmHg}$, a system that is readily available in most operating rooms, increases MoXy fiber durability. Further studies are required to assess if this technique will improve user experience, clinical outcomes, and procedure costs.

\section{UP-59}

Rezūm water vapor therapy for large volume $(\geq 80 \mathrm{~mL})$ benign prostatic enlargement: Large, multicenter cohort

Dean S. Elterman ${ }^{1}$, Naeem Bhojani', Bilal Chughtai ${ }^{3}$, Kevin C. Zorn ${ }^{2}$

${ }^{1}$ University Health Network, Toronto, ON, Canada; ${ }^{2}$ University of Montreal Hospital Centre, Montreal, QC, Canada; ${ }^{3}$ Weill Cornell Medical College, New York, NY, United States

Introduction: Open or laser prostatectomy are the standard treatments for benign prostatic hyperplasia (BPH) of large volume prostates $\geq 80$ $\mathrm{mL}$. Rezūm is a minimally invasive procedure to ablate benign prostatic tissue. Herein, we report the prospective, multicenter results of the largest cohort of prostates $\geq 80 \mathrm{~mL}$ treated with Rezūm.

Methods: A prospective registry was established for Rezūm therapy in Canada (2019) at two high-volume centers. All patients had baseline medical and BPH history documented along with uroflowmetry (maximal flow rate [Qmax] and post-void residual [PVR]) and validated questionnaires (International Prostate Symptom Score [IPSS], IPSS quality of life [QoL], Benign Prostatic Hyperplasia Impact Index [BPHII], International Index of Erectile Function [IIEF]-15, Male Sexual Health Questionnaire for Ejaculatory Dysfunction [MSHQ-EjD] function and bother).

Results: Eight-three patients (mean age 68.7 years) with prostate size $\geq 80$ $\mathrm{ml}$ were treated with Rezūm from April 2019 to December 2020. The average prostate volume was $104.6 \mathrm{ml}$ (range $80-160$ ) and $65 \%$ had a median lobe. Twenty-one patients had prior episode of urinary. Mean number of injections was 13.6 (range 8-28). Mean duration of procedure was 5.9 minutes (range 2.5-14). Mean duration of post-procedure catheterization was 11.8 days. IPSS reduced from a baseline score of 20.9 by $24.3 \%$ (15.8), $56.7 \%$ (9), and $59.1 \%$ (8.4) at one, three, and 12 months, respectively. IPSS QoL score improved from a baseline of 4.2 to $1.8(-56 \%)$ at three months and $1.4(-70 \%)$ at 12 months. Qmax improves from a baseline of $9.2 \mathrm{ml} / \mathrm{s}$ up to $14.3 \mathrm{ml} / \mathrm{s}(55 \%)$ at three months. BPHII improved from a baseline of 6.4 to $2.8(-57 \%)$ at three months and 1.8 $(71 \%)$ at 12 months. IIEF showed no significant change from 52 at baseline to 57 at 12 months. Similarly, no changes in MSHQ function (10.3 to 10.1 at 12 months) or bother (1.4 to 1.3 at 12 months). No Clavien-Dindo events $\geq$ grade 3 occurred.

Conclusions: Rezūm therapy is a safe, effective, quick, out-patient procedure in prostate glands $\geq 80 \mathrm{ml}$ with similar outcomes to prostates $<80 \mathrm{~mL}$. 


\section{UP-60}

The outcomes of top-down holmium laser enucleation of the prostate (HoLEP) vs. traditional HoLEP for the treatment of benign prostatic hyperplasia: A randomized, prospective, comparative study Waleed Shabana', Abdulrhman Ahmed ${ }^{7}$, Fabiola Oquendo ${ }^{7}$, Amr Hodhod $^{1}$, Thomas Tablowski ${ }^{1}$, Shalyn Littlefield ${ }^{1}$, Ahmed Kotb ${ }^{7}$, Walid Shahrour ${ }^{1}$, Hazem Elmansv'

${ }^{1}$ Northen Ontario School of Medicine, Thunder Bay, ON, Canada Introduction: Top-down Holmium laser enucleation of the prostate (HoLEP) was recently introduced as a safe and effective modification of traditional HoLEP. We aimed to compare intraoperative and postoperative outcomes of the top-down technique with traditional HoLEP for the treatment of benign prostatic hyperplasia $(\mathrm{BPH})$.

Methods: Sixty-eight patients participated in this randomized controlled trial. All procedures were performed by a single surgeon experienced with both HoLEP techniques (HE). Patients were followed up at one, three, and six months. Outcome measures, including International Prostate Symptom Score (IPSS), quality of life (QoL,) flow rate (Qmax), post-void residual (PVR), International Index of Erectile Function (IIEF)15, International Consultation on Incontinence Questionnaire-Urinary Incontinence Short Form (ICIQ-SF), prostate-specific antigen (PSA), and transrectal ultrasound (TRUS) prostate volume changes were collected and compared. Perioperative complications were also recorded.

Results: There was no statistically significant difference between both groups with regards to perioperative data, including age, TRUS prostate volume, IPSS, QoL, IIEF-15, ICIQ-SF, and preoperative PSA. Both techniques significantly improved postoperative parameters immediately after surgery and continued the entire followup period. There was no statistical difference in enucleation time. Although stress urinary incontinence was statistically insignificant, there was a trend to a lower percentage in the top-down group (Table 1).

Conclusions: The HoLEP procedure significantly improves patients' urinary functions, regardless of the approach.

\section{UP-61}

Routine use of focal bladder neck cautery in 1116 consecutive Aquablation controls for postoperative bleeding

Dean S. Elterman ${ }^{1}$, Burhard Ubrig

${ }^{1}$ University Health Network, Toronto, ON, Canada; ${ }^{2}$ Witten/Herdecke University, Augusta-Kranken-Anstalt, Bochum, Germany

Introduction: We sought to determine if focal bladder neck cautery effectively prevents blood transfusions across various prostate volumes following prostate tissue resection for benign prostatic hyperplasia using Aquablation.

Methods: Consecutive patients between late 2019 and August 2020 undergoing Aquablation followed by focal bladder neck cautery from 11 countries from Asia, Europe, and North America were evaluated for transfusions.

Results: A total of 1116 Aquablation cases were performed using focal bladder neck cautery with a mean prostate size of 81 cc (range 20-300). The average time spent after removing the handpiece to inserting the urinary catheter was 18 minutes. This segment of the procedure includes flushing, transitioning to the resectoscope, and cauterizing at the bladder neck. Postoperative bleeding requiring transfusion occurred in seven cases $(0.6 \%, 95 \%$ confidence interval $[\mathrm{Cl}] 0.3-1.3 \%)$. This result compares favorably $(p<0.0001)$ to the previously published hemostasis aggregate transfusion rate of $31 / 801(3.9 \%)$ using methods performed in the years 2014-2019.

Conclusions: Routine use of additional focal bladder neck cautery subsequent to Aquablation will bring down the risk of postoperative bleeding to a level known from transurethral resection of the prostate or holmium laser enucleation of the prostate while preserving the main strategic goals of Aquablation: reliable de-obstruction of the prostatic urethra, high safety profile for protection of the urinary sphincter, high efficacy in preserving antegrade ejaculation, and minimizing and standardizing the ablative procedure.

\begin{tabular}{|c|c|c|c|}
\hline & Top-down (34) & Traditional (34) & $\mathbf{p}$ \\
\hline \multicolumn{4}{|l|}{ Preoperative criteria } \\
\hline Age, years & $71.9 \pm 8.1$ & $71.6 \pm 7.8$ & $0.90^{\mathrm{a}}$ \\
\hline Prostate size, $\mathrm{g}$ & $106.5(92-127)$ & $110(90.1-144.5)$ & $0.70^{c}$ \\
\hline Urine retention, $\mathrm{n}$ & 15/34 (44.1\%) & 11/34 (32.4\%) & $0.30^{\mathrm{b}}$ \\
\hline (\%) & $6.4(4.9-9.9)$ & $7.2(5.4-10.7)$ & $0.24^{c}$ \\
\hline Flow rate, $\mathrm{mL} / \mathrm{sec}$ & $348(152-595)$ & $387(126-640)$ & $0.78^{c}$ \\
\hline PVR, mL & $5.3(2.9-6.9)$ & $4.7(3.2-8.2)$ & $0.91^{\mathrm{c}}$ \\
\hline PSA, ng/dl & $25(19.7-28)$ & $23(19.5-26.5)$ & $0.54^{c}$ \\
\hline IPSS & $5(4-6)$ & $5(4-5.5)$ & $0.80^{c}$ \\
\hline $\begin{array}{l}\text { QoL } \\
\text { IIEF-15 }\end{array}$ & $32.5(17.5-48)$ & $36(8-61)$ & $0.68^{c}$ \\
\hline \multicolumn{4}{|l|}{ Operative data } \\
\hline $\begin{array}{l}\text { Enucleation time, } \\
\text { minutes }\end{array}$ & $59.5(48-78)$ & $61(47.5-70)$ & $0.87^{c}$ \\
\hline Resected tissue, $\mathrm{g}$ & $79.5(60-100)$ & $82(56.5-98)$ & $0.83^{c}$ \\
\hline $\begin{array}{l}\text { Morcellation time, } \\
\text { minutes }\end{array}$ & $10(6-13)$ & $8.5(6.5-13.5)$ & $0.51^{c}$ \\
\hline $\begin{array}{l}\text { Intraoperative } \\
\text { complications, } \mathrm{n}\end{array}$ & $0 / 34$ & $0 / 34$ & $0.30^{\mathrm{b}}$ \\
\hline $\begin{array}{l}\text { Postoperative } \\
\text { complications, n }\end{array}$ & $1 / 34$ & $2 / 34$ & $0.30^{\mathrm{b}}$ \\
\hline Hospital stay, hours & $24(24-24)$ & $24(24-24)$ & $0.15^{c}$ \\
\hline $\begin{array}{l}\text { Catheter duration, } \\
\text { hours }\end{array}$ & $24(24-24)$ & $24(24-24)$ & $0.35^{c}$ \\
\hline \multicolumn{4}{|l|}{ Outcomes at 1 month } \\
\hline Flow rate, mL/sec & $26.3(21.5-29)$ & $26.1(18.5-28.9)$ & $0.39^{c}$ \\
\hline $\mathrm{PVR}, \mathrm{mL}$ & $65.5(35-100)$ & 36.5 (14-74) & $0.053^{c}$ \\
\hline IPSS & $7.5(4-9)$ & 7 (3-10.5) & $0.82^{c}$ \\
\hline QoL & $1(0-3)$ & $2(1-2.5)$ & $0.43^{c}$ \\
\hline Stress incontinence, & $2 / 34$ & $3 / 34$ & $0.50^{b}$ \\
\hline
\end{tabular}

\section{Outcomes at 3 \\ months}

Flow rate, $\mathrm{mL} / \mathrm{sec}$

PVR, $m L$

PSA, ng/dl

IPSS

QoL

Stress incontinence,

\section{Outcomes at 6 \\ months}

Postoperative

prostate size, g

Flow rate, $\mathrm{mL} / \mathrm{sec}$

PVR, $\mathrm{mL}$

IPSS

OoL

IIEF-15

Stress incontinence,
$31.1(24.9-35.9)$
$44.5(32-63)$
$0.5(0.3-0.9)$
$5(2-9)$
$2(0-2)$

$0 / 34$

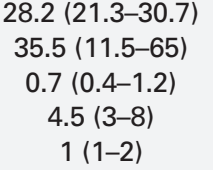

$1 / 34$ $0.04^{c}$

$0.40^{\circ}$

$0.43^{\circ}$

$0.85^{\circ}$

$0.86^{c}$

$0.1^{\mathrm{b}}$

Data are presented as median (IQR1-IQR3), mean $\pm \mathrm{SD}$, or number (\%) as appropriate. ${ }^{\mathrm{a}} \mathrm{t}$-test. ${ }^{\mathrm{b}} \mathrm{C}$ i-squared. ${ }^{\mathrm{c} M a n n-W h i t n e y} \mathrm{U}$ test. ${ }^{*}$ Significant. 


\section{UP-62}

Evaluating the acceptability of an electronic patient decision-aid for the surgical management of lower urinary tract symptoms secondary to benign prostatic hyperplasia

David Bouhadana ${ }^{1}$, David-Dan Nguyen ${ }^{1}$, Brendan Raizenne², Joe Schwarcz', Harvey Gordon ${ }^{3}$, Bilal Chughtai ${ }^{4}$, Dean S. Elterman', Luke T. Lavallee ${ }^{5}$, Paul R. Martin ${ }^{6}$, Kristen McAlpine ${ }^{3}$, Ryan F. Paterson ${ }^{7}$, Hassan Razvi ${ }^{8}$, Kevin C. Zorn ${ }^{2}$, Naeem Bhojani

${ }^{1}$ Faculty of Medicine, McGill University, Montreal, QC, Canada; ${ }^{2}$ Department of Urology, Centre Hospitalier de I'Université de Montréal, Montreal, QC, Canada; ${ }^{3}$ Division of Urology, Department of Surgery, University Health Network, University of Toronto, Toronto, ON, Canada; ${ }^{4}$ Department of Urology, NY-Presbyterian Hospital, Weill Cornell Medical Center, New York,
NY, United States; ${ }^{5}$ Department of Surgery, Division of Urology, University of Ottawa, Ottawa, ON, Canada; ' ${ }^{\circ}$ epartment of Urology, Bluewater Health, Sarnia, ON, Canada; 'Urologic Sciences, University of British Columbia, Vancouver, BC, Canada; ${ }^{8}$ Division of Urology, Department of Surgery, University of Western Ontario, London, ON, Canada

Acknowledgement: The authors thank the CUA for endorsing the development of this PtDA; and lan Langleben and Stella-Kim Nguyen for the programming and designing of this PtDA.

Introduction: With the help of a steering committee that included patient advocates, and both methodological and clinical experts, an electronic patient decision aid (PtDA) that includes all benign prostatic hyperplasia $(\mathrm{BPH})$ guideline-approved surgical modalities was developed. The goal of this study was to assess the acceptability of the PtDA within former BPH surgery patients and urologists that treat $\mathrm{BPH}$ surgically.

\section{UP-62. Table 1. Detailed description of quantitative clinician alpha-testing results specific to each section of the patient} decision aid

\begin{tabular}{|c|c|c|c|c|}
\hline \multicolumn{5}{|c|}{ Small to moderate prostate volumes $(<80 \mathrm{ml})$} \\
\hline & Questions & $\begin{array}{l}\text { Median (IQR) } \\
\text { [range] }\end{array}$ & Mean (SD) & Legend \\
\hline 1 & $\begin{array}{l}\text { The language used was easy to } \\
\text { follow: }\end{array}$ & $4(4-5)[2-5]$ & $4.18(0.87)$ & $\begin{array}{c}1=\text { strongly disagree, } 2 \text { =disagree, } 3=\text { neutral, } 4=\text { agree, } \\
5=\text { strongly agree }\end{array}$ \\
\hline 2 & $\begin{array}{l}\text { The amount of information provided } \\
\text { was: }\end{array}$ & $3(3-4)[3-5]$ & $3.54(0.82)$ & $\begin{array}{l}1=\text { much less than wanted, } 2=a \text { little less than wanted, } 3=\text { about } \\
\text { right, } 4=a \text { little more than wanted, } 5=\text { much more than wanted }\end{array}$ \\
\hline 3 & The length of the decision aid was: & $2(2-3)[2-3]$ & $2.36(0.50)$ & $1=$ too short, $2=$ just right, $3=$ too long \\
\hline 4 & $\begin{array}{l}\text { I agree with the outcomes reported } \\
\text { (rates of benefits and risks): }\end{array}$ & $4(4-5)[3-5]$ & $4.09(0.70)$ & $\begin{array}{c}1=\text { strongly disagree, } 2=\text { disagree, } 3=\text { neutral, } 4=\text { agree, } \\
5=\text { strongly agree }\end{array}$ \\
\hline \multicolumn{5}{|c|}{ Moderate to large prostate volumes $(80-150 \mathrm{ml})$} \\
\hline & Questions & $\begin{array}{l}\text { Median (IQR) } \\
\text { [range] }\end{array}$ & Mean (SD) & Legend \\
\hline 1 & $\begin{array}{l}\text { The language used was easy to } \\
\text { follow: }\end{array}$ & $4(4-5)[2-5]$ & $4.18(0.87)$ & $\begin{array}{c}1=\text { strongly disagree, } 2 \text { =disagree, } 3=\text { neutral, } 4=\text { agree, } \\
5=\text { strongly agree }\end{array}$ \\
\hline 2 & $\begin{array}{c}\text { The amount of information provided } \\
\text { was: }\end{array}$ & $3(3-4)[3-5]$ & $3.54(0.82)$ & $\begin{array}{l}1=\text { much less than wanted, } 2=a \text { little less than wanted, } 3=\text { about } \\
\text { right, } 4=a \text { little more than wanted, } 5=\text { much more than wanted }\end{array}$ \\
\hline 3 & The length of the decision aid was: & $2(2-3)[2-3]$ & $2.36(0.50)$ & $1=$ too short, 2=just right, $3=$ too long \\
\hline 4 & $\begin{array}{l}\text { I agree with the outcomes reported } \\
\text { (rates of benefits and risks): }\end{array}$ & $4(3-4)[3-4]$ & $3.64(0.50)$ & $\begin{array}{c}1=\text { strongly disagree, } 2=\text { disagree, } 3=\text { neutral, } 4=\text { agree, } \\
5=\text { strongly agree }\end{array}$ \\
\hline \multicolumn{5}{|c|}{ Large prostate volumes $(>150 \mathrm{ml})$} \\
\hline & Questions & $\begin{array}{l}\text { Median (IQR) } \\
\text { [range] }\end{array}$ & Mean (SD) & Legend \\
\hline 1 & $\begin{array}{l}\text { The language used was easy to } \\
\text { follow: }\end{array}$ & $4(4-5)[2-5]$ & $4.09(0.83)$ & $\begin{array}{c}1=\text { strongly disagree, } 2=\text { disagree, } 3=\text { neutral, } 4=\text { agree, } \\
5=\text { strongly agree }\end{array}$ \\
\hline 2 & $\begin{array}{l}\text { The amount of information provided } \\
\text { was: }\end{array}$ & $3(3-4)[3-5]$ & $3.45(0.69)$ & $\begin{array}{l}1=\text { much less than wanted, } 2=a \text { little less than wanted, } 3=\text { about } \\
\text { right, } 4=a \text { little more than wanted, } 5=\text { much more than wanted }\end{array}$ \\
\hline 3 & The length of the decision aid was: & $2(2-3)[2-3]$ & $2.36(0.50)$ & $1=$ too short, $2=$ just right, $3=$ too long \\
\hline 4 & $\begin{array}{l}\text { I agree with the outcomes reported } \\
\text { (rates of benefits and risks): }\end{array}$ & $4(4-4)[3-5]$ & $4.00(0.45)$ & $\begin{array}{c}1=\text { strongly disagree, } 2=\text { disagree, } 3=\text { neutral, } 4=\text { agree, } \\
5=\text { strongly agree }\end{array}$ \\
\hline \multicolumn{5}{|c|}{ Section for all prostate volumes } \\
\hline & Questions & $\begin{array}{l}\text { Median (IQR) } \\
\text { [range] }\end{array}$ & Mean (SD) & Legend \\
\hline 5 & $\begin{array}{l}\text { I believe the patient decision } \\
\text { aid would be a useful tool when } \\
\text { counseling a new patient with } \mathrm{BPH} \text { : }\end{array}$ & $4(3-5)[3-5]$ & $4.00(0.77)$ & $\begin{array}{c}1=\text { strongly disagree, } 2=\text { disagree, } 3=\text { neutral, } 4=\text { agree, } \\
5=\text { strongly agree }\end{array}$ \\
\hline 6 & $\begin{array}{c}\text { I anticipate using this patient } \\
\text { decision aid in my practice once it is } \\
\text { complete: }\end{array}$ & $\begin{array}{l}4.00(3-5) \\
{[3-5]}\end{array}$ & $4.00(0.77)$ & $\begin{array}{c}1=\text { strongly disagree, } 2=\text { disagree, } 3=\text { neutral, } 4=\text { agree, } \\
5=\text { strongly agree }\end{array}$ \\
\hline 7 & $\begin{array}{l}\text { I am satisfied with the overall quality } \\
\text { of this patient decision aid: }\end{array}$ & $\begin{array}{c}4.00(4-5) \\
{[3-5]}\end{array}$ & $4.09(0.70)$ & $\begin{array}{c}1=\text { strongly disagree, } 2=\text { disagree, } 3=\text { neutral, } 4=\text { agree, } \\
5=\text { strongly agree }\end{array}$ \\
\hline
\end{tabular}




\begin{tabular}{|c|c|c|c|c|c|c|c|c|c|c|}
\hline Moderate to large $(80-150 \mathrm{ml})$ & 0 & 0 & 0 & 0 & 0 & 0 & 0 & 0 & 0 & 11 \\
\hline Large $(>150 \mathrm{ml})$ & 0 & 0 & 0 & 0 & 0 & 0 & 0 & 1 & 1 & 10 \\
\hline
\end{tabular}

Methods: The Ottawa Decision Support Framework was used to develop a PtDA that addresses monopolar transurethral resection of the prostate (TURP), bipolar TURP, GreenLight photovaporization, enucleation, Rez m, Urolift, Aquablation, open retropubic prostatectomy, and robotic retropubic prostatectomy. The PtDA was divided into three sections according to prostate volumes. Eleven urologists that regularly treat BPH surgically were recruited to review the full PtDA and to complete alpha-testing. Alpha-testing was achieved through a survey developed from a validated acceptability scoring system.

Results: For all sections of the PtDA, the urologists agreed that the language used was easy to follow, that the amount of information provided was about right, that the length of the PtDA was appropriate, and that the outcomes reported were correct (Table 1). All 11 urologist participants $(100 \%)$ found that the description of the treatments within the moderate to large prostate section of the PtDA was well-balanced. For both the small to moderate and large prostate sections, 91\% (10/11) of participants found treatment descriptions were well-balanced (Table 2). Overall, urologists agreed that they anticipate using this PtDA once complete and that they are satisfied with the overall quality of the PtDA. Alpha-testing within the patient population is currently underway, with final results expected before June. Preliminary results for the patient population are listed in Table 3.

Conclusions: Our PtDA was found to be acceptable among clinicians. These results demonstrate that most of the clinician participants were satisfied with the quality of this PtDA and plan to incorporate this tool in their practice.

\section{UP-63}

Carbon footprint of disposable benign prostatic hyperplasia minimally invasive surgical devices: A standardized method for transurethral prostate surgery

Kevin C. Zorn ${ }^{1}$, Enrique Rijo ${ }^{2}$, D. Enikeev ${ }^{3}$, Dean S. Elterman ${ }^{4}$, Naeem Bhojani ${ }^{1}$, Alex De La Taille ${ }^{5}$, Thomas Herrman ${ }^{6}$, Benjamin Pradere ${ }^{7}$, Gregoire Robert ${ }^{8}$, Ahmed Zakaria ${ }^{7}$, Vincent Misrai ${ }^{9}$

'Urology, CHUM - University of Montreal Hospital Centre, Montreal, QC, Canada; ${ }^{2}$ Hospital Quiron Barcelona, Department of Urology, Barcelona, Spain; ${ }^{3}$ Institute for Urology and Reproductive Health, Sechenov University, Moscow, Russian Federation; ${ }^{4}$ University Health Network, University of Toronto, Toronto, ON, Canada; ${ }^{5}$ Assistance Publique Des Hopitaux de Paris, Creteil, France; ${ }^{6}$ Spital Thurgau AG, Department of Urology, Frauenfeld, Switzerland; 'Bordeaux University Hospital, Department of Urology, Bordeaux, France; ${ }^{8}$ Comprehensive Cancer Center, Medical University of Vienna, Vienna, Austria; ${ }^{9} \mathrm{Clinique}$ Pasteur, Department of Urology, Telouse, France

Introduction: The healthcare sector accounts for $4.4 \%$ of annual humaninduced $\mathrm{CO}_{2}$ net emissions $\left(\mathrm{CO}_{2} \mathrm{e}\right)$. Operating rooms are facing the arrival of a plethora of disposable mini-invasive surgical devices (MISDs) made from non-biodegradable materials with negative environmental impact. A standardized methodology for estimating the embodied carbon footprint (CF) of MISDs for transurethral benign prostatic hyperplasia (BPH) surgery is needed.

Methods: The proposed methodology relied on a partial product lifecycle assessment and was restricted to a specific part of Scope 3, which comprised the manufacturing of MISDs and non-device-associated products (packaging and user manual) (NDAPs). The process-sum inventory method was used, which involves collecting data on all the component processes underpinning disposable MISDs. The seven latest disposable MISDs were

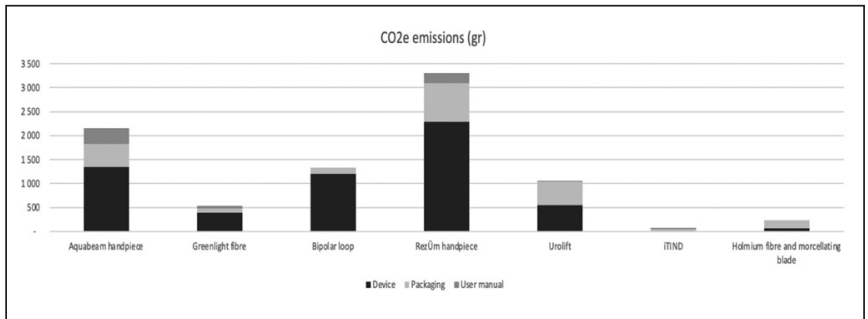

UP-63. Fig. 1. Proportion of non-device-associated products in the MISD embodied carbon footprint. "Urolift carbon footprint is presented for single pistol/implant.

dismantled, and each piece was categorized, sorted into the appropriate raw material group, and weighed. The CF was estimated according to the formula: activity data(wt raw material) $\mathrm{x}$ emission factors of the corresponding raw material $(\mathrm{kg} \mathrm{CO} \mathrm{e} / \mathrm{kg})$.

Results: Total weights of disposable packaging and user manuals ranged from $0.062-1492 \mathrm{~kg}$. Plastic was the most common and least emissive raw material $(2.38 \mathrm{~kg} \mathrm{CO}$ e/ $/ \mathrm{kg}$ ) identified. The estimated embodied CF of MISDs ranged from $0.07-3.3 \mathrm{~kg} \mathrm{CO} \mathrm{C}_{2}$, of which $9-86 \%$ was attributed to NDAPs. Among the two heaviest-weighted devices, Rezūm had the most $\mathrm{CO}_{2}$ e due to the multiplicity of components. Despite its technical simplicity, the disposable plasma loop was found to have the third highest CF due to the manufacturing of cables designed to support a high electric amperage. The lowest use of raw materials was found for the iTind and holmium laser enucleation of the prostate devices, which were also found to have the lowest estimated $\mathrm{CO}_{2} \mathrm{e}$.

Conclusions: This study described a simple and independent calculation method for estimating the embodied CF of MISDs, regardless of country specifications. Using this method, our results showed a wide discrepancy in the estimated $\mathrm{CO}_{2}$ emissions of the most recent disposable MISDs for transurethral $\mathrm{BPH}$ surgery.

\section{UP-64}

A pilot study to assess efficacy and safety of methoxyflurane for pain control during convective thermal therapy using Rezūm system in benign prostatic hyperplasia: Final results

Dean S. Elterman ${ }^{1}$, Bilal Chughtai ${ }^{2}$, Kevin C. Zorn ${ }^{3}$, Naeem Bhojani ${ }^{3}$ ${ }^{1}$ University Health Network, Toronto, ON, Canada; ${ }^{2}$ New York Presbyterian Hospital-Weill Cornell, New York, NY, United States; ${ }^{3}$ University of Montreal Hospital Centre, Montreal, QC, Canada

Introduction: The optimal pain control protocol for Rezūm in benign prostatic hyperplasia (BPH) has not been determined. The use of lowdose methoxyflurane administered via a portable, disposable, single-use handheld inhaler (Penthrox ${ }^{\top M}$ ) was assessed in this study.

Methods: An open-labeled, single-center pilot study was conducted to demonstrate the safety and efficacy in patients undergoing Rezūm using methoxyflurane inhaler on top of standard oral analgesia, including oral lorazepam, oral oxycodone and acetaminophen, and intra-urethral lidocaine gel. Intravenous propofol was used as rescue analgesia. Patients assessed current pain intensity using Visual Analog Scale (VAS) of Pain at four timepoints, including: 1 ) before any medication; 2 ) initially after insertion of the rigid cystoscope and before any Rezūm treatment; 3 ) immediately after final injection of Rezūm treatment; and 4) at discharge. 
Exhibit 3: Endourology

\begin{tabular}{|c|c|c|c|c|}
\hline \multicolumn{5}{|c|}{ Small to moderate prostate volumes $(<80 \mathrm{ml})(\mathrm{n}=3)$} \\
\hline & Questions & $\begin{array}{l}\text { Median (IQR) } \\
\text { [range] }\end{array}$ & Mean (SD) & Legend \\
\hline 1 & $\begin{array}{l}\text { The language used was easy to } \\
\text { follow: }\end{array}$ & $5(4-5)[4-5]$ & $4.67(0.58)$ & $\begin{array}{c}1=\text { strongly disagree, } 2=\text { disagree, } 3=\text { neutral, }=\text { agree, } 5=\text { strongly } \\
\text { agree }\end{array}$ \\
\hline 2 & $\begin{array}{l}\text { The amount of information } \\
\text { provided was: }\end{array}$ & $3(3-3)[3-3]$ & $3(0)$ & $\begin{array}{l}1=\text { much less than wanted, } 2=a \text { little less than wanted, } 3=\text { about } \\
\text { right, } 4=a \text { little more than wanted, } 5=\text { much more than wanted }\end{array}$ \\
\hline 3 & The length of the decision aid was: & $2(2-2)[2-2]$ & $2(0)$ & $1=$ too short, 2 =just right, $3=$ too long \\
\hline 4 & I agree with the outcomes reported: & $4(4-5)[4-5]$ & $4.33(0.58)$ & $\begin{array}{c}1=\text { strongly disagree, } 2=\text { disagree, } 3=\text { neutral, } 4=\text { agree, } 5=\text { strongly } \\
\text { agree }\end{array}$ \\
\hline 5 & $\begin{array}{c}\text { This decision aid would have } \\
\text { been helpful during my treatment } \\
\text { decision making: }\end{array}$ & $5(4-5)[4-5]$ & $4.67(0.58)$ & $\begin{array}{c}1=\text { strongly disagree, } 2=\text { disagree, } 3=\text { neutral, } 4=\text { agree, } 5=\text { strongly } \\
\text { agree }\end{array}$ \\
\hline 6 & $\begin{array}{l}\text { I would recommend this decision } \\
\text { aid for new patients with } \mathrm{BPH} \text { : }\end{array}$ & $5(5-5)[5-5]$ & $5.00(0)$ & $\begin{array}{c}1=\text { strongly disagree, } 2=\text { disagree, } 3=\text { neutral, } 4=\text { agree, } 5=\text { strongly } \\
\text { agree }\end{array}$ \\
\hline 7 & $\begin{array}{l}\text { I am satisfied with the overall } \\
\text { quality of this patient decision aid: }\end{array}$ & $5(4-5)[4-5]$ & $4.67(0.58)$ & $\begin{array}{c}1=\text { strongly disagree, } 2=\text { disagree, } 3=\text { neutral, } 4=\text { agree, } 5=\text { strongly } \\
\text { agree }\end{array}$ \\
\hline \multicolumn{5}{|c|}{ Moderate to large prostate volumes $(80-150 \mathrm{ml})(\mathrm{n}=1)$} \\
\hline & Questions & Median & Mean & Legend \\
\hline 1 & $\begin{array}{l}\text { The language used was easy to } \\
\text { follow: }\end{array}$ & 5 & 5.00 & $\begin{array}{c}1=\text { strongly disagree, } 2=\text { disagree, } 3=\text { neutral, } 4=\text { agree, } 5=\text { strongly } \\
\text { agree }\end{array}$ \\
\hline 2 & $\begin{array}{l}\text { The amount of information } \\
\text { provided was: }\end{array}$ & 3 & 3 & $\begin{array}{l}1=\text { much less than wanted, } 2=a \text { little less than wanted, } 3=\text { about } \\
\text { right, } 4=a \text { little more than wanted, } 5=\text { much more than wanted }\end{array}$ \\
\hline 3 & The length of the decision aid was: & 2 & 2 & $1=$ too short, $2=$ just right, $3=$ too long \\
\hline 4 & I agree with the outcomes reported: & 5 & 5 & $\begin{array}{c}1=\text { strongly disagree, } 2=\text { disagree, } 3=\text { neutral, } 4=\text { agree, } 5=\text { strongly } \\
\text { agree }\end{array}$ \\
\hline 5 & $\begin{array}{l}\text { This decision aid would have } \\
\text { been helpful during my treatment } \\
\text { decision making: }\end{array}$ & 4 & 4 & $\begin{array}{l}1=\text { strongly disagree, } 2=\text { disagree, } 3=\text { neutral, } 4=\text { agree, } 5=\text { strongly } \\
\text { agree }\end{array}$ \\
\hline 6 & $\begin{array}{l}\text { I would recommend this decision } \\
\text { aid for new patients with BPH: }\end{array}$ & 5 & 5 & $\begin{array}{c}1=\text { strongly disagree, } 2=\text { disagree, } 3=\text { neutral, } 4=\text { agree, } 5=\text { strongly } \\
\text { agree }\end{array}$ \\
\hline 7 & $\begin{array}{l}\text { I am satisfied with the overall } \\
\text { quality of this patient decision aid: }\end{array}$ & 5 & 5 & $\begin{array}{c}1=\text { strongly disagree, } 2=\text { disagree, } 3=\text { neutral, } 4=\text { agree, } 5=\text { strongly } \\
\text { agree }\end{array}$ \\
\hline \multicolumn{5}{|c|}{ Large prostate volumes $(>150 \mathrm{ml})(\mathrm{n}=2)$} \\
\hline & Questions & $\begin{array}{l}\text { Median } \\
\text { [range] }\end{array}$ & Mean (SD) & Legend \\
\hline 1 & $\begin{array}{l}\text { The language used was easy to } \\
\text { follow: }\end{array}$ & $4.5[4-5]$ & $4.5(0.71)$ & $\begin{array}{c}1=\text { strongly disagree, } 2=\text { disagree, } 3=\text { neutral, } 4=\text { agree, } 5=\text { strongly } \\
\text { agree }\end{array}$ \\
\hline 2 & $\begin{array}{l}\text { The amount of information } \\
\text { provided was: }\end{array}$ & $2.5[2-3]$ & $2.5(0.71)$ & $\begin{array}{l}1=\text { much less than wanted, } 2=a \text { little less than wanted, } 3=\text { about } \\
\text { right, } 4=\text { a little more than wanted, } 5=\text { much more than wanted }\end{array}$ \\
\hline 3 & The length of the decision aid was: & $1.5[1-2]$ & $1.5(0.71)$ & 1=too short, 2 =just right, $3=$ too long \\
\hline 4 & $\begin{array}{l}\text { I agree with the outcomes reported } \\
\text { (rates of benefits and risks): }\end{array}$ & $4.5[4-5]$ & $4.5(0.71)$ & $\begin{array}{c}1=\text { strongly disagree, } 2=\text { disagree, } 3=\text { neutral, } 4=\text { agree, } 5=\text { strongly } \\
\text { agree }\end{array}$ \\
\hline 5 & $\begin{array}{l}\text { This decision aid would have } \\
\text { been helpful during my treatment } \\
\text { decision making: }\end{array}$ & $5(5-5)[5-5]$ & $5.00(0)$ & $\begin{array}{l}1=\text { strongly disagree, } 2=\text { disagree, } 3=\text { neutral, } 4=\text { agree, } 5=\text { strongly } \\
\text { agree }\end{array}$ \\
\hline 6 & $\begin{array}{l}\text { I would recommend this decision } \\
\text { aid for new patients with BPH: }\end{array}$ & $5(5-5)[5-5]$ & $5.00(0)$ & $\begin{array}{c}1=\text { strongly disagree, } 2=\text { disagree, } 3=\text { neutral, } 4=\text { agree, } 5=\text { strongly } \\
\text { agree }\end{array}$ \\
\hline 7 & $\begin{array}{l}\text { I am satisfied with the overall } \\
\text { quality of this patient decision aid: }\end{array}$ & $4.5[4-5]$ & $4.5(0.71)$ & $\begin{array}{c}1=\text { strongly disagree, } 2=\text { disagree, } 3=\text { neutral, } 4=\text { agree, } 5=\text { strongly } \\
\text { agree }\end{array}$ \\
\hline
\end{tabular}

Alpha testing within the patient population is currently underway and results will be finalized by June. This table demonstrates the data collected thus far. To date, $6 / 20$ participants have been recruited. Among these participants, 3 were from the small to moderate prostate volume cohort, 1 from the moderate to large cohort, and 2 from the large prostate volume cohort. 
Patients were asked to rate on Treatment Satisfaction Questionnaire for Medication (TSQM 1.4) and one question about pain relief at discharge. Treating physician also assessed on TSQM 1.4.

Results: Ten patients were recruited for this pilot study. The average prostate volume was $66.4 \mathrm{cc}$ (range $24-158 \mathrm{cc}$ ). Four of 10 patients had urinary retention before. Patients received average 11 Rezūm injections, and procedure lasted an average 4.5 minutes. Average VAS scores were $0,1.4,1.3$ (primary efficacy outcome), and 0.9 at the four timepoints, respectively. TSQM scores on effectiveness, side effects, convenience and global satisfaction rated by patients were $76.1,87.3,78.3$, and 80.7 , while rated by treating physician were 98.3, 100,94.4, and 96.4. Treatment satisfaction of pain relief was rated as 3.9 (very good). There were no adverse events. Conclusions: Methoxyflurane inhaler on top of standard oral analgesia is a feasible and easy to administer pain management in Rezūm therapy. Further data from a larger comparative study is required.

\section{UP-65}

Rezūm water vapor therapy for catheter-dependent urinary retention: Real-world Canadian experience

Dean S. Elterman ${ }^{1}$, Naeem Bhojani ${ }^{2}$, Bilal Chughtai ${ }^{3}$, Kevin C. Zorn ${ }^{2}$

${ }^{1}$ University Health Network, Toronto, ON, Canada; ${ }^{2}$ University of Montreal Hospital Centre, Montreal, QC, Canada; ${ }^{3}$ Weill Cornell Medical College, New York, NY, United States

Introduction: Catheter-dependent urinary retention is typically treated with medical therapy or, failing that, transurethral surgery. Rezūm is a novel minimally invasive procedure using convective water vapor to ablate benign prostatic tissue. Herein, we study the outcomes of treating catheter-dependent urinary retention with Rezūm.

Methods: Rezūm was introduced to Canada in 2019 as a novel, out-ofhospital, minimally invasive surgical therapy for the treatment of benign prostatic hyperplasia-lower urinary symptoms (BPH-LUTS). A single, high-volume center prospectively collected baseline data, including BPH history, uroflowmetry, and validated questionnaires. This was an analysis of patients with refractory, catheter-dependent urinary retention.

Results: Sixteen patients (mean age 68.7 years) with catheter-dependent urinary retention were treated with Rezūm from April 2019 to December 2020. The average prostate volume was $84.4 \mathrm{ml}$ (range 41-158) and $75 \%$ had a median lobe. All patients had at least one recent failed trial without catheter (TWOC) and $87.5 \%$ were on $\mathrm{BPH}$ oral medical therapy. The mean number of total injections of vapor was 14.5 (range 10-21). The mean duration of the procedure (scope in to scope out time) was 6.1 minutes (range 3.2-10.5). Visibility and bleeding during the procedure were assessed using a five-points scale, and were rated as 1.4 and 1.3, respectively. Anesthesia was either intravenous propofol sedation $(n=13)$ or self-administered methoxyflurane inhaled medication $(n=3)$. Mean catheter-duration until first planned TWOC was 28.4 days. Three patients needed catheter replacement due to initial failed TWOC. At one month followup, 13/14 patients were spontaneously voiding and catheter-free. At three months, 14/14 patients were spontaneously voiding and at six months, 15/15 patients were spontaneously voiding and catheter-free (one patient was lost to followup).

Conclusions: Rezūm water vapor therapy can successfully treat catheterdependent urinary retention after initial failed TWOC in a quick, outpatient setting.

\section{UP-66}

Assessing the accuracy, quality, and readability of online educational health information related to the surgical management of benign prostatic hyperplasia

David Bouhadana ${ }^{1}$, David-Dan Nguyen ${ }^{1}$, Brendan Raizenne², Sai Vangala ${ }^{3}$, Iman Sadri', Bilal Chughtai ${ }^{4}$, Dean S. Elterman ${ }^{3}$, Kevin C. Zorn ${ }^{2}$, Naeem Bhojani ${ }^{2}$

${ }^{1}$ Faculty of Medicine, McGill University, Montreal, QC, Canada; ${ }^{2}$ Division of Urology, Centre Hospitalier de I'Université de Montréal, Montreal, QC, Canada; ${ }^{3}$ Division of Urology, University Health Network, University of Toronto, Toronto, ON, Canada; ${ }^{4}$ Department of Urology, NY-Presbyterian Hospital, Weill Cornell Medical Center, New York, NY, United States

\begin{tabular}{|c|c|c|c|}
\hline $\begin{array}{l}\text { Treatment } \\
\text { modality }\end{array}$ & $\begin{array}{c}\text { Median } \\
\text { accuracy score } \\
\text { (IQR) [range] }\end{array}$ & $\begin{array}{c}\text { Median } \\
\text { quality score } \\
\text { (IQR) [range] }\end{array}$ & $\begin{array}{c}\text { Median } \\
\text { readability grade } \\
\text { level (IQR) [range] }\end{array}$ \\
\hline TURP & $\begin{array}{c}4.00 \\
(4.00-5.00) \\
{[4.00-5.00]}\end{array}$ & $\begin{array}{c}27.00 \\
(21.00-28.00) \\
{[16.00-28.00]}\end{array}$ & $\begin{array}{c}9.00 \\
(8.25-9.50) \\
{[7.02-9.60]}\end{array}$ \\
\hline $\begin{array}{l}\text { GreenLight } \\
\text { PVP }\end{array}$ & $\begin{array}{c}5.00 \\
(4.50-5.00) \\
{[4.00-5.00]}\end{array}$ & $\begin{array}{c}17.00 \\
(15.50-20.50) \\
{[15.00-23.00]}\end{array}$ & $\begin{array}{c}11.10 \\
(9.30-13.10) \\
{[7.00-13.10]}\end{array}$ \\
\hline Enucleation & $\begin{array}{c}5.00 \\
(4.50-5.00) \\
{[4.00-5.00]}\end{array}$ & $\begin{array}{c}21.00 \\
(13.50-26.00) \\
{[10.00-27.00]}\end{array}$ & $\begin{array}{c}11.70 \\
(9.65-14.60) \\
{[8.64-16.10]}\end{array}$ \\
\hline Rezum & $\begin{array}{c}5.00 \\
(4.50-5.00) \\
{[4.00-5.00]}\end{array}$ & $\begin{array}{c}19.00 \\
(15.00-23.00) \\
{[14.00-27.00]}\end{array}$ & $\begin{array}{c}10.40 \\
(9.80-11.95) \\
{[9.34-12.20]}\end{array}$ \\
\hline Urolift & $\begin{array}{c}5.00 \\
(4.50-5.00) \\
{[4.00-5.00]}\end{array}$ & $\begin{array}{c}18.00 \\
(14.50-25.00) \\
{[14.00-25.00]}\end{array}$ & $\begin{array}{c}10.60 \\
(10.20-11.00) \\
{[10.38-11.00]}\end{array}$ \\
\hline Aquablation & $\begin{array}{c}5.00 \\
(5.00-5.00) \\
{[5.00-5.00]}\end{array}$ & $\begin{array}{c}15.00 \\
(11.50-20.50) \\
{[11.00-24.00]}\end{array}$ & $\begin{array}{c}12.70 \\
(11.85-13.60) \\
{[11.42-13.70]}\end{array}$ \\
\hline OSP & $\begin{array}{c}5.00 \\
(5.00-5.00) \\
{[5.00-5.00]}\end{array}$ & $\begin{array}{c}27.00 \\
(22.00-29.00) \\
{[17.00-29.00]}\end{array}$ & $\begin{array}{c}10.20 \\
(8.60-12.65) \\
{[8.54-15.10]}\end{array}$ \\
\hline RSP & $\begin{array}{c}5.00 \\
(4.50-5.00) \\
{[4.00-5.00]}\end{array}$ & $\begin{array}{c}15.00 \\
(10.50-16.50) \\
{[9.00-17.00]}\end{array}$ & $\begin{array}{c}14.35 \\
(13.35-15.58) \\
{[11.04-16.10]}\end{array}$ \\
\hline
\end{tabular}

The 5 reviewers independently assessed the websites related to each respective treatment modality.

Introduction: Given the many treatments available for benign prostatic hyperplasia (BPH), patients may seek to learn more about these treatments with the help of online resources to decide what best meets their personal preferences. Therefore, it is important that such resources are evaluated for their accuracy, quality, and readability to ensure that patients can make use of the provided information.

Methods: Eight treatment modalities, including transurethral resection of the prostate (TURP), GreenLight photovaporization, enucleation, Rezūm, Urolift, Aquablation, open simple prostatectomy, and robotic simple prostatectomy (RSP) were searched to retrieve the first five relevant websites related to each treatment. The retrieved websites were then assessed for their accuracy, quality, and readability by five independent reviewers using validated tools or methods employed in similar studies.

Results: On average, the websites were $97.94 \%$ accurate, of good quality, with a Brief DISCERN score of 19.50, and of poor readability, with a grade level of 11.24. The median quality score was statistically different across the eight treatment modalities ( $p=0.015)$; however, no pairwise comparisons within the treatment groups were found to be statistically significant. The median readability grade level was statistically different across the eight treatment modalities $(p=0.009)$. Websites that described TURP were significantly easier to read than those related to RSP $(p=0.011)$. Detailed accuracy, quality, and readability scores for each treatment can be found in Table 1.

Conclusions: Most websites retrieved were found to be of high accuracy, good quality, and poor readability. Additionally, it was found that none of the retrieved websites included a description of all treatment modalities included in this study. Given these findings, the authors recommend the development of centralized resources, such as patient decision aids 
that include all guideline-approved treatment modalities and provide accurate, readable, and high-quality information related to the surgical treatment of $\mathrm{BPH}$.

\section{UP-67 \\ Incidental prostate cancer in transurethral resection of the prostate: A comparison of modern resection techniques \\ Samuel laquet ${ }^{1}$, Zaineb Ben Mefteh ${ }^{1}$, Kevin C. Zorn ${ }^{2}$, Naeem Bhojani ${ }^{2}$ Dominique Trudel ${ }^{1}$ \\ 'Department of Pathology, Centre Hospitalier de l'Université de Montréal, Montreal, QC, Canada; ${ }^{2}$ Department of Urology, Centre Hospitalier de I'Université de Montréal, Montreal, QC, Canada \\ Introduction: Modern surgical techniques for treatment of benign prostate hyperplasia (BPH) provide pathologists with new challenges in interpreta- tion of transurethral resection of prostate (TURP) specimens. We sought to compare incidentally detected prostate cancer (PCa) rates in holmium/ thulium/Greenlight laser enucleation (LEP), Greenlight photoselective vaporesection (PVRP) and mono/bipolar TURP (mbTURP) for BPH lower urinary tract symptoms (LUTS).}

Methods: We reviewed data from all TURP specimens received at our pathology department from 2016-2020 ( $n=1228)$, including age, pre/ postoperative prostate-specific antigen (PSA) levels, preoperative prostate volume (PV), indication, technique, and pathological reports. After patients with known or suspected PCa or with TURP indication other than LUTS were excluded, PCa rates were calculated.

Results: A total of 976 specimens were included (664 mbTURP, 194 PVRP, and 118 LEP). Mean age was 70.5, 68.3, and 69.3 years, respectively. PV were larger in LEP (mean $=137.7 \mathrm{ml}, \mathrm{p}<0.0001$ ) compared to PVRP $(82.6 \mathrm{ml})$ and $\mathrm{mbTURP}(75.1 \mathrm{ml})$. Preoperative PSA levels were higher in LEP (median=4.9 ng/ml, $\mathrm{p}=0.025$ ) compared with mbTURP (2.9 ng/ $\mathrm{ml}$ ) and PVRP (3.2 $\mathrm{ng} / \mathrm{ml})$. Resected volume/PV ratios were higher in LEP (mean $=72.9 \%, p<0.0001)$ than mbTURP $(29.8 \%)$ and PVRP (8.0\%). Eightyeight $(9.9 \%)$ PCa were identified, with ISUP grade groups distributed as follows: 57 group $1(64.8 \%)$, three group $2(3.4 \%), 21$ group $3(23.9 \%)$, two group $4(2.3 \%)$, and five group $5(5.7 \%)$. Cancer involved more than $5 \%$ of the resected volume (CT1b) in 27 cases $(30.7 \%)$. Incidental PCa was identified in $69 \mathrm{mbTURP}(10.4 \%)$, two PVRP $(1.0 \%)$, and $17 \operatorname{LEP}(14.4 \%)$ specimens, which was significantly different $(p<0.001)$.

Conclusions: Incidental PCa rates were significantly lower in patients who underwent PVRP than mbTURP and LEP likely related to the smaller resected volume. Vaporization technique in PVRP, yielding in lower resected volumes with important cauterization artifacts, could contribute to this difference.

\section{UP-68}

Top-down thulium fiber laser (TFL) enucleation of the prostate: Early postoperative outcomes

Hazem Elmansy', Waleed Shabana', Miranda Waugh', Abdulrahman Ahmad', Ruba Abdul Hadi', Thomas Tablowski', Ahmed Kotb', Walid Shahrour

${ }^{1}$ Northen Ontario School of Medicine, Thunder Bay, ON, Canada

Introduction: Thulium fiber laser (TFL) enucleation of the prostate is an emerging technology for endoscopic prostate enucleation that is notable for its high wavelength and pulsed mode of action. We demonstrate the operative parameters and postoperative outcomes of top-down TFL enucleation of the prostate.

Methods: Between July 2020 and August 2020, 10 patients with a median age of 79 years (66-83) underwent TFL enucleation of the prostate using the top-down approach. The procedures were performed by a single surgeon (HE) using a $28 \mathrm{~F}$ continuous flow resectoscope (Karl Storz, $\mathrm{GmbH}$, Tuttlingen, Germany) and a $550 \mu \mathrm{m}$ thulium fiber laser (Soltive ${ }^{\mathrm{TM}}$ SuperPulsed Laser System, Olympus). Operative parameters, including enucleation time, morcellation time, and perioperative complications, were recorded and statistically analyzed. Early postoperative outcome data were collected after three months and compared to preoperative parameters.

Results: The median preoperative prostate size was $97 \mathrm{~g}$ (85-117) and the median preoperative prostate-specific antigen (PSA) was $3.1 \mathrm{ng} / \mathrm{dl}$
(2.7-3.6). No intraoperative or early postoperative complications were recorded. At three months postoperative, there were significant improvements in postoperative urinary functions including maximum flow rate (7.4 [4.9-9.9] vs. 19.2 [17.1-26.3] mL/sec, $\mathrm{p}<0.01$ ), post-void residual (137.9 [128.3-141.8] vs. 14.5 [11.6-17.9] mL, $p<0.01$ ), International Prostate Symptom Score (20.8 [18.5-22.7] vs. 6.9 [5.7-8.1], $\mathrm{p}<0.001)$ and quality of life score (4.1 [3.7-4.8] vs. $1.5[1.1-1.8], \mathrm{p}<0.001)$.

Conclusions: The top-down enucleation technique is safe and effective with the novel TFL. The preliminary results demonstrate a significant improvement in urinary outcomes.

\section{UP-69}

Autopilot transurethral resection of the prostate: Use of overnight surgical unit to enhance hospital flow and capacity

Lames Hayes ${ }^{1}$, James Ross', Duane R. Hickling', Luke T. Lavallee', Humberto Vigil'

${ }^{1}$ Department of Surgery, Division of Urology, University of Ottawa, Ottawa, ON, Canada

Introduction: At our institution, there are two care pathways following a transurethral resection of the prostate (TURP). The same-day admission (SDA) pathway is the traditional care pathway and includes continuous bladder irrigation, resident-led rounds, and a trial of void (TOV). Patients are discharged postoperative day (POD) 1 typically after $11 \mathrm{am}$. In the surgical daycare overnight (SDON) pathway, patients are not admitted, and similarly receive irrigation and TOV; however, they are discharged before $7 \mathrm{am}$ at the discretion of SDON nursing staff, enhancing patient flow and inpatient capacity. Herein, we set out to compare the SDA and SDON care pathways for TURP patients at our institution. We hypothesize that the SDON pathway provides equivalent care without increased visits to the emergency department (ED).

Methods: We retrospectively reviewed the charts of all elective TURP patients at our two-center academic institution between June 2019 and March 2020. We evaluated patient demographic and baseline factors, surgical details, discharge details and 14-day ED visits. Student's t-test was used to compare continuous variables. Our primary outcome was successful POD 1 discharge without 14-day ED visits.

Results: Care pathways were successful without 14-day ED visits in $72 / 103$ $(70 \%)$ SDA patients and $47 / 65(72 \%)$ SDON patients. Similar patient parameters included mean ASA score (SDA 2.7, SDON 2.6, $\mathrm{p}=0.38$ ), preoperative catheter (SDA 47\%, SDON 45\%), mean age (SDA 72, SDON $70, p=0.19$ ), and mean resection volume (SDA $15.8 \mathrm{~g}$, SDON $17.6 \mathrm{~g}$, $\mathrm{p}=0.31)$. More SDON patients were pre-planned to be discharged with a catheter $(49 \%$ vs. $25 \%)$. Rates of TOV failure were similar between pathways (SDA $17.5 \%$, SDON 15.4\%). ED visit rates within 14 days were similar (23.3\% SDA, 18.5\% SDON). Delayed discharge rates were $13 \%$ for SDA and $14 \%$ for SDON.

Conclusions: The TURP SDON pathway is a safe and efficient discharge alternative to SDA in comparable patient populations without an increase in $\mathrm{ED}$ visits.

\section{UP-70}

Etiology, urine metabolic risk factors, and urine oxalate patterns in patients with significant hyperoxaluria and recurrent nephrolithiasis

Lonathan Moore' ${ }^{1}$, David Mauler', Gopal Narang ${ }^{1}$, Karen Stern ${ }^{1}$, Mitchell $R$ Humphreys ${ }^{1}$, Mira Keddis ${ }^{2}$

'Department of Urology, Mayo Clinic Arizona, Phoenix, AZ, United States; 2Department of Nephrology, Mayo Clinic Arizona, Phoenix, AZ, United States

Introduction: The goal of this study was to characterize the etiology of significant hyperoxaluria, along with urine metabolic risk factors, rates of genetic testing, and change in hyperoxaluria over time in a large, multidisciplinary, adult stone clinic.

Methods: A retrospective review was performed of patients evaluated in the multidisciplinary stone clinic from a single institution between 2006 and 2019. The American Urological Association (AUA) guideline suggesting genetic workup for patients with urine oxalate $(\mathrm{uOx})>75 \mathrm{mg} /$ day. 
This cutoff was used to define significant hyperoxaluria. Patients without an identifiable enteric cause were considered idiopathic. Results from 24-hour urines, stone events, and labs were collected.

Results: A total of 4229 separate 24-hour urine collections in 1302 individual patients were reviewed. A total of 103 (7.9\%) patients had a UOx above $75 \mathrm{mg}$ /day (Table 1). Enteric hyperoxaluria (EH) was diagnosed in $27 \%$ and idiopathic hyperoxaluria $(\mathrm{IH})$ in $74 \%$. Etiology of EH is shown in Fig.1. The median uOx level for all hyperoxaluric patients was 100.6 $\mathrm{mg} /$ day, with a higher level in the $\mathrm{EH}$ group (93.0 vs. $121.0 \mathrm{mg} /$ day). Complete 24-hour urine parameters are shown in Table 2. For the entire cohort, there was a significant drop in uOx $(-33.8 \mathrm{mg} /$ day $)$ after medical and dietary therapy at median followup of 46.6 months. The final uOx remained significantly higher in $\mathrm{EH}(88.9$ vs. $60.1 \mathrm{mg} /$ day, $\mathrm{p}=0.002)$. Only one patient had referral for genetic testing and was found to have primary hyperoxaluria type 2 .

Conclusions: The most common cause of significant hyperoxaluria in patients with recurrent nephrolithiasis remains idiopathic. Patients with IH have more improvement in uOx with therapy compared to those with $\mathrm{EH}$; however, both groups continued to show significant hyperoxaluria at last followup. The current rate of genetic referral and testing is low despite guideline recommendations and represents an unmet need in this population.

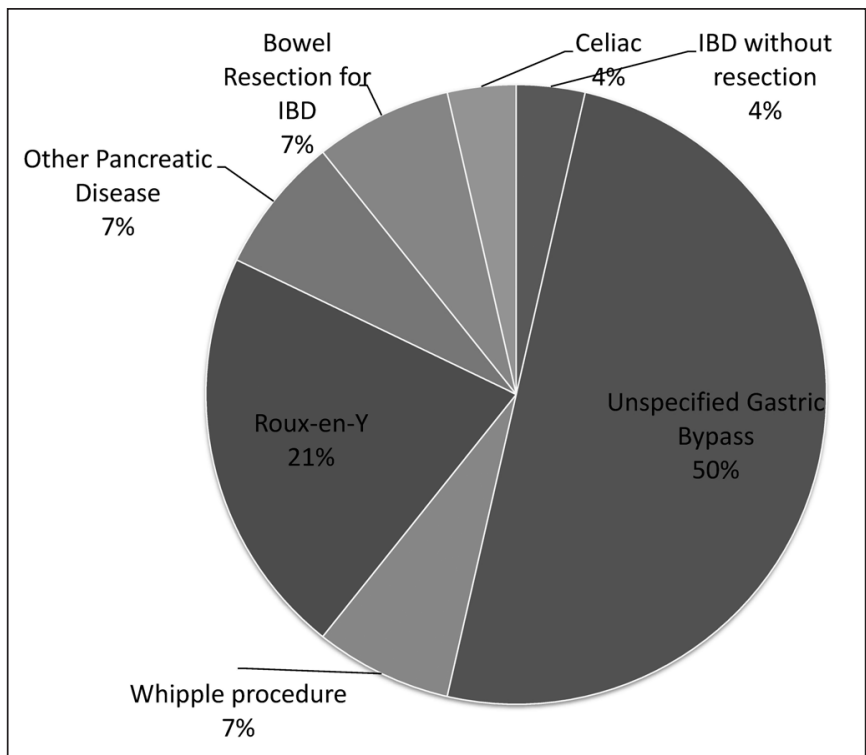

UP-70. Fig. 1. Etiology of enteric hyperoxaluria in patients with levels above $75 \mathrm{mg} / \mathrm{day}$

\begin{tabular}{|c|c|c|c|c|}
\hline Parameter & Total $(n=103)$ & Idiopathic (n=75) & Enteric $(n=28)$ & $\mathbf{p}$ \\
\hline Age at first collection & $62.2(13.3 ; 20-85)$ & $62.0(13.3 ; 20-85)$ & $59.7(11.3 ; 41-81)$ & 0.414 \\
\hline Gender $=\mathrm{M}(\%)$ & $51(67.1 \%)$ & $50(66.7 \%)$ & $22(78.6 \%)$ & 0.241 \\
\hline BMI (SD, range) & $30.0(7.61,14.0-59.1)$ & $29.8(7.97,19.3-59.1)$ & $30.6(6.75,14.0-42.9)$ & 0.649 \\
\hline \multicolumn{5}{|l|}{ Past medical history } \\
\hline CKD III-V & $6(6 \%)$ & $4(5.3 \%)$ & $2(7 \%)$ & 0.662 \\
\hline Liver failure & $3(3 \%)$ & $3(3.9 \%)$ & $0(0 \%)$ & 0.561 \\
\hline Bone/joint disorder & $19(18 \%)$ & $13(17.1 \%)$ & $6(21 \%)$ & 0.634 \\
\hline Cardiac arrhythmia & $13(13 \%)$ & $12(16 \%)$ & $1(4 \%)$ & 0.108 \\
\hline Gross hematuria & 7 (7\%) & $6(7.9 \%)$ & $1(4 \%)$ & 0.671 \\
\hline Diabetes type II & $23(22 \%)$ & $20(26.3 \%)$ & $3(11 \%)$ & 0.084 \\
\hline Hyperparathyroidism & $5(5 \%)$ & $4(5.3 \%)$ & $1(4 \%)$ & 1.000 \\
\hline Distal renal tubular acidosis & $1(1 \%)$ & $1(1.3 \%)$ & $0(0 \%)$ & 1.000 \\
\hline \multicolumn{5}{|l|}{ Personal stone history } \\
\hline Age of first stone, y (range) & $46.5(9-81)$ & $45.5(9-81)$ & $49(20-78)$ & 0.272 \\
\hline Median number stone episodes (range) & $3.0(1-400)$ & $11.4(1-400)$ & $4.0(1-50)$ & 0.443 \\
\hline Family history of stones (\%) & $11(14.5 \%)$ & & & \\
\hline Primary stone type & & & & 0.393 \\
\hline $100 \% \mathrm{CaOx}$ monohydrate & $26(25 \%)$ & $19(25 \%)$ & $7(25 \%)$ & \\
\hline Mixed $\mathrm{CaOx}$ primary & $46(45 \%)$ & $34(45 \%)$ & $12(43 \%)$ & \\
\hline UA primary & $6(6 \%)$ & $3(4 \%)$ & $3(11 \%)$ & \\
\hline CaP primary & $8(8 \%)$ & 7 (9\%) & $1(4 \%)$ & \\
\hline Other & $1(1 \%)$ & $0(0 \%)$ & $1(4 \%)$ & \\
\hline No stone analysis performed & $16(16 \%)$ & $12(16 \%)$ & $4(14 \%)$ & \\
\hline Followup time, months (SD, range) & $46.6(40,0-154.3)$ & $47.7(24.1,0-154.4$ & $43.5(34.3,0-128.8)$ & 0.633 \\
\hline Number of $24 \mathrm{~h}$ tests done (SD, range) & $3.80(3.36,1-19)$ & $4.27(3.57,1-19)$ & $2.54(2.33,1-11)$ & 0.010 \\
\hline
\end{tabular}


Exhibit 3: Endourology

\begin{tabular}{lcccc}
\hline UP-70. Table 2. Initial 24-hour urine results for patients with hyperoxaluria above $\mathbf{7 5} \mathbf{~ m g / d a y}$ \\
\hline $\begin{array}{l}\text { 24-hour urine parameter } \\
\text { (SD, range) }\end{array}$ & Total $(\mathbf{n}=\mathbf{1 0 3})$ & Idiopathic $(\mathbf{n}=\mathbf{7 5})$ & Enteric $(\mathbf{n}=\mathbf{2 8})$ & $\mathbf{p}$ \\
\hline Volume (L) & & & & \\
SS calcium oxalate & $2.67(0.91,0.72-6.2)$ & $2.75(0.93,0.72-6.20)$ & $2.46(0.84,1.00-3.96)$ & 0.150 \\
Calcium (mg/d) & $7.76(3.58,1.84-19.5)$ & $8.06(3.73,1.84-19.5)$ & $6.96(3.05,1.98-16.6)$ & 0.166 \\
Oxalate (mg/d) & $178.4(139.6,13.11-772.5)$ & $200.3(144.7,13.1-772.5)$ & $119.95(106.70,24.1-477.8)$ & 0.009 \\
Most recent oxalate (mg/d, & $100.6(35.3,75.2-294.5)$ & $93.0(20.6,75.2-180.1)$ & $121.0(54.3,75.7-294.5)$ & $<0.001$ \\
n=69) & $66.0(32.2,21.8-178.0)$ & $60.1(28.1,21.8-157.5)$ & $88.9(37.8,24.3-178.0)$ & 0.002 \\
Citrate (mg/d) & & & & \\
SS calcium phosphate & $758.8(489.7,10.8-2448.8)$ & $841.4(504.2,10.8-2448.8)$ & $539.6(373.4,38.7-1289.4)$ & 0.005 \\
pH & $0.821(0.86,0.01-4.50)$ & $0.989(0.915,0.01-4.50)$ & $0.37(0.14,0.02-1.86)$ & 0.001 \\
SS uric acid & $6.24(0.67,5.0-8.73)$ & $6.39(0.647,5.1-8.73)$ & $5.85(0.579,5.03-7.54)$ & $<0.001$ \\
Uric acid (g/d) & $0.61(0.64,0.0-3.1)$ & $0.499(0.613,0.0-3.10)$ & $0.901(0.639,0.01-2.58)$ & 0.004 \\
\hline
\end{tabular}

\section{UP-71}

Miniaturized ambulatory percutaneous nephrolithotomy (miniPCNL) vs. flexible ureteroscopy (F-URS) in the management of lower calyceal renal stones 10-20 $\mathrm{mm}$ : A propensity score matching analysis

Waleed Shabana ${ }^{1}$, Fabiola Oquendo ${ }^{1}$, Abdulrhman Ahmed ${ }^{1}$, Amr Hodhod $^{1}$, Sabrina Trigo ${ }^{1}$, Jill Skogberg', Amer Alaref', Ahmed Kotb', Walid Shahrour ${ }^{1}$, Hazem Elmansy

${ }^{1}$ Northen Ontario School of Medicine, Thunder Bay, ON, Canada Introduction: We aimed to compare the effectiveness of miniaturized ambulatory percutaneous nephrolithotomy (mini-PCNL) and flexible ureteroscopy (F-URS) in treating 10-20 mm lower calyceal stones using a logistic regression model with propensity score matching (PSM) to create similar patient groups for accurate comparison.

Methods: We carried out a retrospective analysis of adult patients that underwent mini-PCNL or F-URS at our institution from September 2018 to August 2020. Patients were discharged on the same day of their procedure. A non-contrast helical computed tomography was performed at three months postoperatively to detect residual stones accurately. Patients' clinical characteristics, stone demographics, and perioperative outcomes were collected and statistically analyzed.

Results: After PSM, 60 patients from the F-URS cohort were matched to 60 similar patients from the mini-PCNL group. The results of clinical characteristics and postoperative outcomes following PSM are listed in Table 1. The stone-free rate (SFR) after PSM was not significantly higher in the mini-PCNL group than in the F-URS group (91.6\% vs. $81.6 \%$, respectively, $\mathrm{p}=0.1$ ). The median operative time for the $\mathrm{F}-\mathrm{URS}$ group was significantly shorter than for the mini-PCNL group (54 [64.25-49] and 68.2 [73.5-62], respectively, $p=0$. 045) (Table 1).

Conclusions: Ambulatory mini-PCNL and F-URS have comparable hospital stay, SFR, and complication rates when treating lower calyceal stones $10-20 \mathrm{~mm}$ in size.

\section{UP-72}

Development of a new Canadian Endourology Group Stent Symptom Score (CEGSSS)

Naeem Bhojani', Jason Y. Lee², Shubhadip (Shubha) K. De ${ }^{3}$, Andrea Lantz Powers ${ }^{4}$, Sri Sivalingam ${ }^{5}$, Michael Ordon ${ }^{2}$, Kymora Scotland ${ }^{6}$, Sero Andonian, Ben H. Chew ${ }^{8}$

${ }^{1}$ Urology, University of Montreal, Montreal, QC, Canada; ${ }^{2}$ Urology, University of Toronto, Toronto, ON, Canada; ${ }^{3}$ Urology, University of Alberta, Edmonton, AB, Canada; ${ }^{4}$ Urology, Dalhousie University, Halifax, NS, Canada; ${ }^{5}$ Urology, Cleveland Clinic, Cleveland, $\mathrm{OH}$, United States; ${ }^{6}$ Urology, University of California Los Angeles, Los Angeles, CA, United States; ${ }^{7}$ Urology, McGill University, Montreal, QC, Canada; ${ }^{8}$ Urology, University of British Columbia, Vancouver, BC, Canada; Canadian Endourology Group

Introduction: Placement of a ureteral stent is a common urological intervention that can significantly impact quality of life (QoL). The ureteral

\begin{tabular}{|c|c|c|c|}
\hline $\begin{array}{l}\text { Characteristics and } \\
\text { outcomes }\end{array}$ & $\begin{array}{c}\text { Group I: } \\
\text { F-URS ( } n=60)\end{array}$ & $\begin{array}{l}\text { Group II: Mini- } \\
\text { PCNL (n=60) }\end{array}$ & $\mathbf{p}$ \\
\hline \multicolumn{4}{|l|}{ Gender, n (\%) } \\
\hline $\begin{array}{l}\text { Male } \\
\text { Female }\end{array}$ & $\begin{array}{l}30(50 \%) \\
30(50 \%)\end{array}$ & $\begin{array}{l}40(66.7 \%) \\
20(33.3 \%)\end{array}$ & $0.06^{b}$ \\
\hline Age, years & $58.5(46.25-66)$ & $62(54-68)$ & $0.43^{a}$ \\
\hline $\mathrm{BMI}, \mathrm{kg} / \mathrm{m}^{2}$ & $29(24-33)$ & $28(22-34)$ & $0.74^{\mathrm{a}}$ \\
\hline Stone size, $\mathrm{mm}$ & $13.5(11-16)$ & $14.3(11.3-16.8)$ & $0.49^{a}$ \\
\hline Hounsfield unit & $636(450-964)$ & $572(457-900)$ & $0.36^{a}$ \\
\hline Hydronephrosis, n (\%) & $10(16.7 \%)$ & $20(33.3 \%)$ & $0.057^{\mathrm{b}}$ \\
\hline \multicolumn{4}{|l|}{ Operation side, n (\%) } \\
\hline $\begin{array}{l}\text { Right } \\
\text { Left }\end{array}$ & $\begin{array}{l}26(43.3 \%) \\
34(56.7 \%)\end{array}$ & $\begin{array}{l}36(60 \%) \\
24(40 \%)\end{array}$ & $0.06^{b}$ \\
\hline $\begin{array}{l}\text { Operative time, } \\
\text { minutes }\end{array}$ & $54(49-64.3)$ & $68.2(62-73.5)$ & $0.045^{\mathrm{a}}$ \\
\hline Hospital stay, hours & $4(4-5)$ & $6(6-7)$ & $0.04^{\mathrm{a}}$ \\
\hline JJ stenting, n (\%) & $59(98.3 \%)$ & $6(10 \%)$ & $<0.001^{b}$ \\
\hline Stone-free rate, n (\%) & $49 / 60(81.7 \%)$ & $55 / 60(91.7 \%)$ & $0.10^{\mathrm{b}}$ \\
\hline \multicolumn{4}{|c|}{$\begin{array}{l}\text { Clavien-Dindo complications } \\
\text { grade, } \mathrm{n}(\%)\end{array}$} \\
\hline $\begin{array}{l}\text { Grade I (hematuria) } \\
\text { Grade II (fever) }\end{array}$ & $\begin{array}{c}11(18.3 \%) \\
2(3.3 \%)\end{array}$ & $\begin{array}{c}14(23.3 \%) \\
1(1.7 \%)\end{array}$ & $0.98^{b}$ \\
\hline
\end{tabular}

aMann-Whitney $\mathrm{U}$ test. ${ }^{\mathrm{b}} \mathrm{Chi}$-squared test $\left(\mathrm{X}^{2}\right) /$ Yates correction. Data are presented as median (IQR1-IQR3) or number (\%) as appropriate.

stent symptom questionnaire (USSQ) has been used since its development in 2003 but its length hinders its use in clinical practice. Therefore, we sought to develop a new, shorter, practical, and validated tool.

Methods: Phase 1: Using the USSQ as a starting point, nine Canadian Endourology Group (CEG) members and 21 patients evaluated each item of the USSQ (Likert scale 1-5) to determine its importance/relevance in assessing symptoms associated with a ureteral stent. All accepted items were than discussed with face-to-face meetings. Phase 2 (pilot trial): Patients undergoing stent placement completed the newly developed CEGSSS, in addition to a short survey evaluating the tool itself. Five rounds of five patients, with modifications of the CEGSSS based on feedback after every round was anticipated.

Results: Phase 1: After consultation with patients and CEG experts, items were accepted if the mean patient or expert rating was $\geq 4.0$ (out of 5 ), 


\begin{tabular}{lc}
\hline UP-72. Table 1. CEGSSS pilot trial data analysis & \\
\hline Number of participants & 16 \\
Number of cycles & 3 \\
Mean time for completion (minutes) & 8 \\
Median time for completion (minutes) & 7 \\
Minimum time for completion (minutes) & 2 \\
Maximum time for completion (minutes) & 20 \\
Participants that needed help to complete & $2 / 16$ \\
Mean score of difficulty (Likert scale on 5) & 1.75 \\
Mean score of visual appearance (Likert scale on 5) & 2.53 \\
\hline
\end{tabular}

with a standard deviation (SD) of $\leq 0.75$. Questions with mean patient or mean expert ratings of $\geq 4.0$ but $S D \geq 0.75$ or with divergent results between patients and experts were flagged for discussion. Those items that did not meet these requirements were rejected. The final CEGSSS contains 15 questions divided into three domains: urination (eight questions), pain (three questions), and QoL (two questions). Phase 2: Sixteen patients were recruited. After three rounds of patient feedback, no new feedback was received and therefore this process was deemed complete (Table 1). Median time to complete the CEGSSS was seven minutes (2-20 minutes). Two of 16 patients required assistance to complete the questionnaire, but all patients rated it as easy to navigate. Mean level of difficulty was 1.75/5. Conclusions: Through a process of expert and patient consultation and a pilot trial, a new stent symptom questionnaire was developed that is short, easy for patients to understand, and clinically relevant. The next step will be external validation of the newly developed CEGSSS.

\section{UP-73}

The impact of surgery and stone passage on kidney stone patient quality of life

Brendan Raizenne ${ }^{1}$, Zhe Tian ${ }^{1}$, Kristina L. Penniston ${ }^{2}$, Roger L. Sur ${ }^{3}$, Jodi A. Antonelli ${ }^{4}$, Necole M. Streeper ${ }^{5}$, Sri Sivalingam ${ }^{6}$, Davis P. Viprakasit ${ }^{7}$, Timothy D. Averch ${ }^{8}$, Thomas Chi $i^{9}$, Vernon M. Pais Jr ${ }^{10}$, Ben H. Chew ${ }^{11}$, Vincent G. Bird ${ }^{12}$, Sero Andonian ${ }^{13}$, Noah E. Canvasser ${ }^{14}$, Jaime Landman ${ }^{15}$, Naeem Bhojani'

'Division of Urology, Centre Hospitalier de I'Université de Montréal, Montreal, QC, Canada; ${ }^{2}$ Department of Urology, University of Wisconsin School of Medicine and Public Health, Madison, WI, United States; ${ }^{3}$ Department of Urology, University of California San Diego, San Diego, CA, United States; ${ }^{4}$ Department of Urology, University of Texas Southwestern Medical Center, Dallas, TX, United States; ${ }^{5}$ Division of Urology, Pennsylvania State University College of Medicine, Hershey, PA, United States; ${ }^{6}$ Glickman Urological and Kidney Institute, Cleveland Clinic, Cleveland, $\mathrm{OH}$, United States; ${ }^{7}$ Department of Urology, University of North Carolina School of Medicine, Chapel Hill, NC, United States; ${ }^{8}$ Department of Urology, Palmetto Health USC Medical Group, Columbia, SC, United States; ${ }^{9}$ Department of Urology, University of California San Francisco, San Francisco, CA, United States; ${ }^{10}$ Urology Section, Dartmouth Hitchcock Medical Center, Lebanon, NH, United States; ${ }^{11}$ Department of Urologic Sciences, University of British Columbia, Vancouver, BC, Canada; ${ }^{12}$ Department of Urology, University of Florida College of Medicine, Gainesville, FL, United States; ${ }^{13}$ Division of Urology, McGill University Health Centre, Montreal, QC, Canada; ${ }^{14}$ Department of Urology, University of California Davis, Sacramento, CA, United States; ${ }^{15}$ University of California Irvine School of Medicine, Orange, CA, United States

Introduction: With a five-year stone recurrence rate of 30-50\%, kidney stone formers are subject to significant morbidity, which negatively impacts their health-related quality of life (HRQOL). Spontaneous stone passage is associated with frequent emergency room visits, significant pain, and discomfort in performing daily activities. We sought to determine the impact of stone surgery and stone passage on patients' individual HRQOL by querying the validated and prospectively collected Wisconsin Stone Quality of Life (WISQOL) database.

\begin{tabular}{|c|c|c|c|c|c|c|}
\hline & $\beta$ & $\mathbf{C l}$ & $\mathbf{p}$ & $\beta$ & $\mathbf{C l}$ & p \\
\hline Caucasian (Ref.) & 0 & - & - & 0 & - & - \\
\hline Non-Caucasian & -9.32 & $(-13.4-5.22)$ & $<0.001$ & -7.64 & $(-11.5--3.81)$ & $<0.001$ \\
\hline Occupation category & - & - & - & - & - & - \\
\hline Homecare giver (Ref.) & 0 & - & - & 0 & - & - \\
\hline Management/professional & 19.0 & $(12.9-25.1)$ & $<0.001$ & 13.5 & (7.59-19.4) & $<0.001$ \\
\hline Manual/labor & 13.4 & (5.34-21.5) & $<0.05$ & 6.48 & $(-1.58-14.5)$ & 0.1 \\
\hline Sales & 15.7 & (8.81-22.5) & $<0.001$ & 11.5 & $(4.95-18.1)$ & $<0.001$ \\
\hline Presence of LUTS & -8.47 & $(-15.4--1.57)$ & $<0.05$ & -8.71 & $(-15.2-2.23)$ & $<0.05$ \\
\hline Absence of rUTls (Ref.) & 0 & - & - & 0 & - & - \\
\hline Presence of rUTls & -15.0 & $(-20.0--10.1)$ & $<0.001$ & -7.72 & $(-12.4-3.02)$ & $<0.05$ \\
\hline $\begin{array}{l}\text { Absence of depression/anxiety } \\
\text { (Ref.) }\end{array}$ & 0 & - & - & 0 & - & - \\
\hline Presence of depression/anxiety & -13.0 & $(-16.7--9.31)$ & $<0.001$ & -9.27 & $(-12.8-5.74)$ & $<0.001$ \\
\hline
\end{tabular}


Exhibit 3: Endourology

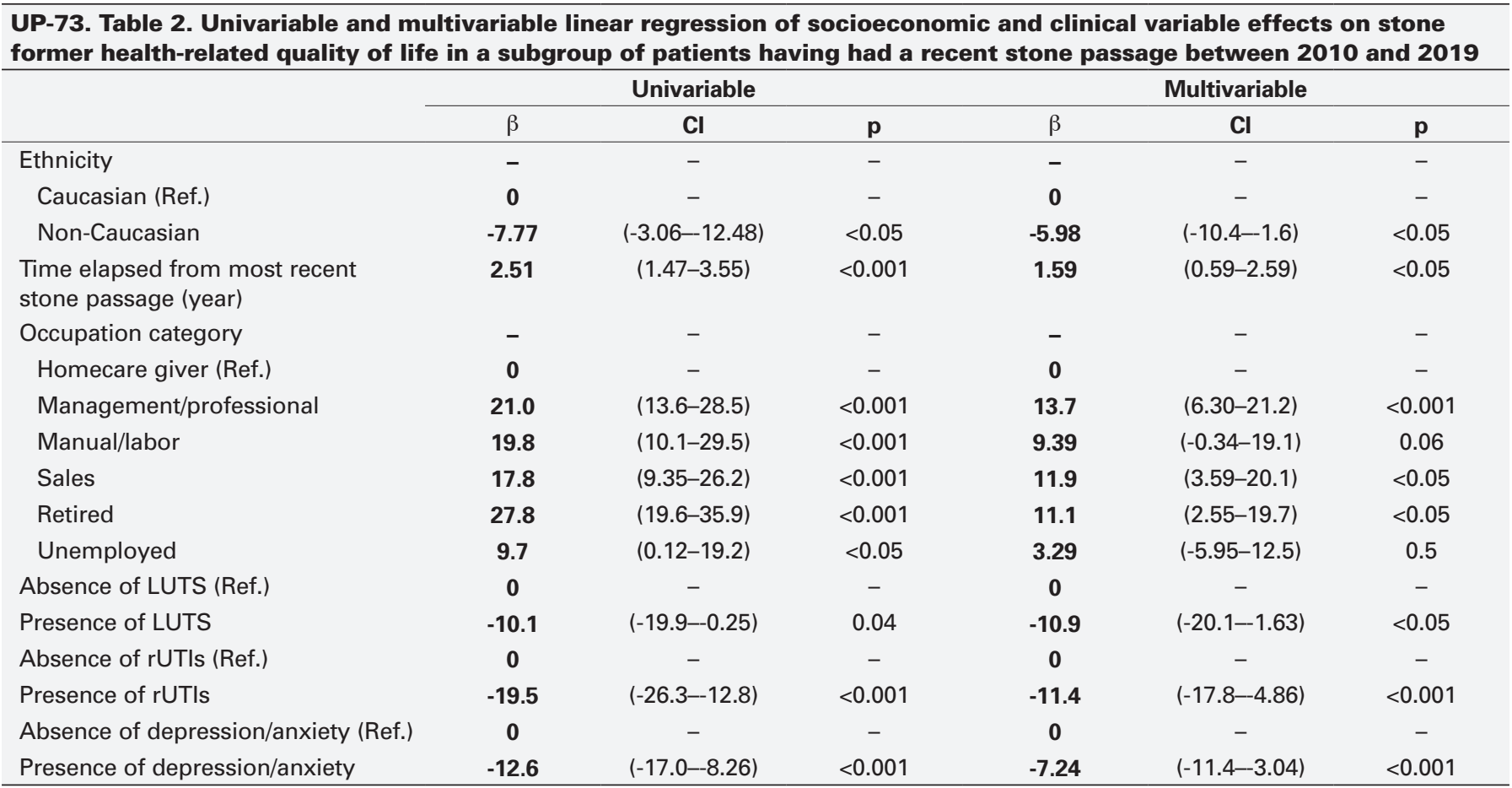

Methods: Cross-sectional data was obtained from a total of 3207 kidney stone formers from 14 institutions in North America who completed the WISQOL questionnaire from 2014-2019. The 28-question survey has a 1-5 point scale for each item (total score range $0-140$ ) and is divided into four domains: D1 social functioning, D2 emotional functioning,
D3 stone-related impact, and D4 vitality. Univariable and multivariable linear regression models were used to assess the impact of time since most recent surgery and time since most recent stone passage on $\mathrm{HRQOL}$. Results: Of the 1376 kidney stone formers who had surgery from 20102019 , time since most recent surgery was an independent predictor of

UP-73. Table 3. Univariable and multivariable linear regression of socioeconomic and clinical variable effects on stone former health-related quality of life in a subgroup of patients having had a recent stone event (surgery or passage) between 2010 and 2019

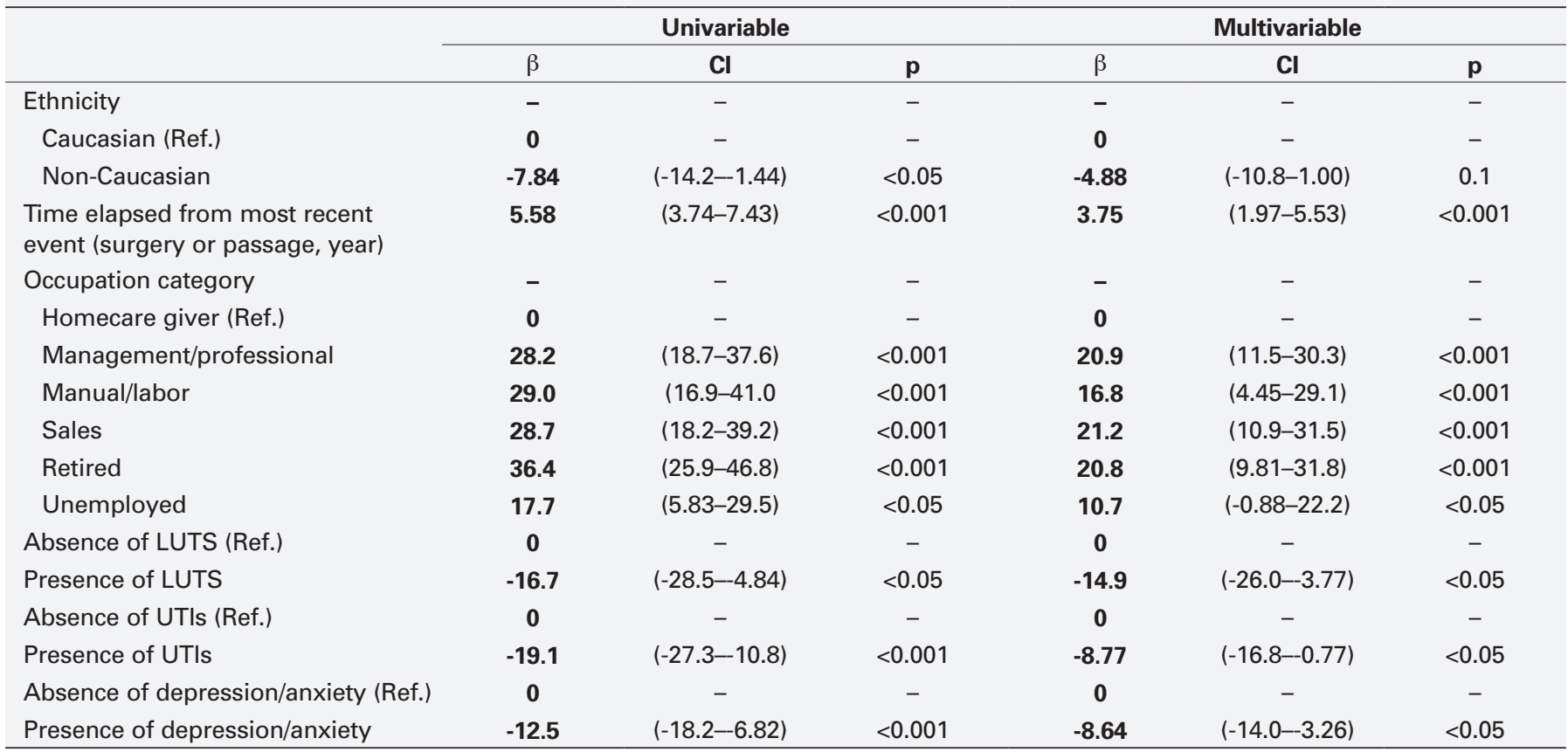


UP-76. Table 1. Comparation of clinical characteristics between patients that underwent URS due to urolithiasis vs. UTUC or obstruction

\begin{tabular}{|c|c|c|c|c|}
\hline & $\begin{array}{c}\text { Overall } \\
\mathrm{n}=99(100.0 \%)\end{array}$ & $\begin{array}{c}\text { Urolithiasis } \\
\mathrm{n}=73(73.7 \%)\end{array}$ & $\begin{array}{c}\text { UTUC or obstruction } \\
n=26(26.3 \%)\end{array}$ & $\mathbf{p}$ \\
\hline Age (y) & $61.2 \pm 13.7$ & $57.6 \pm 12.8$ & $71.4 \pm 10.8$ & $<0.001$ \\
\hline \multicolumn{5}{|l|}{ Sex } \\
\hline Male & $55(55.6 \%)$ & $36(49.3 \%)$ & $19(73.1 \%)$ & \\
\hline Female & $44(44.4 \%)$ & 37 (50.7\%) & $7(26.9 \%)$ & 0.036 \\
\hline Fluoro time (s) & $56.5(30.8-96.3)$ & $56(31-89.8)$ & $62(25.8-111.8)$ & 0.666 \\
\hline Unilateral & $93(93.9 \%)$ & 71 (97.3\%) & $22(84.6 \%)$ & \\
\hline Bilateral & $6(6.1 \%)$ & $2(2.7 \%)$ & $4(15.4 \%)$ & 0.040 \\
\hline \multicolumn{5}{|l|}{ Transplanted kidney } \\
\hline Yes & $3(3.0 \%)$ & $2(2.7 \%)$ & $1(3.8 \%)$ & \\
\hline No & $96(97.0 \%)$ & $71(97.3 \%)$ & $25(96.2 \%)$ & 0.999 \\
\hline Intra-renal & $41(41.4 \%)$ & $28(38.4 \%)$ & $14(53.8 \%)$ & 0.475 \\
\hline Largest stone diameter $(\mathrm{mm})^{*}$ & - & $6(4-7)$ & - & \\
\hline Number of stones on the side of interest* & - & $2(1-3)$ & - & \\
\hline \multicolumn{5}{|l|}{ Previous ureteric stent } \\
\hline Yes & $23(23.2 \%)$ & $18(24.7 \%)$ & $5(19.2 \%)$ & \\
\hline No & $76(76.8 \%)$ & $55(75.3 \%)$ & $21(80.8 \%)$ & 0.574 \\
\hline \multicolumn{5}{|l|}{ Access sheath used } \\
\hline Yes & $33(33.3 \%)$ & $26(35.6 \%)$ & $7(26.9 \%)$ & \\
\hline No & $66(66.7 \%)$ & $47(64.4 \%)$ & $19(73.1 \%)$ & 0.419 \\
\hline \multicolumn{5}{|l|}{ Laser used } \\
\hline No & $78(78.8 \%)$ & $54(74 \%)$ & $24(92.3 \%)$ & 0.050 \\
\hline \multicolumn{5}{|l|}{ Biopsy taken } \\
\hline Yes & $7(7.1 \%)$ & $1(1.4 \%)$ & $6(23.1 \%)$ & \\
\hline No & $92(92.9 \%)$ & $72(98.6 \%)$ & $20(76.9 \%)$ & $<0.001$ \\
\hline \multicolumn{5}{|l|}{ Post-URS stent insertion } \\
\hline Yes & $81(81.8 \%)$ & $65(89.0 \%)$ & $16(61.5 \%)$ & \\
\hline No & $18(18.2 \%)$ & $8(11.0 \%)$ & $10(38.5 \%)$ & 0.006 \\
\hline Fentanyl $(\mu \mathrm{g})$ & $100(10-150)$ & $100(100-150)$ & $100(100-100)$ & 0.084 \\
\hline Midazolam (mg) & $3(2-4)$ & $3(3-4)$ & $2(2-3.75)$ & 0.017 \\
\hline \multicolumn{5}{|l|}{ Successful procedure } \\
\hline Yes & $83(83.8 \%)$ & $59(80.8 \%)$ & $24(92.3 \%)$ & 0.225 \\
\hline No & $16(16.2 \%)$ & $14(19.2 \%)$ & $2(7.7 \%)$ & \\
\hline
\end{tabular}

${ }^{*}$ Only stone-related procedures. 
UP-76. Table 2. Comparation of clinical characteristics between patients that underwent URS that had a successful vs. unsuccessful outcome

\begin{tabular}{|c|c|c|c|}
\hline & $\begin{array}{c}\text { Successful } \\
n=83(83.8 \%)\end{array}$ & $\begin{array}{l}\text { Unsuccessful } \\
n=16(16.2 \%)\end{array}$ & $\mathbf{p}$ \\
\hline \multicolumn{4}{|l|}{ Group } \\
\hline Urolithiasis & 59 (71.1\%) & $14(87.5 \%)$ & \\
\hline UTUC or other & $24(28.9 \%)$ & $2(12.5 \%)$ & 0.225 \\
\hline Age (y) & $61.4 \pm 14.1$ & $60.2 \pm 11.8$ & 0.741 \\
\hline \multicolumn{4}{|l|}{ Sex } \\
\hline Male & $46(55.4 \%)$ & $9(56.3 \%)$ & \\
\hline Female & $37(44.6 \%)$ & $7(43.8 \%)$ & 0.999 \\
\hline Fluoro time (s) & $53.5(25.8-86.8)$ & $87.5(53-156)$ & 0.039 \\
\hline \multicolumn{4}{|l|}{ Side } \\
\hline Unilateral & 77 (92.8\%) & $16(100.0 \%)$ & \\
\hline Bilateral & $6(7.2 \%)$ & $0(0.0 \%)$ & 0.585 \\
\hline \multicolumn{4}{|l|}{ Transplanted kidney } \\
\hline Yes & $1(1.2 \%)$ & $2(12.5 \%)$ & \\
\hline No & $82(98.8 \%)$ & $14(87.5 \%)$ & 0.067 \\
\hline \multicolumn{4}{|l|}{ Location of interest } \\
\hline Distal ureter & $27(32.5 \%)$ & $1(6.3 \%)$ & \\
\hline Mid ureter & $6(7.2 \%)$ & $0(0.0 \%)$ & \\
\hline Proximal ureter & $16(19.3 \%)$ & $7(43.8 \%)$ & \\
\hline Intra-renal & $34(41.0 \%)$ & $8(50.0 \%)$ & 0.043 \\
\hline $\begin{array}{l}\text { Largest stone diameter } \\
(\mathrm{mm})^{*}\end{array}$ & $6(4-7)$ & $5.5(4.8-7.5)$ & 0.600 \\
\hline $\begin{array}{l}\text { Number of stones on } \\
\text { the side of interest* }\end{array}$ & $2(1-3)$ & $2.5(1-4)$ & 0.609 \\
\hline \multicolumn{4}{|l|}{ Previous ureteric stent } \\
\hline Yes & $18(21.7 \%)$ & $5(31.3 \%)$ & \\
\hline No & $65(78.3 \%)$ & $11(68.8 \%)$ & 0.518 \\
\hline \multicolumn{4}{|l|}{ Access sheath used } \\
\hline Yes & $28(33.7 \%)$ & $5(31.3 \%)$ & \\
\hline No & $55(66.3 \%)$ & $11(68.8 \%)$ & 0.847 \\
\hline \multicolumn{4}{|l|}{ Laser used } \\
\hline Yes & $39(47.0 \%)$ & $4(25.0 \%)$ & \\
\hline No & $44(53.0 \%)$ & $12(75.0 \%)$ & 0.104 \\
\hline \multicolumn{4}{|l|}{ Basket used } \\
\hline Yes & $55(66.3 \%)$ & $7(43.8 \%)$ & \\
\hline No & $28(33.7 \%)$ & $9(56.3 \%)$ & 0.088 \\
\hline \multicolumn{4}{|l|}{ Dilation } \\
\hline Yes & $18(21.7 \%)$ & $3(18.8 \%)$ & \\
\hline No & $65(78.3 \%)$ & $13(81.3 \%)$ & 0.792 \\
\hline \multicolumn{4}{|l|}{ Biopsy taken } \\
\hline Yes & $7(8.4 \%)$ & $0(0.0 \%)$ & \\
\hline No & $76(91.6 \%)$ & $16(100.0 \%)$ & 0.594 \\
\hline \multicolumn{4}{|l|}{ Post-URS stent insertion } \\
\hline Yes & $65(78.3 \%)$ & $16(100.0 \%)$ & \\
\hline No & $18(21.7 \%)$ & $0(0.0 \%)$ & 0.038 \\
\hline Fentanyl ( $\mu \mathrm{g}$ ) & $100[100-150]$ & $100[100-150]$ & 0.916 \\
\hline Midazolam (mg) & $3[2-4]$ & $3[2-3]$ & 0.150 \\
\hline
\end{tabular}

UP-76. Table 3. Subset descriptive explanations for unsuccessful URS by urolithiasis vs. UTUC or obstruction

\begin{tabular}{lccc}
\hline Reason for failure & $\begin{array}{c}\text { Overall } \\
\mathbf{n = 1 6} \\
(\mathbf{1 6 . 2 \% )}\end{array}$ & $\begin{array}{c}\text { Urolithiasis } \\
\mathbf{n = 1 4} \\
(\mathbf{1 9 . 2 \% )}\end{array}$ & $\begin{array}{c}\text { UTUC or } \\
\text { obstruction } \\
\mathbf{n = 2}(\mathbf{7 . 7} \%)\end{array}$ \\
\hline $\begin{array}{l}\text { High stone burden/ } \\
\text { impaction* }\end{array}$ & $4(\mathbf{2 5 . 0 \% )}$ & $4(28.6 \%)$ & - \\
Poor visualization & $6(37.5 \%)$ & $6(42.9 \%)$ & 0 \\
Tortuous/tight ureter & $5(31.3 \%)$ & $3(21.4 \%)$ & $2(100.0 \%)$ \\
Unable to tolerate sedation & $1(6.3 \%)$ & $1(0.07 \%)$ & 0 \\
\hline *Only stone-related procedures. & & & \\
\hline
\end{tabular}

UP-76. Table 4. Multivariable adjusted analysis showing the association between clinical characteristics and successful outcome after URS

\begin{tabular}{lccc}
\hline & OR & $\mathbf{9 5 \%} \mathbf{C l}$ & $\mathbf{p}$ \\
\hline $\begin{array}{l}\text { Group } \\
\quad \text { UTUC or obstruction }\end{array}$ & 1 & & \\
$\quad$ Urolithiasis & 0.157 & $0.025-0.973$ & $\mathbf{0 . 0 4 7}$ \\
Age (per y) & 1.005 & $0.947-1.066$ & 0.880 \\
Sex & & & \\
$\quad$ Male & 1 & & \\
$\quad$ Female & 1.048 & $0.276-3.971$ & 0.945 \\
Location of interest & & & \\
$\quad$ Distal ureter & 1 & & \\
$\quad$ Mid and Proximal ureter & 0.135 & $0.013-1.381$ & 0.091 \\
$\quad$ Intra-renal & 0.138 & $0.014-1.332$ & 0.087 \\
Fluoro time (per s) & 0.994 & $0.987-1.002$ & 0.132 \\
Fentanyl (per $\mu \mathrm{g}$ ) & 0.998 & $0.981-1.016$ & 0.837 \\
Midazolam (per mg) & 2.496 & $1.057-5.892$ & $\mathbf{0 . 0 3 7}$ \\
\hline
\end{tabular}

UP-76. Table 5. Exploratory multivariable adjusted analysis showing the association between clinical characteristics and successful outcome in patients with urolithiasis

\begin{tabular}{lccc}
\hline & OR & $\mathbf{9 5 \%} \mathbf{C l}$ & $\mathbf{p}$ \\
\hline $\begin{array}{l}\text { Age (per 1 year) } \\
\text { Sex }\end{array}$ & 1.001 & $0.936-1.071$ & 0.970 \\
$\quad$ Male & 1 & & \\
$\quad$ Female & 1.151 & $0.258-5.127$ & 0.854 \\
$\begin{array}{l}\text { Location of interest } \\
\quad \text { Distal ureter }\end{array}$ & 1 & & \\
$\quad$ Mid and Proximal ureter & 0.195 & $0.017-2.231$ & 0.189 \\
$\quad$ Intra-renal & 0.163 & $0.014-1.917$ & 0.149 \\
$\begin{array}{l}\text { Largest stone diameter } \\
\text { (per 1 mm) }\end{array}$ & 0.982 & $0.732-1.319$ & 0.906 \\
$\begin{array}{l}\text { Number of stones on the } \\
\text { side of interest (per 1 stone) }\end{array}$ & 0.880 & $0.620-1.250$ & 0.476 \\
$\begin{array}{l}\text { Fluoro time (per 1 s) } \\
\text { Fentanyl (per 1 } \mu \mathrm{g} \text { ) }\end{array}$ & 0.994 & $0.982-1.007$ & 0.361 \\
Midazolam (per 1 mg) & 0.993 & $0.974-1.011$ & 0.439 \\
\hline & 3.419 & $1.081-10.820$ & $\mathbf{0 . 0 3 6}$ \\
\hline
\end{tabular}


better WISQOL scores in univariable and multivariable analysis $(\beta=2.55$ points/year, confidence interval $[\mathrm{Cl}] 1.67-3.42, \mathrm{p} \leq 0.001$; and $\beta=2.26$ points/year, $\mathrm{Cl} 1.44-3.08, \mathrm{p} \leq 0.001$ ) (Table 1). Of the 1027 kidney stone formers with stone passage from 2010-2019, time since most recent stone passage was an independent predictor of better WISQOL scores in univariable and multivariable analysis ( $\beta=2.51$ points/year, $\mathrm{Cl} 1.47-3.55, \mathrm{p} \leq 0.001$; and $\beta=1.59$ points/year, $\mathrm{Cl} 0.59-2.59, \mathrm{p} \leq 0.05$ ) (Table 2). We performed a subgroup analysis with 626 kidney stone formers with surgery and stone passage from 2010-2019. Time since most recent event (surgery or stone passage) was an independent predictor of better WISQOL scores in univariable and multivariable analysis ( $\beta=5.58$ points/year, $\mathrm{Cl} 3.74-7.43, \mathrm{p}<0.001$; and $\beta=3.75$ points/year, $\mathrm{Cl} 1.97-5.53, \mathrm{p}<0.001$ ) (Table 3 ).

Conclusions: Our study demonstrates that increased time from most recent surgery and increased time from most recent stone passage were independent predictors associated with better HRQOL in kidney stone formers. Further studies should focus on optimizing stone-related modifiable risk factors to decrease the amount of recurrent stone episodes.

\section{UP-74}

Trends in the surgical management of adult urolithiasis in Ontario, Canada: $A$ population-based, retrospective cohort study Dor Golomb ${ }^{7}$, Andrew McClure ${ }^{2}$, Sumit Dave ${ }^{1}$, Jennifer Bjazevic ${ }^{1}$, Brendan B. Wallace ${ }^{T}$, Hassan Razvi ${ }^{1}$

'Division of Urology, Schulich School of Medicine and Dentistry, Western University, London, ON, Canada; ${ }^{2}$ Epidemiology and Biostatistics, Western University, London, ON, Canada

Introduction: The incidence of urinary stone disease is increasing. The aim of this review was to document the trends and incidence of surgical intervention for adults with upper urinary tract stones in Ontario, Canada Methods: We carried out a retrospective, population-based cohort study using administrative databases held at the Institute of Clinical Evaluative Sciences to identify all adults (>18 years) who underwent their first surgical treatment for urolithiasis as recorded in the Canadian Institute for Health Information, Discharge Abstract Database, or via physician billing information using the Ontario Health Insurance Plan database from 2002-2018. During this period, we assessed the incidence of surgically treated urolithiasis, age and gender distribution, and modality of surgical treatment. Descriptive statistics were used to summarize patient demographics and surgical trends were analyzed using the Cochrane-Armitage test for trend. Results: From 2002-2018, 140263 patients were treated surgically for urolithiasis in Ontario. The median ages were 57 (interquartile range [IQR] 21), 55 (IQR 25), and 52 (IQR 20) for percutaneous nephrolithotomy $(\mathrm{PCNL})$, ureteroscopy, and shock wave lithotripsies $(\mathrm{SWL})$, respectively. The number of stone-related surgical procedures increased from 5946 cases in 2002 to 10732 cases in 2018. By type of procedure, PCNL increased by $35 \%$, ureteroscopy increased by $38.6 \%$, while SWL declined by $68 \%$. While the adult population increased by $24.8 \%$, the increase in procedures exceeded what would be expected based on population growth alone, with $0.07 \%$ of patients in 2002 requiring intervention vs. $0.1 \%$ in 2018 .

Conclusions: The total number of surgical procedures performed for upper urinary tract stones rose significantly and cannot be accounted for by population growth alone. The reasons for the increase in procedures are likely multifactorial and may imply an increasing incidence of stone disease. These findings may have future resource-planning implications.

\section{UP-75}

Not every low-dose is low-dose: Impact of revising low-dose computed tomography protocol on mean effective radiation exposure

Claudia Deyirmendjiann ${ }^{1,2}$, Seohyuk Lee ${ }^{2}$, Yasser Noureldin², Gyorgy Hegyi $^{3}$, Lawrence Stein ${ }^{3}$, Giovanni Artho ${ }^{3}$, Sero Andonian ${ }^{2}$

${ }^{1}$ Faculty of Medicine, Université de Montréal, Montreal, QC, Canada; 2Division of Urology, McGill University Health Centre, Montreal, QC, Canada; ${ }^{3}$ Division of Diagnostic Imaging, McGill University Health Centre, Montreal, QC, Canada

Support: Endourological Society.
Introduction: According to the American Urological Association imaging guidelines, patients presenting with renal colic should undergo low-dose (LD) rather than standard-dose (SD) non-contrast computed tomography (CT). The aim of the present study was to assess how often physicians ordered LD CT scans and to calculate mean effective radiation exposures (ERE) from CT scans from dose length products (DLP), as well as to determine mean cumulative ERE over a one-year followup period.

Methods: After obtaining ethics approval, a retrospective chart review was conducted for patients with renal colic presenting to the emergency department between August 1, 2015 and July 31, 2016 (phase I), and between April 1, 2019 and October 1, 2019 (phase II). All imaging studies performed within one-year of initial presentation were catalogued. A two-way ANOVA was used to quantify the effect of imaging modality and hospital center on mean ERE per scan.

Results: In phase I, 146 patients, with mean age of 51 years and mean body mas index (BMI) of $28.6 \mathrm{~kg} / \mathrm{m}^{2}$ underwent 218 CT scans. In phase II, 225 patients with mean age of 55 years and mean BMI of $26.7 \mathrm{~kg} / \mathrm{m}^{2}$ underwent 273 CT scans. Urologists were the only physicians ordering LD CT scans and they ordered significantly more LD than SD CT scans $(71.3 \%$ vs. $28.7 \%$, $\mathrm{p}<0.01$ ). In phase $\mathrm{I}$, there was no significant difference in mean ERE of LD vs. SD CT scans (6.5 mSv vs. $8.9 \mathrm{mSv}$, p>0.05). In phase II, after revision of LD CT scan protocol in March 2019, the mean ERE per LD CT significantly decreased $(6.5 \mathrm{mSv}$ vs. $2.8 \mathrm{mSv}$, $\mathrm{p}<0.01)$. In addition, there were significant differences in mean ERE from LD CT scans between two hospitals in the same health system $(1.6 \mathrm{mSv}$ vs. $7.8 \mathrm{mSv}, \mathrm{p}<0.01)$. The mean cumulative ERE over one-year period was $19.4 \mathrm{mSv}$, with $6.9 \%$ of patients exceeding $50 \mathrm{mSv}$. Conclusions: Although LD CT scans are being ordered, a small percentage of patients continue to exceed the $50 \mathrm{mSv}$ annual threshold. It is important to keep track of mean ERE of LD CT scans and collaborate with medical physicists and the diagnostic imaging department to further refine LD CT scan protocols since not every low-dose is low-dose.

\section{UP-76}

Ureteroscopy with conscious sedation is safe and efficacious: A single-center, prospective study

Kunal Jain', Amanda Eng', Ruben Blachman-Braun², Esha M Jain ${ }^{3}$, Brian G. Peters ${ }^{1}$, Premal Patel ${ }^{\prime}$

${ }^{1}$ Section of Urology, Department of Surgery, University of Manitoba, Winnipeg, MB, Canada; ${ }^{2}$ Department of Urology, University of Miami, Miami, FL, United States; ${ }^{3}$ College of Medicine, American University of Antigua, St. John's, Antigua and Barbuda

Introduction: Ureteroscopy (URS) is a common, minimally invasive surgical procedure for upper urinary tract conditions. While URS has been typically performed with general or spinal anesthesia, our center has published on the feasibility of using conscious sedation for distal ureteric stones. ${ }^{1}$ Given the reduction of operating slates during the COVID-19 pandemic and the advent of smaller, semirigid and flexible ureteroscopes, we sought to study whether URS with conscious sedation is safe and effective. Methods: From November 2019 to June 2020, we prospectively collected data from patients undergoing URS with local anesthetic and urologistdirected, nursing-administered intravenous sedation. Using SPSS, continuous and categorical variables were analyzed with student T-test or Mann-Whitney U-tests and Chi-squared or Fisher's exact test, respectively. Multivariate-adjusted logistic regression analysis was performed to assess associations with successful URSs.

Results: All 99 URSs were included: 73 for urolithiasis, 24 for upper tract urothelial carcinoma (UTUC), and two for obstruction. Mean age was $61.2 \pm 13.7$ years, with 55 males and 44 females. Mean sedation used was $3 \mathrm{mg}$ (interquartile range [IQR] 2-4) of midazolam and $100 \mu \mathrm{g}$ (IQR 100-150) of fentanyl. Median fluoroscopy time was 56.5 seconds (IQR 30.8-96.3). The overall success rate was $83.8 \%$ (83/99) (Tables 1-3). URS for urolithiasis was associated with a lower success rate than those for UTUC or obstruction (odds ratio [OR] $0.157,95 \%$ confidence interval [Cl] 0.025-0.973, $\mathrm{p}=0.047)$. Increased use of midazolam was associated with a higher success rate (OR 2.496, 95\% Cl 1.057-5.892, $\mathrm{p}=0.037$ ) (Tables 4, 5).

Conclusions: This is the first study to demonstrate the safety and efficacy of URS with conscious sedation. Our findings must be understood within 
Exhibit 3: Endourology

the limitations of a single-center analysis. We plan to prospectively collect patient-reported outcomes to assess patient tolerability of URS with conscious sedation.

Reference

1. Kroczak TJ, Kaler KS, Patel P, et al. Ureteroscopy with conscious sedation for distal ureteric calculi: 10-year experience. Can Urol Assoc / 2016;10:E12-6. https://doi.org/10.5489/cuaj.3302

UP-77

Over-the-counter alkali agents to raise urine $\mathrm{pH}$ and citrate excretion: A randomized, crossover study in healthy adults Naeem Bhojani' ${ }^{1}$, Noah E. Canvasser ${ }^{2}$, Marcelino Rivera $^{3}$, Seth K. Bechis ${ }^{4}$ Johann Ingimarsson ${ }^{5}$, John Knoedler ${ }^{6}$, Karen Stern ${ }^{7}$, Christa Stoughton ${ }^{3}$, Daniel Wollin ${ }^{8}$, Michael Borofsky ${ }^{9}$, Marawan El Tayeb ${ }^{10}$, Guido Kamphuis ${ }^{11}$ David Leavitt ${ }^{12}$, Ryan S. Hsi ${ }^{13}$, Kymora B Scotland ${ }^{14}$

${ }^{1}$ Urology, University of Montreal, Montreal, QC, Canada; ${ }^{2}$ Urology, University of California Davis, Sacramento, CA, United States; ${ }^{3}$ Urology, Indiana University, Indianapolis, IN, United States; ${ }^{4}$ Urology, University of California San Diego, San Diego, CA, United States; ${ }^{5}$ Urology, Maine Medical Center, South Portland, ME, United States; ${ }^{6}$ Urology, Penn State University, Hershey, PA, United States; ${ }^{7}$ Urology, Mayo Clinic, Phoenix, AZ, United States; ${ }^{8}$ Urology, Brigham and Women's Hospital, Boston, MA, United States; ${ }^{9}$ Urology, University of Minnesota, Minneapolis, MN, United States; ${ }^{10}$ Urology, Baylor Scott and White Health, Temple, TX, United States; ${ }^{11}$ Urology, Amsterdam University Medical Center, Amsterdam, Netherlands; ${ }^{12}$ Urology, Henry Ford Health System, Detroit, MI, United States; ${ }^{13}$ Urology, Vanderbilt University Medical Center, Nashville, TN, United States; ${ }^{14}$ Urology, University of California Los Angeles, Los Angeles, CA, United States

Support: Collaborative for Research in Endourology (CORE).

Introduction: We sought to prospectively study the effect of over-thecounter LithoLyte $^{\circledR}$ and KSPtabs ${ }^{\mathrm{TM}}$ on urinary stone risk.

Methods: Ten healthy volunteers without a history of kidney stones were recruited to complete a baseline 24-hour stone risk urinalysis with a four-day diet inventory. Participants were randomized 1:1 to take either LithoLyte $^{\circledR}$ (20 mEq two times per day) or KSPtabs ${ }^{\mathrm{TM}}$ (1 tablet two times per day) while maintaining the same diet and submit another 24-hour urinalysis. Finally, the process was repeated with the other supplement. Urinary parameters including citrate, $\mathrm{pH}$, and ammonium were compared to baseline. Side effects of each supplement were elicited with a questionnaire after each urine collection.

Results: LithoLyte intake resulted in a non-significant increase in median citrate (597 to $758 \mathrm{mg} /$ day, $\mathrm{p}=0.058$ ), an increase in urine $\mathrm{pH}$ (6.46 to $6.66, p=0.028$ ), and a decrease in urine ammonium ( 41 to $36 \mathrm{mmol} / \mathrm{day}$, $\mathrm{p}=0.005)$ compared to baseline. KSPtabs resulted in an increase in citrate (597 to $797 \mathrm{mg} /$ day, $\mathrm{p}=0.037$ ) and urine $\mathrm{pH}$ (6.46 to $6.86, \mathrm{p}=0.037$ ), with a non-significant decrease in ammonium ( 41 to $34 \mathrm{mmol} / \mathrm{day}, \mathrm{p}=0.059$ ). No significant differences were seen comparing urinary analytes between LithoLyte and KSPtabs supplements (all p>0.09). With Litholyte, no side effects, mild, moderate, and severe side effects were seen in $50 \%, 40 \%$,

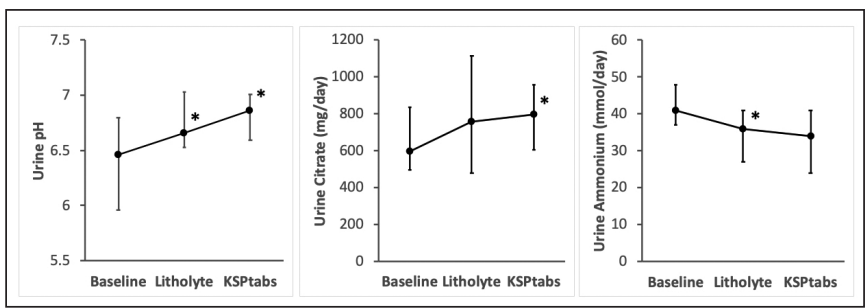

UP-77. Fig. 1. Changes in urine parameters based on alkali supplement. ${ }^{*} p<0.05$ compared to baseline.

$10 \%$, and $0 \%$, respectively. With KSPtabs, rates were $60 \%, 20 \%, 10 \%$, and $10 \%$, respectively (Fig. 1 , Table 1 ).

Conclusions: In healthy participants without a history of kidney stones, LithoLyte and KSPtabs are effective over-the-counter alkali supplements to increase urine $\mathrm{pH}$ and citrate excretion. Their side effect profile appears similar to prescription potassium citrate.

\section{UP-78}

Making the grade: Can intraoperative fragmentation grading during shockwave lithotripsy predict treatment success? Callum Lavoie ${ }^{1}$, Ryan McLarty', Shubhadip (Shubha) K. De ${ }^{1}$ Division of Urology, University of Alberta, Edmonton, AB, Canada Introduction: Extracorporeal shockwave lithotripsy (ESWL) is a widely used, non-invasive treatment modality with varying success rates. Fluoroscopy is an integral part of this procedure, allowing for stone targeting and real-time assessment of fragmentation. However, the role of intraoperative imaging in predicting treatment effectiveness has not previously been thoroughly investigated. Therefore, the goal of this study was to assess whether subjective intraoperative grading of fragmentation correlates with treatment success at followup.

Methods: A retrospective review of patients undergoing ESWL treatment of proximal ureteric calculi (diagnosed on computed tomography imaging) was performed. Patient demographics, stone characteristics, and surgeonreported fragmentation scores were recorded. The primary outcomes of interest were SWL success at routine followup on kidney-ureter-bladder (KUB) X-ray imaging, and the association of fragmentation scores with SWL outcomes.

Results: A total of 141 patients were identified, with $54 \%(n=76)$ having a successful treatment with stone resolution at followup imaging. There was no difference between groups in body mass index (BMI) (29 vs. $31, p=0.42$ ) or time to followup (12.6 vs. 11.2 days, $p=0.85$ ). Average stone size was smaller in the successful SWL cohort (7.3 vs. $8.5 \mathrm{~mm}$, $\mathrm{p}=0.006$ ) but there was no difference in stone density ( 779 vs. $832 \mathrm{HU}$, $\mathrm{p}=0.12)$, or skin-to-stone distance (13.8 vs. $14.1 \mathrm{~cm}, \mathrm{p}=0.41)$. Surgeonreported fragmentation score was a positive predictor of SWL success, with patients receiving good fragmentation scores being more likely to have SWL success (odds ratio [OR] 2.75, $\mathrm{p}=0.016$ ) and those receiving

\begin{tabular}{|c|c|c|c|c|c|c|c|c|}
\hline & \multicolumn{2}{|c|}{ Baseline } & \multicolumn{3}{|c|}{ Litholyte $^{\circledast}$} & \multicolumn{3}{|c|}{ KSPtabs $^{\mathrm{TM}}$} \\
\hline & Median & IQR & Median & IQR & $\mathbf{p}$ & Median & IQR & $\mathbf{p}$ \\
\hline Volume (L) & 2.42 & $1.68-2.88$ & 2.73 & $2.06-3.58$ & 0.059 & 2.27 & $1.75-3.05$ & 0.4 \\
\hline Citrate (mg) & 597 & $496-833$ & 758 & 479-1116 & 0.058 & 797 & $606-959$ & 0.037 \\
\hline $\mathrm{pH}$ & 6.46 & $5.96-6.80$ & 6.66 & $6.53-7.03$ & 0.028 & 6.86 & $6.59-7.01$ & 0.037 \\
\hline Ammonium (mmol) & 41 & $37-48$ & 36 & 27-41 & 0.005 & 34 & 24-41 & 0.059 \\
\hline Urine creatinine (mg) & 1603 & 1334-1974 & 1620 & $1433-2245$ & 0.58 & 1624 & $1297-2265$ & 0.7 \\
\hline
\end{tabular}


poor scores showing a negative association with treatment success (OR $0.24, \mathrm{p}=0.012$ ).

Conclusions: This retrospective analysis illustrates surgeon-reported fragmentation scores can be an independent predictor of SWL success for proximal ureteric calculi. Further study in the field to improve fragmentation grading could, in turn, enhance patient counselling and disposition planning.

\section{UP-79}

Antibiotic prophylaxis for prevention of infectious complications after shockwave lithotripsy: A systematic review and metaanalysis

Borna Tadayon Najafabadi', Maryam Kandi', Maylynn Ding², Tejan Bladeh ${ }^{1}$, Kathrin Bausch ${ }^{3}$, Matthias Briel ${ }^{4}$, Kari Tikkinen ${ }^{5}$, Thomas Tailly, Philippe D. Violette ${ }^{1,2}$

${ }^{1}$ Health Research Methods Evidence and Impact, McMaster University, Hamilton, ON, Canada; ${ }^{2}$ Division of Urology, McMaster University, Hamilton, ON, Canada; ${ }^{3}$ Urology, University Hospital Basel, Basel, Switzerland; ${ }^{4}$ Department of Clinical Research, Basel Institute for Clinical Epidemiology and Biostatistics (CEB), Basel, Switzerland; ${ }^{5}$ Department of Urology, Helsinki University Hospital, Helsinki, Finland; ${ }^{6}$ Department of Urology, University Hospital Ghent, Ghent, Belgium
Introduction: The use of antibiotics before shockwave lithotripsy (SWL) varies greatly globally. Guidelines have been hampered by reliance on limited evidence summaries and data for this issue. To address this gap, we performed a systematic review and meta-analysis of trials investigating the effects of antibiotic prophylaxis on infectious outcomes after SWL.

Methods: A systemic search was conducted in the Cochrane central register of controlled trials, Medline, EMBASE, CINAHEL, Web of Science, and PubMed to December 2019. Studies were screened independently and in duplicates for randomized and quasi-randomized controlled trials investigating the effects of antibiotic prophylaxis for prevention of infectious outcomes after SWL for renal or ureteral stones. The Cochrane Risk of Bias 2.0 was used for the assessment of risk of bias. We used the GRADE methodology to evaluate the certainty of evidence (PROSPERO CRD42020196574).

Results: We included 17 trials (five quasi-randomized, six placebo-controlled) with approximately 3000 patients. Only four studies recruited participants after 2000. Meta-analysis was only feasible for urine culture, fever, and urinary tract infection (UTI) since reporting for other outcomes, such as sepsis or major complication, was limited. All the included studies were at a high risk of bias. UTI was found not to be decreased statistically compared to placebo, however, the certainty in this effect estimate is very low. Also, reduction in positive urine cultures was detected compared to no prophylaxis; fever was not significantly reduced (Table1).

UP-79. Table 1. Summary of findings for antibiotic prophylaxis vs. no prophylaxis

Antibiotic prophylaxis compared to no prophylaxis for patients undergoing shockwave lithotripsy for renal or ureteral stones

Patient or population: Patients undergoing shockwave lithotripsy for renal or ureteral stones

Intervention: Antibiotic prophylaxis

Comparison: No prophylaxis

\begin{tabular}{|c|c|c|c|c|c|c|}
\hline \multirow[t]{2}{*}{ Outcomes } & \multicolumn{2}{|c|}{$\begin{array}{l}\text { Anticipated absolute } \\
\text { effects* }(95 \% \mathrm{Cl})\end{array}$} & \multirow[t]{2}{*}{$\begin{array}{l}\text { Relative effect } \\
\quad(95 \% \mathrm{CI})\end{array}$} & \multirow{2}{*}{$\begin{array}{c}\text { No. of } \\
\text { participants } \\
\text { (studies) }\end{array}$} & \multirow{2}{*}{$\begin{array}{l}\text { Certainty of } \\
\text { the evidence } \\
\text { (GRADE) }\end{array}$} & \multirow[t]{2}{*}{ Comments } \\
\hline & $\begin{array}{l}\text { Risk with no } \\
\text { prophylaxis }\end{array}$ & $\begin{array}{c}\text { Risk with } \\
\text { antibiotic } \\
\text { prophylaxis }\end{array}$ & & & & \\
\hline $\begin{array}{l}\text { Positive urine } \\
\text { culture } \\
\text { followup: } \\
\text { median } 7 \text { days }\end{array}$ & 110 per 1,000 & $\begin{array}{c}52 \text { per } 1,000 \\
(27-98)\end{array}$ & $\begin{array}{c}\text { OR } 0.44 \\
(0.22-0.88)\end{array}$ & $\begin{array}{c}1336 \\
\text { (9 RCTs) }\end{array}$ & $\begin{array}{l}\oplus \oplus O O \\
\mathrm{LOW}^{\mathrm{a}, \mathrm{b}}\end{array}$ & $\begin{array}{l}\text { The evidence suggests antibiotic } \\
\text { prophylaxis results in a reduction in } \\
\text { positive urine culture. The evidence } \\
\text { suggests that the administration of } \\
\text { prophylactic antibiotics vs. no prophylaxis } \\
\text { in patients undergoing shockwave } \\
\text { lithotripsy results in } 58 \text { fewer positive urine } \\
\text { cultures in every } 1000 \text { patients ( } 95 \% \mathrm{Cl} \text { from } \\
83 \text { fewer to } 12 \text { fewer). }\end{array}$ \\
\hline $\begin{array}{l}\text { Fever } \\
\text { followup: } \\
\text { median } 7 \text { days }\end{array}$ & 136 per 1,000 & $\begin{array}{c}69 \text { per } 1,000 \\
(28-164)\end{array}$ & $\begin{array}{c}\text { OR } 0.47 \\
(0.18-1.24)\end{array}$ & $\begin{array}{c}840 \\
\text { (6 RCTs) }\end{array}$ & $\begin{array}{l}\oplus \oplus O O \\
\mathrm{LOW}^{\mathrm{a}, \mathrm{c}}\end{array}$ & $\begin{array}{l}\text { Antibiotic prophylaxis may result in a } \\
\text { reduction in fever. The evidence suggests } \\
\text { that, in every } 1000 \text { patients undergoing } \\
\text { shockwave lithotripsy, antibiotic } \\
\text { prophylaxis can result in } 67 \text { fewer post- } \\
\text { procedure fevers ( } 95 \% \mathrm{Cl} \text { from } 108 \text { fewer to } \\
\qquad 28 \text { more). }\end{array}$ \\
\hline
\end{tabular}

\section{GRADE Working Group grades of evidence}

High certainty: We are very confident that the true effect lies close to that of the estimate of the effect

Moderate certainty: We are moderately confident in the effect estimate: The true effect is likely to be close to the estimate of the effect, but there is a possibility that it is substantially different

Low certainty: Our confidence in the effect estimate is limited: The true effect may be substantially different from the estimate of the effect

Very low certainty: We have very little confidence in the effect estimate: The true effect is likely to be substantially different from the estimate of effect

*The risk in the intervention group (and its $95 \%$ confidence interval) is based on the assumed risk in the comparison group and the relative effect of the intervention (and its $95 \% \mathrm{Cl}$ ) a the included studies are at a high risk of bias. Especially, studies are suffering the risk of bias in the randomization process which is considered a highly important domain. Therefore, we decided to rate down the certainty in the evidence for risk of bias by one level. bAlthough the visual investigation of the Forest plot is borderline regarding inconsistency, the I square of $40 \%$ and marginally significant Chi-squared test of heterogeneity $(\mathrm{p}=0.09)$ compelled us to rate down the certainty in evidence for inconsistency by one level. ${ }^{\mathrm{C}} \mathrm{The}$ number of events observed across all the included studies is less than 100 . Furthermore, the confidence intervals of effect size include both significant benefit and harm (108 fewer to 28 more events). 
Conclusions: Low-quality clinical trials suggest limited reduction in infectious outcomes with use of antibiotic prophylaxis for SWL. A wellconducted, randomized trial is warranted.

UP-80

Assessing the assessment: Inter-user variability and proficiency of ureteral wall thickness measurements in stone patients Patrick Albers ${ }^{1}$, Nick Dean ${ }^{2}$, Alexandra Bain ${ }^{2}$, Matthew Mancuso ${ }^{1}$, Ryan McLarty², Sentil Senthilselvan ${ }^{3}$, Tim Wollin ${ }^{2}$, Gillian Shiau ${ }^{4}$, Shubhadip (Shubha) K. De

${ }^{1}$ Faculty of Medicine, University of Alberta, Edmonton, AB, Canada; 2Department of Surgery, University of Alberta, Edmonton, AB, Canada; ${ }^{3}$ Division of Mathematics and Statistics, University of Alberta, Edmonton, $\mathrm{AB}$, Canada; ${ }^{4}$ Department of Radiology, University of Alberta, Edmonton, AB, Canada

Introduction: Ureteral wall thickness (UWT) has been shown to predict shockwave lithotripsy outcomes, spontaneous stone passage, and stent insertion success rates. ${ }^{1,2}$ The primary objective was to evaluate inter-user variability in the measurement of UWT. Secondary objectives included a proficiency analysis of time spent.

Methods: Index cases were selected from our retrospective nephrostomy tube (NT) database (2013-2019), having computed tomography imaging for an obstructing ureteric stone prior to NT decompression. A six-minute standardized teaching video was created to teach measurement techniques. Four evaluators (two students and two residents) independently measured UWT $(\mathrm{mm})$ and ureteric density $(\mathrm{HU})$. Intraclass correlation (ICC) was calculated using MedCalc with single and average measurement, absolute agreement two-way mixed model. Proficiency was assessed from serial time-per-study assessments (TPS).

Results: Eighty-nine index subjects were identified, comprising the study series. Average stone size was $10.9 \mathrm{~mm}$, UWT $2.9 \mathrm{~mm}$, and ureteric density 33.7 HU. The individual ICC was calculated at 0.314 (95\% confidence interval [Cl] 0.191-0.443), and average ICC was 0.647 (95\% Cl 0.485-0.761). The first 30 measures had an individual ICC of 0.232 (95\% Cl $0.070-0.438$ ) and average ICC of $0.547(95 \% \mathrm{Cl} 0.232-0.757)$; whereas the last 30 measures had an individual ICC of $0.442(95 \% \mathrm{Cl} 0.258-0.634)$ and average ICC of 0.760 (95\% Cl $0.582-0.874)$. The initial time per study (TPS) was $142 \pm 95 \mathrm{~s}$ for the first 10 cases, improving to $69 \pm 27 \mathrm{~s}$ for the final 10 cases. Inexperienced readers (medical students) took significantly longer to make measurements than resident physicians (152 s vs. $61 \mathrm{~s}, \mathrm{p}<0.001)$, though all groups showed 1.5-3.1x decrease in TPS.

Conclusions: Our analysis suggests that even though the reliability of individual UWT measures by novice users is initially poor, reliability can be improved with grouped outcomes (average intraclass correlation). Repetition also seems to play a role in improving reliability and time per study.

\section{References}

1. Yamashita S, Kohimoto Y, Iguchi T, et al. Ureteral wall volume at ureteral stone site is a critical predictor for shockwave lithotripsy outcomes: Comparison with ureteral wall thickness and area. Urolithias 2020;48:361-8. https://doi.org/10.1007/s00240-019-01154-w

2. Sarica $\mathrm{K}$, Eryildirim B, Akdere $\mathrm{H}$, et al. Could ureteral wall thickness have an impact on the operative and postoperative parameters in ureteroscopic management of proximal ureteral stones? Actas Urol Esp 2019;43:474-9. https://doi.org/10.1016/j.acuroe.2018.10.007

\section{UP-81}

Ureteral wall thickness as a novel predictor for failed retrograde stent placement

Nick Dean ${ }^{1}$, Patrick Albers', Sentil Senthilselvan², Alexandra Bain ${ }^{1}$, Ryan McLarty ${ }^{1}$, Gillian Shiau ${ }^{3}$, Matthew Mancuso ${ }^{1}$, Tim Wollin'1, Trevor D Schuler ${ }^{1}$, Shubhadip (Shubha) K. De

${ }^{1}$ Department of Surgery, University of Alberta, Edmonton, AB, Canada; Edmonton, AB, Canada; ${ }^{2}$ Mathematics and Statistics, University of Alberta Edmonton, AB, Canada; ${ }^{3}$ Radiology, University of Alberta
Introduction: Ureteric wall thickness (UWT) has been used to predict outcomes in shockwave lithotripsy, ureteroscopy, and spontaneous stone passage. Our purpose was to identify novel stone characteristics that can help predict failed retrograde ureteric stent placement in the setting of obstructing ureteric calculi.

Methods: We performed a retrospective, case-control study including 34 patients who were identified to have failed urgent cystoscopic stent insertion and required nephrostomy tube insertion between 2013 and 2019. This group was compared to 75 consecutive patients in 2019 who underwent successful urgent retrograde stent placement for an obstructing ureteric calculi. All patients required a pre-decompression non-contrast computed tomography scan. Patient demographics and stone characteristics were collected from our electronic medical record and provincial wide imaging system. Statistical analysis was performed using univariate and multivariate logistic regression analysis in collaboration with a university-affiliated statistician.

Results: On univariate analysis, non-septic indications for retrograde stent insertion, time since ureteral stone diagnosis, severe hydronephrosis, presence of renal atrophy, stone craniocaudal distance, stone circumference, and ureteral wall thickness were associated with failed retrograde stent placement. On multivariate analysis, both a non-septic indication for stenting (odds ratio [OR] 9.16, $\mathrm{p}=0.006$ ) and UWT (OR 0.34, $\mathrm{p}=0.007$ ) were found to be significantly associated with failed retrograde stent placement. A ROC analysis demonstrates an optimal UWT cutoff of 3.2 $\mathrm{mm}$, with a sensitivity of $60.6 \%$ and specificity of $83.3 \%$.

Conclusions: An elevated UWT and non-septic indication for urgent urinary decompression in the setting of obstructing ureteric stones are predictive of failed retrograde stent placement. These patients may benefit from upfront nephrostomy tube insertion.

\section{UP-82}

Are video gamers better urologists? The impact of video games on surgical skill in flexible ureteroscopy

Bruce Gao ${ }^{1}$, Suzy Melody Djuimo ${ }^{1}$, Nuley Seo ${ }^{2}$, Brian Carrillo ${ }^{1}$, Jason Y. Lee $^{1}$, Monica Farcas ${ }^{1}$

${ }^{1}$ Urology, University of Toronto, Toronto, ON, Canada; ${ }^{2}$ Undergraduate Medicine, University of Toronto, Toronto, ON, Canada

Introduction: Popular video games such as Fortnite, Call of Duty, and Mario Bros. are taking society by storm. Disturbing negative correlations with video gameplay in adolescents include lower grades and aggressive emotions and actions. ${ }^{1}$ However, studies have suggested positive effects of video games on laparoscopy. ${ }^{2}$ Although similar effects may be true for flexible ureteroscopy (fURS), it has not yet been shown.

Methods: Urology residents (PGY 1-3) were enrolled. Video gamers were defined as greater than three hours per week at the highest point of the participant's gaming history. ${ }^{3,4} \mathrm{~A}$ tablet game (Cube Runner ${ }^{\circ}$ ) was played to compare baseline video-gaming skills. All participants then performed ureteroscopic tasks using a 3D printed anatomical kidney model from a patient computed tomography scan. Objective Structured Assessment of Technical Skills (OSATS) and performance on multi-institutionally validated fURS tasks were recorded (Fig. 1). ${ }^{5}$

Results: Thirteen urology residents were enrolled in the study with three urology residents excluded due to previous simulator use. There were no significant demographical or fURS experience differences between gamers $(n=6)$ and non-gamers $(n=4)$ (Table 1$)$. Gamers had significantly higher previous gaming experience (gamers 15.67 vs. non-gamers 0.75 $\mathrm{hrs} / \mathrm{wk}, \mathrm{p}=0.001$ ) and demonstrated a trend towards better performance on CubeRunner (gamers 767.40 vs. non-gamers 402.60, $\mathrm{p}=0.153$ ) (Table 1). Gamers demonstrated a significantly higher global assessment score in fURS compared to non-video gamers (gamers 24.33 vs. non-gamers 20.75, $\mathrm{p}=0.045$ ) (Table 2). In addition, video gamers were significantly better as assists (gamers 3.33 vs. non-gamers 2.75, $\mathrm{p}=0.014$ ) and had higher instrument knowledge (gamers 3.67 vs. non-gamers $3, p=0.025$ ). There was no difference in fURS task scores, timing, or other OSATS domains.

Conclusions: Video gamers may perform better globally in fURS than nongamers. Additional participants are required and currently being enrolled. 


\begin{tabular}{|c|c|c|c|c|c|}
\hline \multicolumn{4}{|c|}{$\begin{array}{l}\text { FLEXIBLE URETEROSCOPY EXERCISE } \\
{ }^{*} \text { Total time } \quad \text { sec }\end{array}$} & & \\
\hline \multicolumn{6}{|c|}{ Navigation of all calices } \\
\hline \multicolumn{6}{|c|}{ Locating the stone } \\
\hline \multicolumn{2}{|c|}{$\begin{array}{l}\text { Basketing and relocation of the stone from } \\
\text { lower calix to upper calix }\end{array}$} & & & \multicolumn{2}{|c|}{$\begin{array}{l}\text { If this task correct, record: } \\
\# \text { of basketing attempts }=\_(\min =1) \\
\# \text { of accidental stone drops }=\_(\min =0)\end{array}$} \\
\hline $\begin{array}{l}\text { Respect for } \\
\text { tissue }\end{array}$ & $\begin{array}{l}\text { Frequently used unnecessary } \\
\text { force or pushed scope into } \\
\text { mucosa (white-out) or lost } \\
\text { tunnel vision }\end{array}$ & & $\begin{array}{l}\text { Careful handling of tissues } \\
\text { but occasionally pushed } \\
\text { scope into mucosa (white- } \\
\text { out) and lost tunnel vision }\end{array}$ & & $\begin{array}{l}\text { Consistently handled tissues with } \\
\text { minimal force \& maintained } 360^{\circ} \\
\text { (tunnel vision) of ureter during } \\
\text { passage of scope }\end{array}$ \\
\hline $\begin{array}{l}\text { Time \& } \\
\text { motion }\end{array}$ & 1 & 2 & 3 & 4 & 5 \\
\hline \multirow[t]{2}{*}{$\begin{array}{l}\text { Handling } \\
\text { scope }\end{array}$} & $\begin{array}{l}\text { Awkward \& tentative moves } \\
\text { and use of inappropriate } \\
\text { instruments }\end{array}$ & & $\begin{array}{l}\text { Competent use of instrument } \\
\text { but occasional awkward } \\
\text { moves }\end{array}$ & & $\begin{array}{l}\text { Fluid moves with instruments \& } \\
\text { no awkwardness }\end{array}$ \\
\hline & 1 & 2 & 3 & 4 & 5 \\
\hline \multirow[t]{2}{*}{$\begin{array}{l}\text { Knowledge of } \\
\text { instruments }\end{array}$} & $\begin{array}{l}\text { Frequently used wrong or } \\
\text { inappropriate instrument }\end{array}$ & & $\begin{array}{l}\text { Mostly used appropriate } \\
\text { instruments }\end{array}$ & & $\begin{array}{l}\text { Obviously familiar with \& used all } \\
\text { appropriate instruments }\end{array}$ \\
\hline & 1 & 2 & 3 & 4 & 5 \\
\hline $\begin{array}{l}\text { Flow of } \\
\text { operations }\end{array}$ & $\begin{array}{l}\text { Frequently stopped operating } \\
\text { and seemed unsure }\end{array}$ & & $\begin{array}{l}\text { Had forward planning but } \\
\text { progressed tentatively at } \\
\text { times }\end{array}$ & & $\begin{array}{l}\text { Planned operations well and had } \\
\text { effortless flow of all moves }\end{array}$ \\
\hline $\begin{array}{l}\text { Knowledge } \\
\text { of specific } \\
\text { procedures }\end{array}$ & \multicolumn{4}{|c|}{ Add together all circled numbers for TOTAL GPSS SCORE } & \\
\hline
\end{tabular}

UP-82. Fig. 1. Multi-institutionally validated flexible ureteroscopy training tasks.

\section{References}

1. Gentile DA, Lynch PJ, Linder JR, et al. The effects of violent video game habits on adolescent hostility, aggressive behaviors, and school performance. J Adolesc 2004;27:5-22. https://doi.org/10.1016/j.adolescence.2003.10.002

2. Glassman D, Yiasemidou M, Ishii $\mathrm{H}$, et al. Effect of playing video games on laparoscopic skills performance: A systematic review. J Endourol 2016;30:146-52. https://doi.org/10.1089/end.2015.0425

3. Shane MD, Pettitt BJ, Morgenthal CB, et al, Should surgical novices trade their retractors for joysticks? Videogame experience decreases the time needed to acquire surgical skills. Surg EndosC 2008;22:1294-7. https://doi.org/10.1007/s00464-007-9614-0

4. Rosser JC, Lynch PJ, Cuddihy L, et al. The impact of video games on training surgeons in the 21st century. Arch Surg 2007;142:181-6. https://doi.org/10.1001/archsurg.142.2.181

5. Argun OB, Chrouser K, Chauhan S, et al. Multi-institutional validation of an OSATS for the assessment of cystoscopic and ureteroscopic skills. J Urol 2015;194:1098-1106. https://doi.org/10.1016/j. juro.2015.02.2959

\section{UP-83}

Are postoperative nephrostomy tubes needed in the mini percutaneous nephrolithotomy era?

Jo-Lynn Tan ${ }^{1}$, Matthew Farag', Lih-Ming Wong 1,2, Damien Bolton' ${ }^{2,3}$, Daniel Lenaghan

'Department of Urology, St Vincent's Hospital, Melbourne, Australia; 2Department of Surgery, University of Melbourne, Melbourne, Australia; ${ }^{3}$ Department of Urology, Austin Health, Melbourne, Australia

Introduction: Percutaneous nephrolithotomy (PCNL), the standard procedure for large intrarenal calculi may be performed using a mini ( $\mathrm{mPCNL}$ ) or conventional (CPCNL) approach, differentiated by way of the access tract size (14-20 Fr vs. $>24 \mathrm{Fr}$ ). mPCNL gained momentum in clinical practice due to purported higher safety profiles but has longer operating times without superior stone clearance rates. Owing to small, published study sizes and study heterogeneity, a lack of consensus on the superiority of one technique over the other remains. We hypothesised that perioperative outcomes between $\mathrm{mPCNL}$ and CPCNL are now comparable, with a lesser need for nephrostomy tubes. We aimed to compare and report on the perioperative and surgical outcomes of CPCNL vs. mPCNL. 


\begin{tabular}{lccc}
\hline $\begin{array}{l}\text { UP-82. Table 1. Video gamer and non-video gamer } \\
\text { demographics, previous experience with ureteroscopic }\end{array}$ \\
surgery, video gaming experience and CubeRunner score \\
\hline Demographics & Gamers (n=6) & $\begin{array}{c}\text { Non-gamers } \\
\text { (n=4) }\end{array}$ & p \\
\hline & & $28.50 \pm 1.29$ & 0.6034 \\
\hline Age (mean years \pm SD) & $29.67 \pm 2.66$ & $3 / 1$ & 0.3910 \\
Gender (M/F) & $6 / 0$ & $2 / 1 / 1$ & 0.4943 \\
Year of training & $1 / 3 / 2$ & & \\
$\begin{array}{l}\text { (PGY1/2/3) } \\
\text { Hand dominance (R/L) }\end{array}$ & $5 / 1$ & $4 / 0$ & 0.3632 \\
$\begin{array}{l}\text { URS cases as primary } \\
\text { (mean cases } \pm \text { SD) }\end{array}$ & $4.16 \pm 4.75$ & $5.25 \pm 9.85$ & 0.8479 \\
$\begin{array}{l}\text { URS cases as assist } \\
\text { (mean cases } \pm \text { SD) }\end{array}$ & $7.67 \pm 6.65$ & $6.7 \pm 8.92$ & 0.8673 \\
$\begin{array}{l}\text { Current video game } \\
\text { experience (hours/week } \\
\pm \text { SD) }\end{array}$ & $1.83 \pm 1.1 .84$ & $0 \pm 0$ & 0.0581 \\
$\begin{array}{l}\text { Previous video game } \\
\text { experience (hours/week } \\
\pm \text { SD) }\end{array}$ & $15.67 \pm 5.89$ & $0.75 \pm 1.50$ & 0.0011 \\
$\begin{array}{l}\text { CubeRunner score } \\
\text { (mean } \pm \text { SD) }\end{array}$ & $767.40 \pm 511.00$ & $402.60 \pm 173.70$ & 0.1534 \\
\hline
\end{tabular}

\begin{tabular}{|c|c|c|c|}
\hline \multicolumn{4}{|c|}{$\begin{array}{l}\text { UP-82. Table 2. Flexible ureteroscopy task and OSAT } \\
\text { scores for video gamers vs. non-video gamers }\end{array}$} \\
\hline & $\begin{array}{c}\text { Gamers } \\
(\mathrm{n}=6)\end{array}$ & $\begin{array}{c}\text { Non- } \\
\text { gamers } \\
(n=4)\end{array}$ & p \\
\hline fURS task score (mean \pm SD) & $2.167 \pm 0.41$ & $2.250 \pm 0.50$ & 0.7915 \\
\hline $\begin{array}{l}\text { Basketing attempts } \\
\text { (mean } \pm \text { SD) }\end{array}$ & $1.167 \pm 0.41$ & $1.25 \pm 0.50$ & 0.7915 \\
\hline $\begin{array}{l}\text { Accidental stone drops } \\
(\text { mean } \pm \text { SD) }\end{array}$ & $1.17 \pm 0.41$ & $1.25 \pm 0.50$ & 0.7915 \\
\hline $\begin{array}{l}\text { Total time (mean minutes } \pm \\
\text { SD) }\end{array}$ & $8.52 \pm 0.91$ & $7.76 \pm 1.03$ & 0.2771 \\
\hline $\begin{array}{l}\text { Global psychomotor } \\
\text { assessment score (mean } \pm \text { SD) }\end{array}$ & $24.33 \pm 2.66$ & $20.75 \pm 2.06$ & $0.0448^{*}$ \\
\hline $\begin{array}{l}\text { Respect for tissue } \\
\text { (mean } \pm \text { SD) }\end{array}$ & $3.67 \pm 0.52$ & $3.25 \pm 0.50$ & 0.2448 \\
\hline Time and motion (mean \pm SD) & $3.50 \pm 0.55$ & $3.00 \pm 0.82$ & 0.3336 \\
\hline Handling scope (mean \pm SD) & $3.33 \pm 0.52$ & $3.25 \pm 0.50$ & 0.8065 \\
\hline $\begin{array}{l}\text { Knowledge of instruments } \\
\text { (mean } \pm \text { SD) }\end{array}$ & $3.6 \pm 0.52$ & $3 \pm 0$ & $0.0250 *$ \\
\hline $\begin{array}{l}\text { Flow of operations } \\
\text { (mean } \pm \text { SD) }\end{array}$ & $3.33 \pm 0.52$ & $2.75 \pm 0.50$ & 0.1193 \\
\hline Use of assistants (mean \pm SD) & $3.33 \pm 0.52$ & $2.25 \pm 0.50$ & $0.0136^{*}$ \\
\hline $\begin{array}{l}\text { Knowledge of specific } \\
\text { procedure }(\text { mean } \pm \text { SD) }\end{array}$ & $3.50 \pm 0.55$ & $3.25 \pm 0.50$ & 0.4803 \\
\hline & & & \\
\hline
\end{tabular}

Methods: We retrospectively reviewed all cases of PCNL between January 2016 to July 2020 at two high-volume tertiary centers. Baseline data collected included age, body mass index (BMI), previous stone surgery, stone size and location. Perioperative (tract size, operation time, patient position) and postoperative (change in haemoglobin $[\mathrm{Hb}]$, renal function, hospital length of stay [LOS], rate of stone clearance) outcomes were studied. Mann-Whitney U-tests and Fisher's exact t-tests were used to analyze continuous, and Pearson's Chi-squared tests were used for categorical variables. Statistical significance was set at $p<0.05$.

Results: Ninety-fine patients were included in our analysis $(n=76 \mathrm{mPCNL}$ vs. $\mathrm{n}=19 \mathrm{CPCNL}$ ). Baseline characteristics were similar between groups except for $\mathrm{BMl}$, which was higher in the $\mathrm{CPCNL}$ group (mean $31 \mathrm{vs.} 27 \mathrm{~kg} / \mathrm{m}^{2}, \mathrm{p}=0.03$ ). Preoperative stone size and location were similar between groups. No significant differences were found for change in estimated glomerular filtration rate (mean 6.5 vs. $6.1 \mathrm{~mL} / \mathrm{min}, \mathrm{p}=0.95$ ), change in $\mathrm{Hb}$ (mean 13.9 vs. $18.2, p=0.18)$, transfusion rates $(p=0.78)$, operation time (mean 212 vs. 195 min, $p=0.48)$, or rate of stone clearance by tract size $(p=0.41)$. Total stone clearance rate was greater with prone positioning $(p=0.001)$. Interestingly, nephrostomy tube insertion was associated with increased LOS $(p=0.03)$ but did not correlate with stone or residual fragment size.

Conclusions: $\mathrm{mPCNL}$ demonstrates equivalent perioperative and functional outcomes to CPCNL. Furthermore, routine postoperative nephrostomy tube insertion after PCNL may not confer additional benefit and warrants further study.

\section{UP-84}

Impact of travel distance on clinical outcomes in patients receiving treatment for urolithiasis

Danielle Jenkins' ${ }^{1}$, Marlo Whitehead', Gregory Hosier', Darren T. Beiko', Thomas McGregor ${ }^{1}$, D. Robert Siemens

${ }^{1}$ Department of Urology, Queen's University, Kingston, ON, Canada; ${ }^{2}$ Institute for Clinical Evaluative Sciences, Queen's University, Kingston, ON, Canada

Introduction: Treatment for urolithiasis is limited to regions with a practicing urologist and specialized centers with additional resources and expertise. Patients commonly must travel to access these services. This study assessed the relationship between the distance traveled to receive treatment for urolithiasis and early outcomes.

Methods: This is a population-based study of patients who received interventions for urolithiasis in Ontario between July 1, 2013 and September 30, 2017 using administrative data. Patients were stratified into three groups according to the distance travelled to receive their treatment. Descriptive statistics and the Chi-squared test was used to examine differences between these groups based on the urolithiasis treatment of choice. The primary outcomes were re-operation rates and re-admission rates, with secondary outcomes including emergency department visits. Results: A total of 18001 patients were included in the final analysis. Of these, 13686 travelled between 0 and $30 \mathrm{~km}, 2971$ travelled between 30 and $90 \mathrm{~km}$, and 1344 travelled greater than $90 \mathrm{~km}$. Type of procedure and region of residence were the only covariates that appeared to have any clinically relevant association with greater distance travelled. Those who received extracorporeal shockwave lithotripsy were more likely to have travelled over $90 \mathrm{~km}(22 \%)$ compared to percutaneous nephrolithotomy $(3 \%)$ or ureteroscopy $(4 \%)$. On univariate analysis, the only association between distance travelled and any outcome was re-operation $(23 \%$ for those that travelled $>90 \mathrm{~km}$ ); however, there appeared to be an interaction between distance travelled and procedure type with outcomes. No significant trends were seen when analyzing the impact of distance travelled on early outcomes for each individual procedure.

Conclusions: This study found no clinically relevant association between the distance travelled to receive treatment for urolithiasis and early surgical outcomes. 


\section{UP-85 \\ Characterizing patients with multiple same-sided ureteric stones}

Matthew Mancuso ${ }^{1}$, Mark Assmus ${ }^{1}$, Callum Lavoie', Shubhadip (Shubha) K. De

${ }^{1}$ Faculty of Medicine and Dentistry, University of Alberta, Edmonton, AB, Canada

Introduction: Currently, there is no information on how to counsel patients who present with multiple same-sided ureteric stones (MUS). Therefore, the objective of this study is to understand the differences in outcomes of patients with MUS vs. those with single ureteric stones (SUS). Methods: A prospectively collected cohort of patients with MUS was created. Inclusion criteria consisted of: two ipsilateral ureteral stones on imaging, age $>18$, no prior treatment for current stone burden. A comparison cohort was then used from our Acute Stone Clinic (inclusion: one ureteral stone, $>18$, no prior treatment for current stone). Univariate logistic regression analyses and descriptive statistics were performed with SPSS ${ }^{\circledR} 20.0$ (significance $\mathrm{p}<0.05$ ).

Results: Seventy-nine MUS patients were compared to 101 SUS patients. MUS patients had $2.21 \pm 0.66$ ureteric stones, were $57 \pm 13$ years old, and $71 \%$ male (vs. $49 \pm 15$ years, $65 \%$ male SUS). There was a difference in stone size (MUS $6.4 \mathrm{~mm}$ vs. SUS $7.2 \mathrm{~mm}, \mathrm{p}=0.03$ ), and MUS patients were more likely to have had prior stones ( $66 \%$ vs. $42 \%, p=0.001)$ being 5.9 times more likely to have had a prior stone procedure. MUS were exposed to more imaging studies at presentation (odds ratio [OR] 5.4, 95\% confidence interval $[\mathrm{Cl}] 2.8-10$ ) and followup (OR 3.2, 95\% CI1.7$6, p=0.000$ ) and were more likely to spontaneously pass a stone prior to planned intervention (OR 41, 95\% Cl 12-141, $\mathrm{p}=0.0001)$. Conservative management was successful in 33\% MUS vs. 34\% SUS ( $p=0.932)$, and there were no differences in resolution time $(p=0.4)$. Ureteroscopy (URS) was performed on $58 \%$ MUS vs. $51 \%$ SUS patients $(p=0.30)$, and shockwave lithotripsy (SWL) in 10\% MUS vs. 26\% SUS $(p=0.01)$.

Conclusions: This retrospective study has identified MUS patients as more likely to be recurrent stone formers who have undergone previous stone

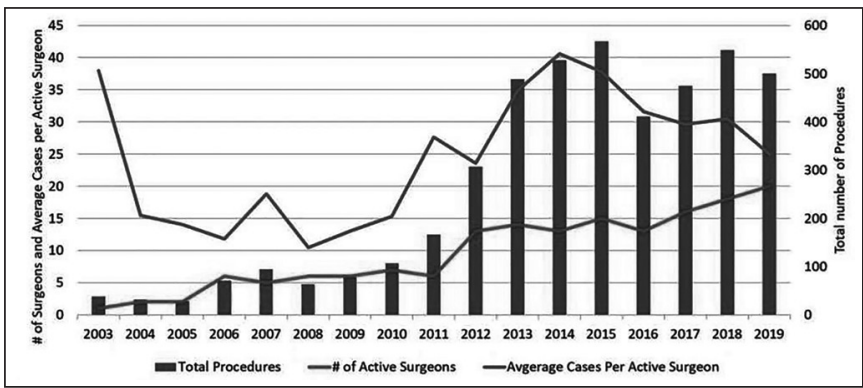

UP-86. Fig. 1A. Total procedures vs. number of active surgeons vs. average.

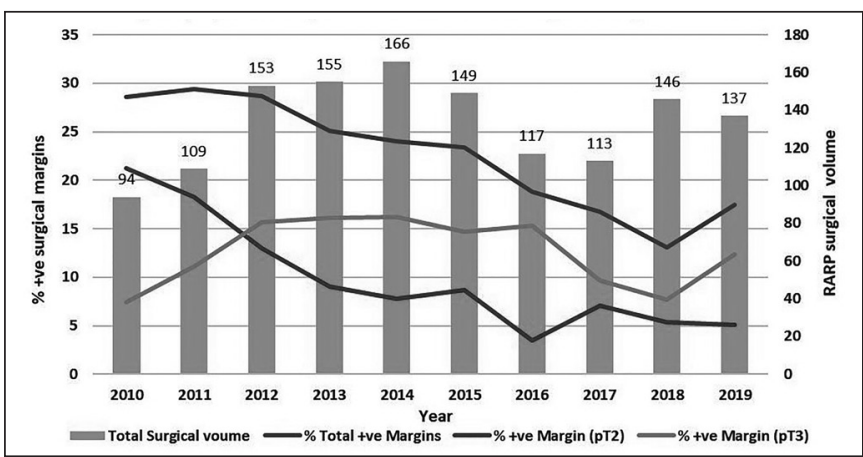

UP-86. Fig. 1B. Total surgical volume and positive surgical margins over time. interventions. Conservative management appears to be as successful in those with SUS, with no differences in time to resolution of their stone events. Though SWL is used less frequently, there were no differences in the use of URS between populations.

\section{UP-86}

Impact of growing multispecialty use of robotic surgery on delivery of robotic urologic surgery in Canada: A 10-year review of two academic centers

Ahmed S. Zakaria Ahmed', David-Dan Nguyen ${ }^{2}$, Iman Sadri' ${ }^{2}$, Adel Arezki $^{2}$, Félix Couture ${ }^{3}$, Ali Abdullah' ${ }^{7}$ Ronald Denis ${ }^{4}$, Assaad El-Hakim ${ }^{4}$, Kevin C. Zorn ${ }^{1}$

${ }^{1}$ Department of Surgery, Division of Urology, Centre Hospitalier de I'Université de Montréal (CHUM), Montreal, QC, Canada; ${ }^{2}$ Faculty of Medicine, McGill University, Montreal, QC, Canada; ${ }^{3}$ Department of Surgery, Division of Urology, McGill University Health Centre (MUHC), Montreal, QC, Canada; ${ }^{4}$ Department of Surgery, Division of Robotic surgery, Hôpital du Sacré Coeur de Montréal (HSCM), Montreal, QC, Canada Introduction: The vast majority of robotic-assisted surgery (RAS) systems in Canada (30 robots) are donor-funded, with significant limitations on implementation and operation due to their cost that precludes their public coverage. This study aimed to characterize the impact of growing multispecialty use of RAS on urological RAS outcomes during the last decade. Methods: We conducted a retrospective review of all RAS performed by different surgical specialties in two high-volume academic centers between 2010 and 2019. The assessed outcomes included the effect of increased robot access over the years on annual robotic-assisted radical prostatectomy (RARP) volumes, surgical waiting times (SWT), and pathological positive surgical margins (PSM)

Results: In total, six specialties (urology, general, cardiac, thoracic, gynecology, and otorhinolaryngologic surgery) developed RAS programs. RAS access by specialty doubled since 2010 (from three to six). The number of active robotic surgeons tripled from seven surgeons in 2010 to 20 surgeons in 2019. Over years, there was a significant drop in average case volume per active robotic surgeon (all specialties included) from a peak of 40 cases in 2014 to 25 cases in 2019 (Fig. 1A). RARP annual case volume followed a similar pattern, reaching a maximum of 166 cases in 2014 then declining to 113 and 137 cases in 2017 and 2019, respectively. Furthermore, mean SWT increased from 52 days in 2014 to 73 days in 2019. PSM rates were not affected by the reduction in surgical volumes (Fig. 1B).

Conclusions: Over the last decade, RAS access by specialty has increased at our academic center. There was a steady reduction in the number of RAS performed per surgeon over time, as well as a gradual increase in the SWT. Relying on the current low number of robots and the nonsustainable funding resources might affect universal patient access to RAS. More national multispecialty studies are required to confirm results and inform future policy on RAS coverage and access.

\section{UP-87}

Global Greenlight group: Largest international Greenlight experience for benign prostatic hyperplasia with five-year outcomes

Kyle Law ${ }^{1}$, Côme Tholomier ${ }^{2}$, David-Dan Nguyen ${ }^{1}$, Iman Sadri ${ }^{1}$, Félix Couture $^{3}$, Ahmed S. Zakaria ${ }^{4}$, David Bouhadana ${ }^{7}$, Franck Bruyère ${ }^{5}$, Hannes Cash ${ }^{6}$, Maximilian Reimann ${ }^{7}$, Luca Cindolo $^{8}$, Giovanni Ferrari ${ }^{8}$, Carlos Vasquez-Lastra ${ }^{9}$, Tiago J. Borelli-Bovo ${ }^{10}$, Edgardo F. Becher ${ }^{11}$, Vincent Misrai ${ }^{12}$, Dean S. Elterman ${ }^{13}$, Naeem Bhojani ${ }^{4}$, Kevin C. Zorn ${ }^{4}$ ${ }^{1}$ Faculty of Medicine, McGill University, Montreal, QC, Canada; ${ }^{2}$ Division of Urology, McGill University, Montreal, QC, Canada; ${ }^{3}$ Division of Urology, Centre Hospitalier Universitaire de Sherbrooke, Sherbrooke, QC, Canada; ${ }^{4}$ Division of Urology, University of Montreal Hospital Center CHUM, Montreal, QC, Canada; ${ }^{5}$ Department of Oncology and Urology, Centre Hospitalier Universitaire de Tours, Centre-Val De Loire, France; ${ }^{6}$ Department of Urology, PROURO, Berlin, Germany; ${ }^{7}$ Department of Urology, Charité - Universitaetsmedizin Berlin, Berlin, Germany; ${ }^{8}$ Department of Urology, Hesperia Hospital, Modena, Italy; ${ }^{9}$ Department of Urology, ABC Medical Center, Mexico City, Mexico; ${ }^{10}$ Department 


\begin{tabular}{|c|c|c|c|}
\hline \multicolumn{4}{|c|}{$\begin{array}{l}\text { UP-87. Table 1. Perioperative and early postoperative } \\
\text { complications ( }<30 \text { days) }\end{array}$} \\
\hline Complication & $\begin{array}{l}\text { Clavien- } \\
\text { Dindo grade }\end{array}$ & $\begin{array}{l}\text { Number of } \\
\text { patients (\%) }\end{array}$ & $\begin{array}{l}\text { Sample } \\
\text { size }\end{array}$ \\
\hline \multicolumn{4}{|l|}{ Perioperative } \\
\hline $\begin{array}{l}\text { Prostatic capsule } \\
\text { perforation }\end{array}$ & Illa & $21(1.4 \%)$ & 1471 \\
\hline Conversion to TURP & Illa & $47(2.8 \%)$ & 1659 \\
\hline \multicolumn{4}{|l|}{$\begin{array}{l}\text { Early postoperative }(<30 \\
\text { days) }\end{array}$} \\
\hline $\begin{array}{l}\text { 30-day readmission } \\
\text { \# on anti-coagulants }\end{array}$ & - & $\begin{array}{c}192(13.3 \%) \\
58(30 \%)\end{array}$ & $\begin{array}{l}471 \\
192\end{array}$ \\
\hline Fever & I & $62(4.0 \%)$ & 2158 \\
\hline UTI & I & $118(5.3 \%)$ & 2219 \\
\hline LUTS* & I & $500(22.6 \%)$ & 2217 \\
\hline $\mathrm{OAB}$ & I & $6(1.1 \%)$ & 555 \\
\hline Incontinence & I & $232(10.5 \%)$ & 2217 \\
\hline Retention & I & 164 (7.4\%) & 2217 \\
\hline Hematuria & I & $219(9.9 \%)$ & 2217 \\
\hline Paraphimosis & I & $1(0.2 \%)$ & 555 \\
\hline Hematuria & II & $32(4.3 \%)$ & 746 \\
\hline Osteitis Pubis & II & $1(0.2 \%)$ & 555 \\
\hline Urosepsis & II & $8(0.5 \%)$ & 1471 \\
\hline $\begin{array}{l}\text { Stenosis (urethra, meatus, } \\
\text { bladder neck) }\end{array}$ & IIlb & $1(0.1 \%)$ & 1471 \\
\hline Arrhythmia & IVa & $6(0.4 \%)$ & 1471 \\
\hline Major cardiac event** & $\mathrm{IVb}$ & $12(0.8 \%)$ & 1471 \\
\hline $\begin{array}{l}\text { Respiratory distress } \\
\text { (desaturation) }\end{array}$ & $\mathrm{IVb}$ & $3(0.2 \%)$ & 1471 \\
\hline Death & V & $4(0.3 \%)$ & 1471 \\
\hline \multicolumn{4}{|l|}{$\begin{array}{l}\text { Long-term at } 5 \text {-year } \\
\text { followup }\end{array}$} \\
\hline Bladder neck contracture & Illb & $11(1.93 \%)$ & 569 \\
\hline Urethral stricture & Illb & $5(0.89 \%)$ & 569 \\
\hline $\begin{array}{l}\text { BPH recurrence requiring } \\
\text { medical reintervention }\end{array}$ & II & $19(3.34 \%)$ & 569 \\
\hline $\begin{array}{l}\mathrm{BPH} \text { recurrence requiring } \\
\text { surgical reintervention }\end{array}$ & IIllb & $10(1.5 \%)$ & 569 \\
\hline $\begin{array}{l}{ }^{*} \text { Dysuria, frequency, urgency. }{ }^{* *} \text { Ang } \\
\text { attack, stroke, deep vein thrombosis } \\
\text { exacerbation. }\end{array}$ & $\begin{array}{l}\text { na, myocardial inf } \\
\text { pulmonary emboli }\end{array}$ & $\begin{array}{l}\text { arction, transient } \\
\text { ism, congestive he }\end{array}$ & $\begin{array}{l}\text { ichemic } \\
\text { art failure }\end{array}$ \\
\hline
\end{tabular}

of Urology, Borelli Urologia, Ribeirão Presto, Brazil; ${ }^{11}$ Department of Urology, Centro de Urologia, Buenos Aires, Argentina; ${ }^{12}$ Department of Urology, Clinique Pasteur, Toulouse, France; ${ }^{13}$ Division of Urology, University of Toronto, Toronto, ON, Canada

Introduction: Greenlight photo-selective vaporization of the prostate (GL-PVP) has gained international acceptance as a safe and effective alternative procedure for the treatment of benign prostatic hyperplasia $(\mathrm{BPH})$, especially in anticoagulated men. This descriptive analysis aims to characterize the current state of GL-PVP, pooling data from international centers.

Methods: Data from 3627 patients who underwent GL-PVP with the XPS-180W system in seven international centers performed by eight expert surgeons between 2011 and 2019 were retrospectively analyzed. Demographic, perioperative, and postoperative data were collected, including International Prostate Symptom Score (IPSS), quality of life (QoL), maximal flow rate (Qmax), post-void residual (PVR), prostatespecific antigen PSA, and complications.

Results: At baseline, median age, prostate volume, PSA, and IPSS were 70 years (interquartile range 64-77), 64 (47-90), $3.1 \mathrm{ng} / \mathrm{mL}(1.8-6)$, and 22 (19-27), respectively. Median lasing and operative time were 34 (23-48) and 62 minutes (46-85), respectively. Median energy use was $250.0 \mathrm{~kJ}$ (168.4-367.9), with $92.6 \%$ of procedures being completed with one laser fiber. In $60.1 \%$ of cases, catheter was removed on postoperative day 1 , with median length of two days. All-cause mortality within 30 days was $0.3 \%$. Median PSA reduction at three months and 60 months compared to baseline was $43.9 \%$ and $46.4 \%$, respectively $(p<0.001)$. All functional outcomes (IPSS, QoL, Qmax, and PVR) were significantly improved across study period when compared to baseline $(p<0.001)$. With a five-year followup, the surgical and observed medical $\mathrm{BPH}$ retreatment rate was $1.5 \%$ and $3.3 \%$, respectively.

Conclusions: Using the largest multi-user, international database of GL-PVP, Greenlight XPS laser treatment in experienced hands is a safe, effective, and durable BPH treatment option.

\section{UP-88}

Three-year outcomes after Aquablation compared to transurethral resection of the prostate: Longest reported followup with sustained efficacy and ejaculatory improvements

Kevin C. Zorn ${ }^{1}$, Peter Gilling ${ }^{2}$, Neil Barber ${ }^{3}$, Mohamed Bidair ${ }^{3}$, Paul Anderson ${ }^{4}$, Mark Sutton ${ }^{5}$, Tev Aho ${ }^{3}$, Eugene Kramolowsky, Dean S. Elterman ${ }^{1}$, Andy Thomas ${ }^{3}$, Barrett Cowan ${ }^{7}$, Ronald P. Kaufman J $r^{7}$, Andrew Trainer ${ }^{7}$, Gopal Badlani ${ }^{7}$, Mark Plante ${ }^{7}$, Mihir Desai $^{7}$, Leo Doumanian ${ }^{7}$, Alex E. Te ${ }^{8}$, Mark DeGuenther ${ }^{9}$, Claus Roehrborn ${ }^{9}$

${ }^{1}$ Urology, CHUM - University of Montreal Hospital Centre, Montreal, QC, Canada; ${ }^{2}$ Urology, Urology Bay of Plenty, Tauranga, New Zealand; ${ }^{3}$ Urology, Frimley Health NHS, Surrey, United Kingdom; ${ }^{4}$ Urology, Royal Melbourne Hospital, Melbourne, Australia; ${ }^{5}$ Urology, Houston Methodist Hospital, Houston, TX, United States; ${ }^{6}$ Urology, Virginia Urology, Richmond, VA, United States; 'Urology, Keck Hospital of USC, Los Angeles, CA, United States; ${ }^{8}$ Urology, Weill Cornell Medicine, New York, NY, United States; ${ }^{9}$ Urology, UT Southwestern, Dallas, TX, United States Introduction: We aimed to compare three-year (last followup of the protocol) safety and efficacy outcomes after Aquablation or transurethral resection of the prostate (TURP) for the treatment of lower urinary tract symptoms (LUTS) related to benign prostate hyperplasia (BPH).

Methods: A total of 181 patients with BPH were assigned at random (2:1 ratio) to either Aquablation or TURP. Patients and followup assessors at each site were blinded to treatment. Assessments included International Prostate Symptom Score (IPSS), Male Sexual Health Questionnaire (MSHQ), International Index of Erectile Function (IIEF) and uroflow.

Results: At three years, IPSS scores improved by 14.2 points in the Aquablation group and 15 points in TURP ( $p=0.7050,95 \%$ confidence interval $[\mathrm{Cl}]$ for difference $-3.6-5.3$ points). Three-year improvements in maximum flow rate (Qmax) were large in both groups, at 10 and $9.7 \mathrm{cc} /$ sec for Aquablation (dark lines/black sqares) and TURP (grey dashed lines/ triangles), respectively ( $p=0.9078,95 \% \mathrm{Cl}$ for difference $-2.9-6.4)$. Sexual function as assessed by MSHQ-EjD was stable in the Aquablation group and decreased slightly in the TURP group; these changes persisted at year 3. At three years, prostate-specific antigen (PSA) was reduced significantly in both groups but showed no difference between groups ( $p=0.4074$ for difference). The average annual retreatment occurrence was less than $2 \%$ in both treatment groups.

Conclusions: Three-year efficacy outcomes after TURP and Aquablation were similar and the rate of surgical retreatment was low and similar to TURP. Efficacy results have maintained their improvement since the 90-day followup for both groups that are consistent with all other resective surgical techniques.

Trial Registration: ClinicalTrials.gov number: NCT02505919. 


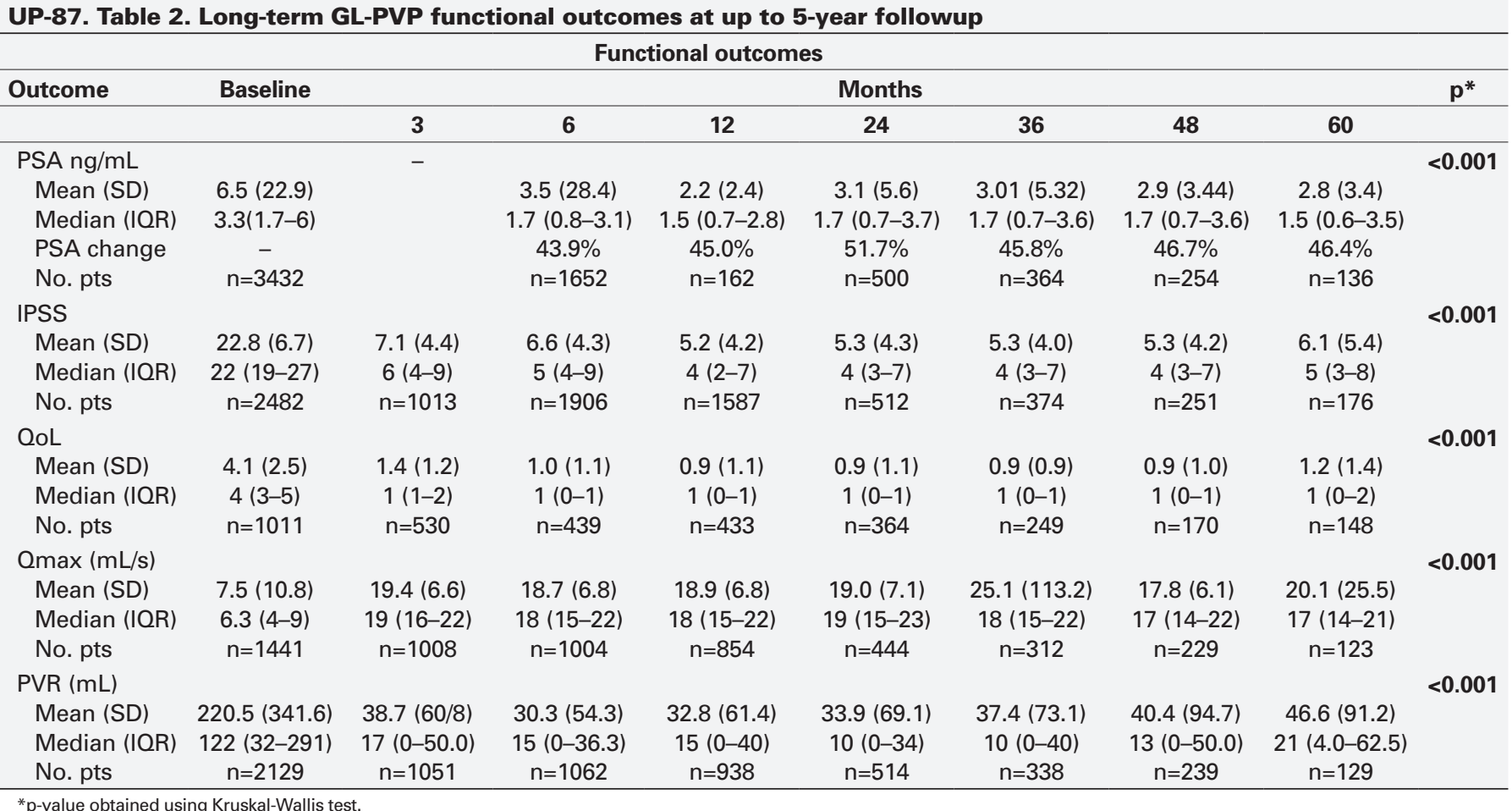

\section{UP-89}

Nephrostomy tube vs. ureteral stent for obstructing septic calculi: A nationwide propensity score matched analysis

Rachel Wong ${ }^{1}$, Sylvain Lother ${ }^{2,3}$, Premal Patel ${ }^{1}$, Barret Rush ${ }^{2}$

${ }^{1}$ Section of Urology, Department of Surgery, University of Manitoba, Winnipeg, MB, Canada; ${ }^{2}$ Section of Critical Care Medicine, Department of Medicine, University of Manitoba, Winnipeg, MB, Canada; ${ }^{3}$ Section of Infectious Diseases, Department of Medicine, University of Manitoba, Winnipeg, MB, Canada

Introduction: Sepsis secondary to obstructive uropathy is a urological emergency associated with significant mortality and morbidity. Decompression with retrograde placement of a ureteric stent (US) or a percutaneous nephrostomy tube (PCN) remains the gold standard of treatment in conjunction with fluid resuscitation and antibiotics. Prior literature suggests that advantages to PCN include higher insertion success rate, as well as a shorter procedural time, which may account for the benefit in mortality. However, scant data exists regarding the optimal method of decompression.

Methods: Using the National Inpatient Sample (NIS) database from 20062014 , we included patients $\geq 18$ years of age with a diagnosis of sepsis and a ureteral/renal calculi that underwent US or PCN. A multivariate logistic regression model predicting in-hospital mortality was created incorporating the 29 Elixhauser comorbidities, hemodialysis, shock, and mechanical ventilation. Additionally, a propensity score matched cohort was created based on the propensity to receive each treatment.

Results: Of these, 9828 (28.9\%) patients underwent ureteral stenting and $24181(71.1 \%)$ underwent PCN. The unadjusted mortality rate for US patients was $2.8 \%$ compared to $5.3 \%$ in the PCN group $(p<0.01)$. Patients who received US were more likely to be female $(61.7 \%$ vs. $53.8 \%$, $\mathrm{p}<0.01)$ and White $(69.3 \%$ vs. $64.5 \%, \mathrm{p}<0.01)$ (Table 1$)$. After adjustment for baseline characteristics, US compared to PCN was associated with a lower risk of mortality (odds ratio [OR] 0.72, 95\% confidence interval [Cl] $0.63-0.83, \mathrm{p}<0.01)$. After matching patients based on propensity score, the mortality rate for patients who received a US was 3.5\% compared to $3.9 \%$ in the PCN group $(p=0.26)$.

Conclusions: This large national analysis demonstrates that US placement in septic obstructive uropathy is associated with lower mortality compared to PCN. After propensity score matching this finding was no longer statistically significant. Further prospective, randomized trials are needed to address this important clinical question. 
Exhibit 3: Endourology

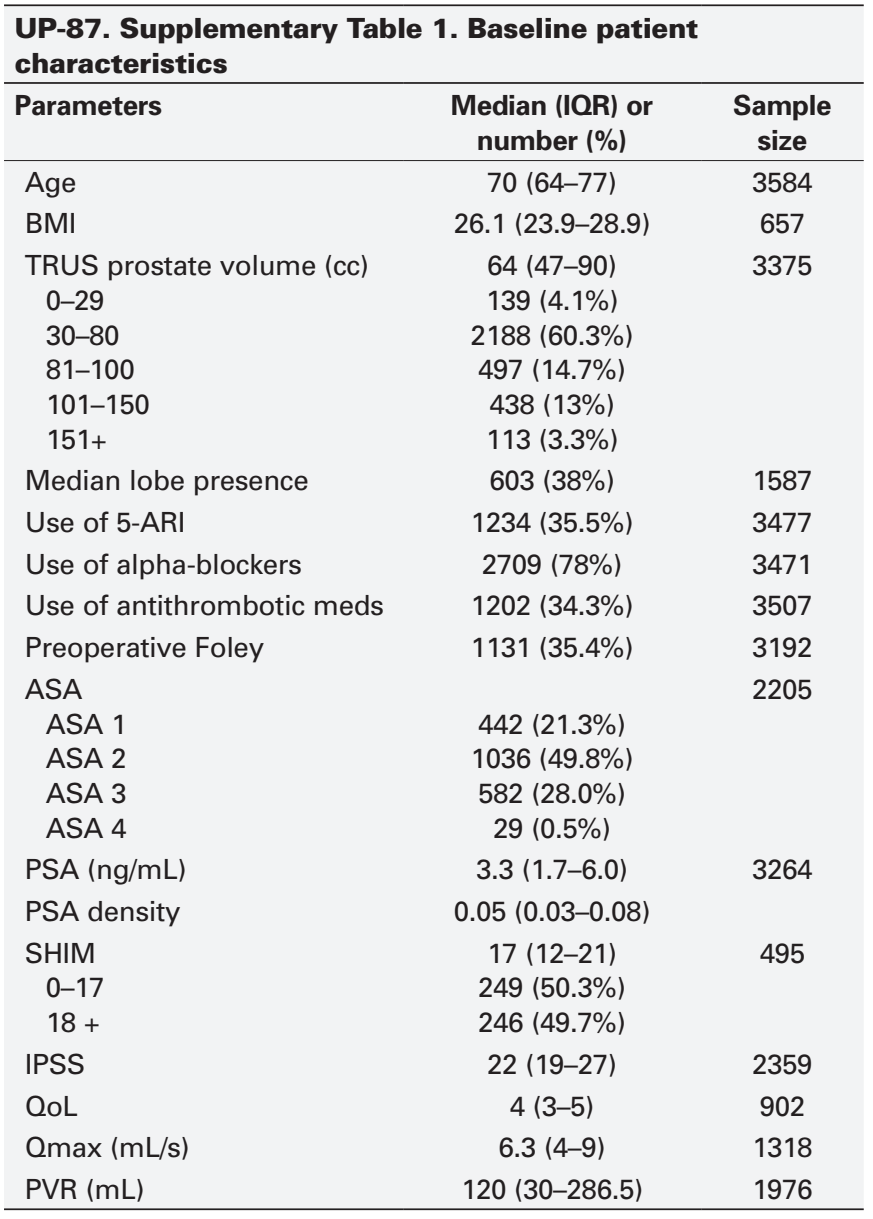

\begin{tabular}{|c|c|c|}
\hline \multicolumn{2}{|c|}{$\begin{array}{l}\text { UP-87. Supplementary Table } 2 \text {. Perioperative and } \\
\text { postoperative characteristics }\end{array}$} & \multirow[b]{2}{*}{$\begin{array}{c}\text { Sample } \\
\text { size }\end{array}$} \\
\hline Parameters & $\begin{array}{l}\text { Median (IQR) or } \\
\text { number (\%) }\end{array}$ & \\
\hline OR time (min) & $62(46-85)$ & 3356 \\
\hline Laser time (min) & $34(23-48)$ & 3314 \\
\hline Laser/OR time ratio & $0.4(0.3-0.6)$ & 2996 \\
\hline Energy used (kJ) & $250.0(168.4-367.9)$ & 3497 \\
\hline $\begin{array}{l}\text { Energy used/preoperative prostate } \\
\text { volume }(\mathrm{kJ} / \mathrm{mL})\end{array}$ & $3.9(2.9-5.0)$ & 3283 \\
\hline$<3 \mathrm{~kJ} / \mathrm{cc}$ & $1099(31.6 \%)$ & \\
\hline $3-4 \mathrm{~kJ} / \mathrm{cc}$ & $840(24.1 \%)$ & \\
\hline$>4 \mathrm{~kJ} / \mathrm{cc}$ & $1541(42.5 \%)$ & \\
\hline Fibers used & & 2969 \\
\hline 1 & $2749(92.6 \%)$ & \\
\hline 2 & $204(6.9 \%)$ & \\
\hline $3+$ & $16(0.5 \%)$ & \\
\hline Perioperative transfusion & $22(0.8 \%)$ & 2651 \\
\hline \# on antithrombotics & $11(50.0 \%)$ & 22 \\
\hline \# using ARI & $8(36.4 \%)$ & 22 \\
\hline \# TRUS >80 cc & $6(27.3 \%)$ & 22 \\
\hline Hospital stay (days), median & $2(1-3)$ & 3487 \\
\hline North America & $0(0-1)$ & 655 \\
\hline South America & $1(0-1)$ & 404 \\
\hline Europe & $2(1-2)$ & 2428 \\
\hline Foley catheterization duration (days) & $1(1-2)$ & 2751 \\
\hline 0 & $95(3.5 \%)$ & \\
\hline 1 & $1653(60.1 \%)$ & \\
\hline 2 & $587(21.3 \%)$ & \\
\hline 3 & $240(8.7 \%)$ & \\
\hline $4+$ & $176(6.40 \%)$ & \\
\hline Required re-catheterization & $161(5.9 \%)$ & 2724 \\
\hline Adenocarcinoma on pathology & $14(1.7 \%)$ & 803 \\
\hline Tissue at pathology $(\mathrm{g})$ & $4.7(5.9)$ & 465 \\
\hline
\end{tabular}



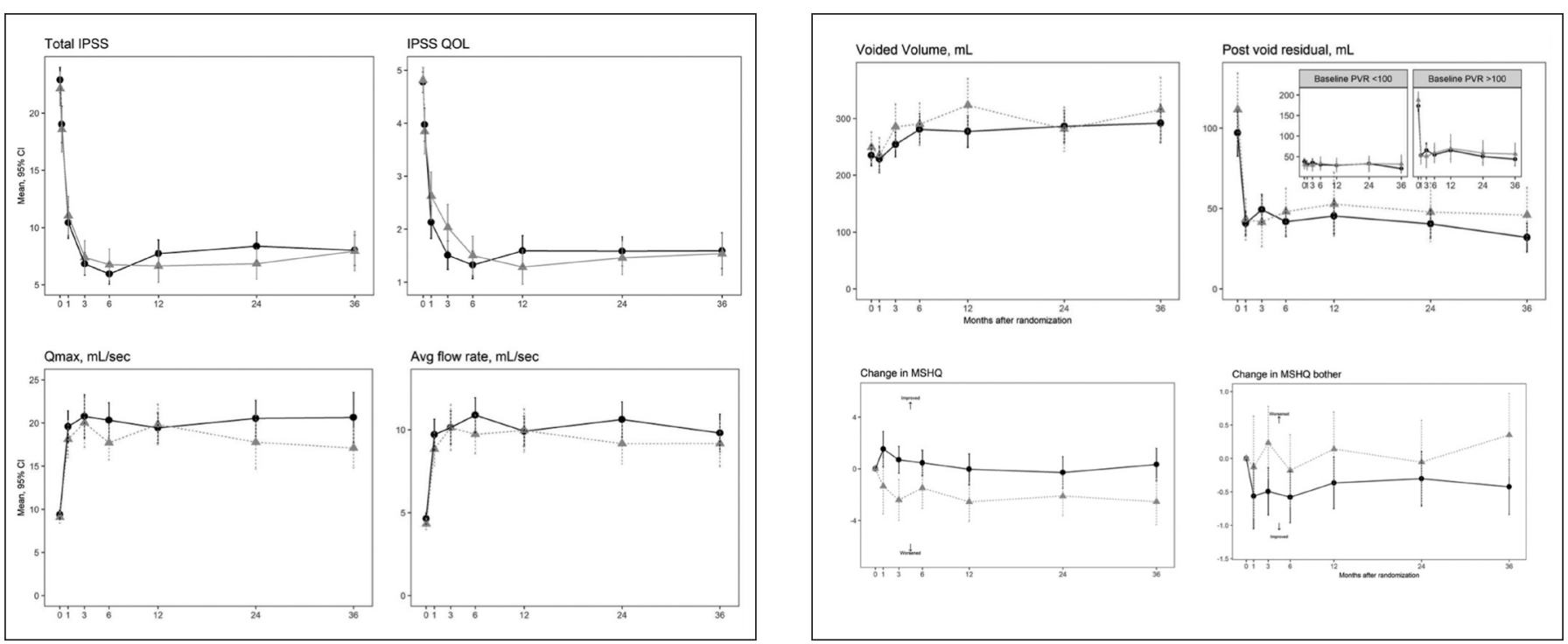

UP-88. Fig. 1. Three-year outcomes after Aquablation compared to TURP.

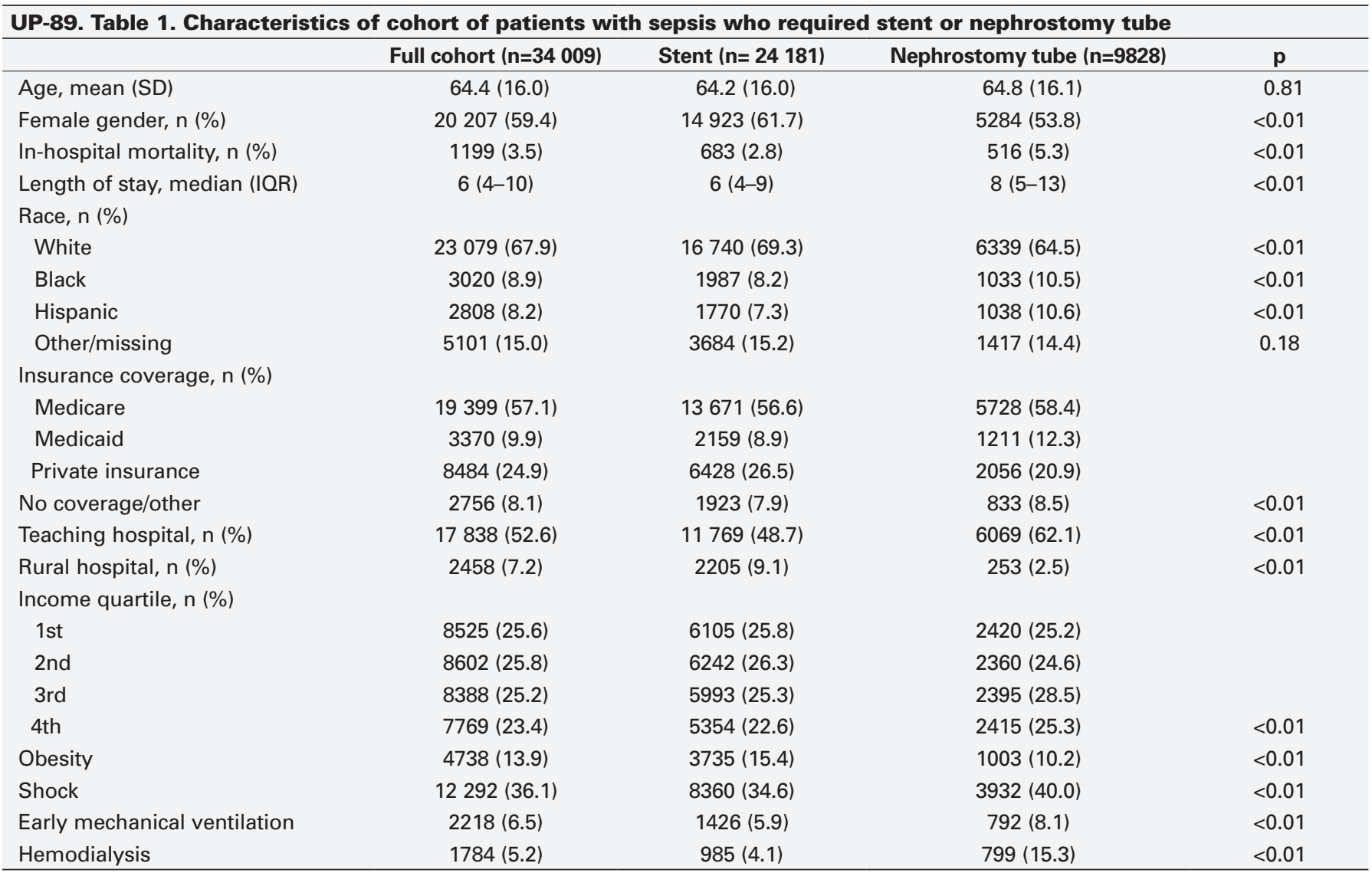

